Universidad de Lima

Facultad de Ciencias Empresariales y Económicas

Carrera de Marketing

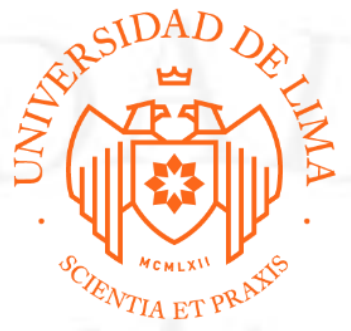

\title{
PLAN DE MARKETING PARA SERVICIO DIFERENCIADO DE CONFECCIÓN A MEDIDA
}

Trabajo de investigación para optar el título profesional de Licenciado en Marketing

\section{Mayra Elizabeth Palomino Córdova}

Código 20081653

\author{
Asesor \\ Juan Miguel Coriat Nugent
}

Lima - Perú

Octubre de 2018 


\section{PLAN DE MARKETING PARA SERVICIO DIFERENCIADO DE CONFECCIÓN A MEDIDA}




\section{TABLA DE CONTENIDO}

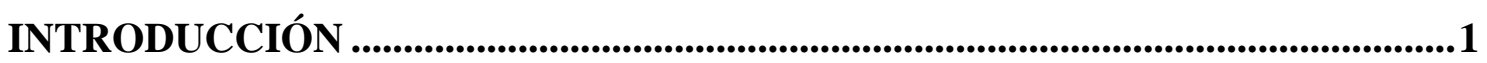

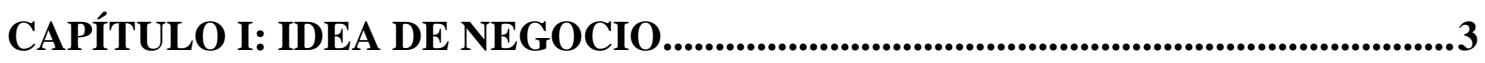

1.1. Descripción y justificación de la oportunidad identificada ................................ 3

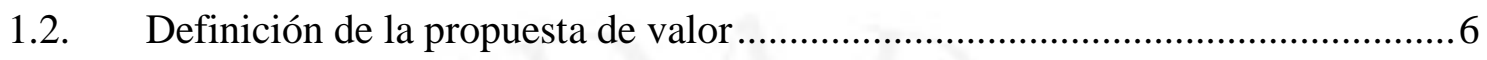

1.3. Descripción del modelo de negocio....................................................................6

1.4. Diseño del modelo de negocio mediante el modelo Canvas .............................. 7

CAPÍTULO II: ANÁLISIS DE SITUACIÓN.......................................................................8

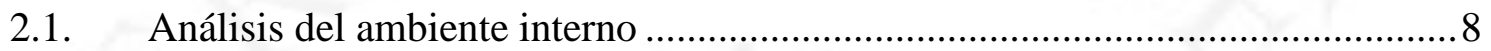

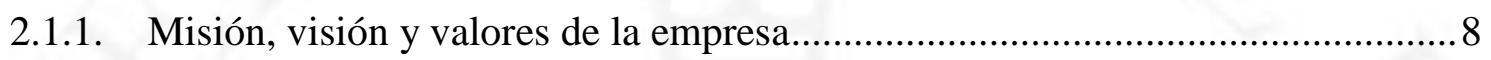

2.1.2. Análisis de recursos: fortalezas y debilidades ............................................... 8

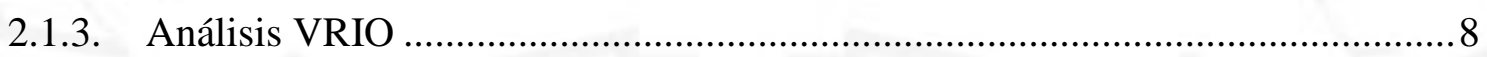

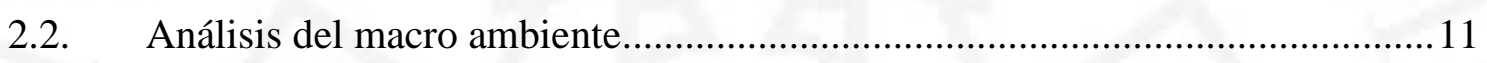

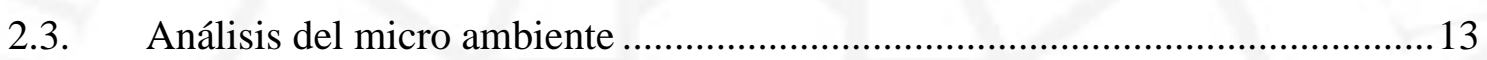

2.3.1. Determinación y descripción del entorno específico......................................... 13

2.3.2. Identificación y descripción de los competidores directos ................................. 13

2.3.3. Cuantificación del entorno específico en unidades y valor de la venta de la

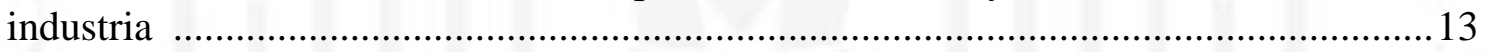

2.3.4. Clasificación CIIU de la actividad económica .............................................. 15

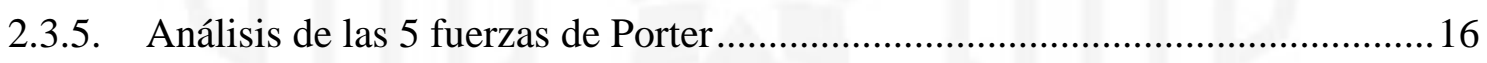

CAPÍTULO III: INVESTIGACIÓN DEL CLIENTE ................................................19

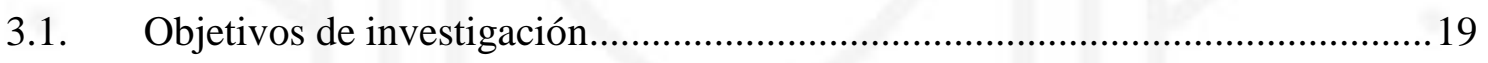

3.2. Metodología de investigación..................................................................... 19

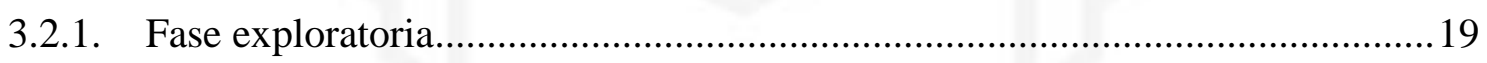

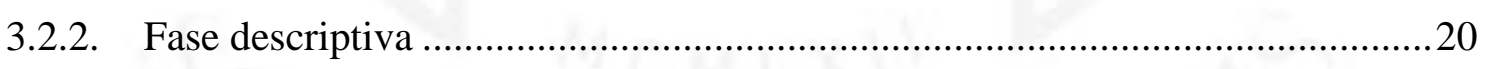

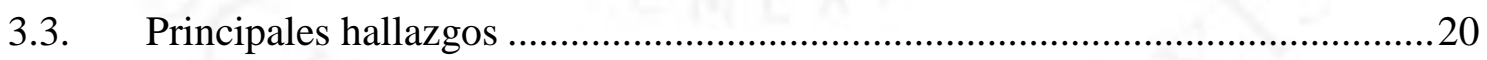

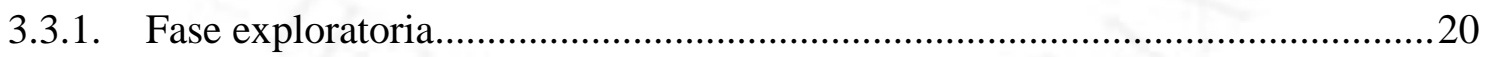

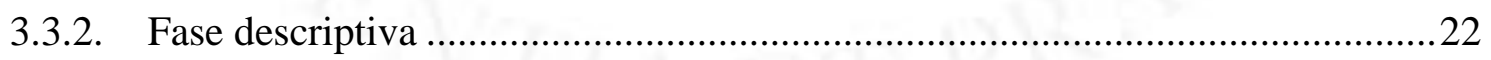

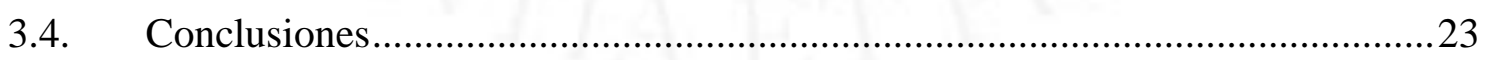

CAPÍTULO IV: ESTIMACIÓN Y PRONÓSTICO DE LA DEMANDA.................24

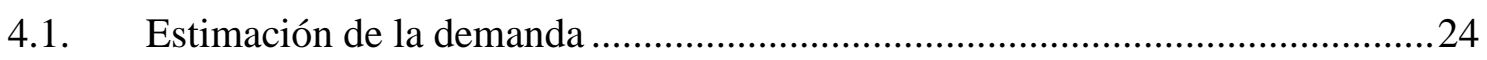

CAPÍTULO V : PLANEACIÓN ESTRATÉGICA DE MARKETING .....................26

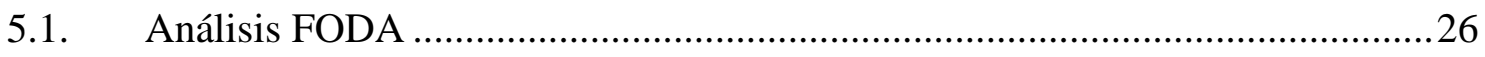

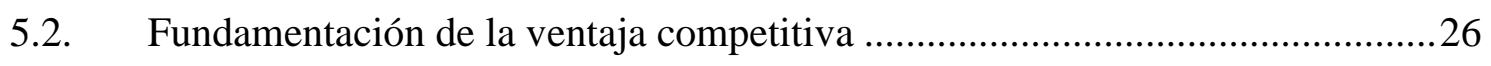

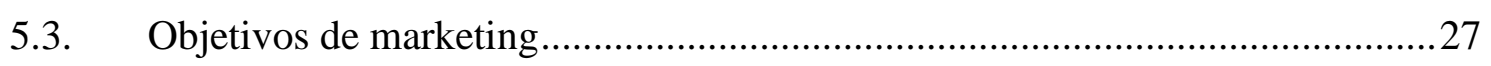




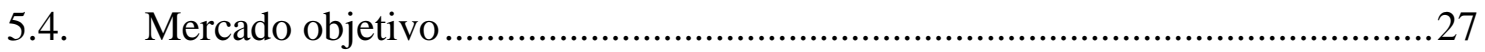

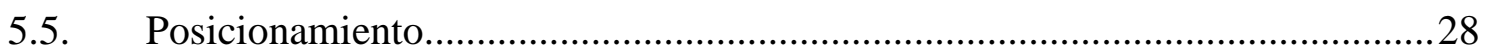

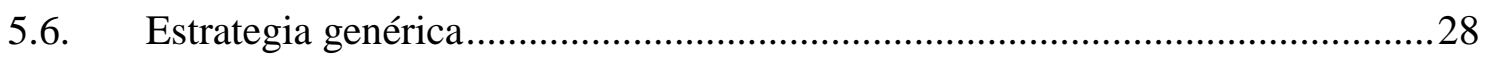

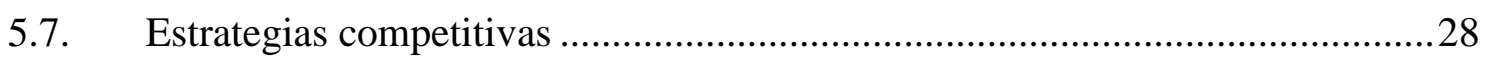

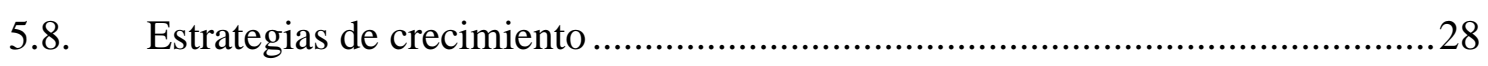

CAPÍTULO VI: IMPLEMENTACIÓN ............................................................................229

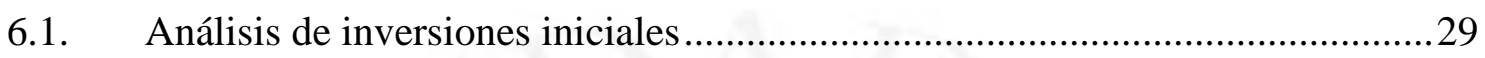

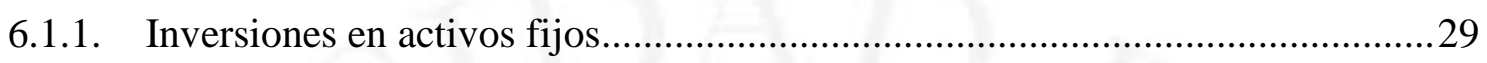

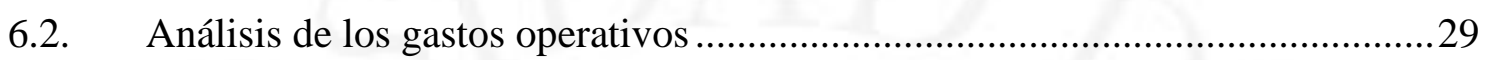

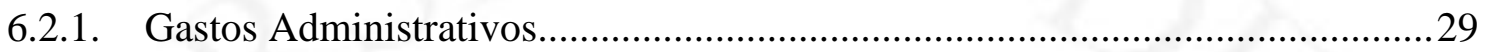

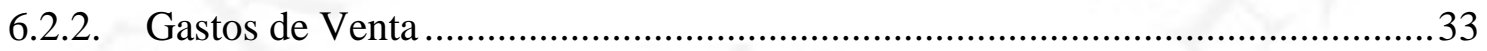

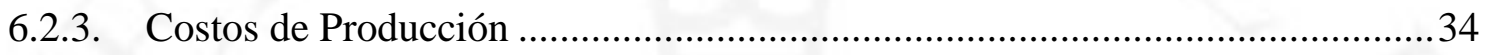

CAPÍTULO VII: MARKETING MIX ..................................................................4 42

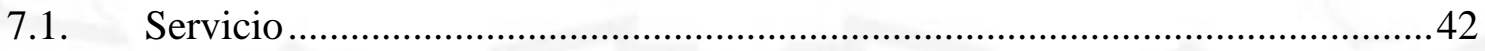

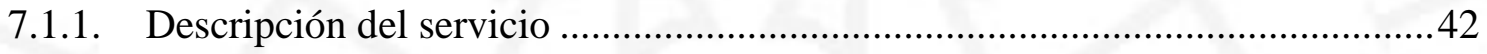

7.1.2. Descripción e ilustración del tangible (producto híbrido) .................................42

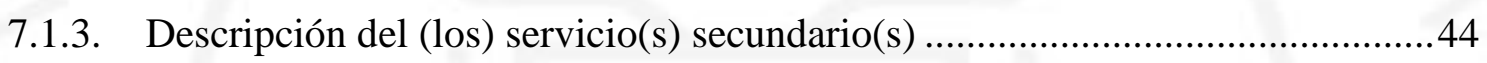

7.1.4. Descripción de la Flor de servicios complementarios de facilitación ................44

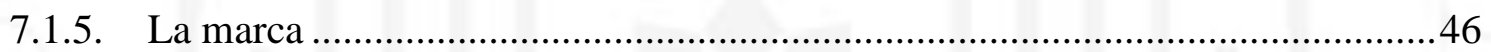

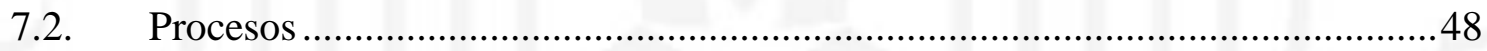

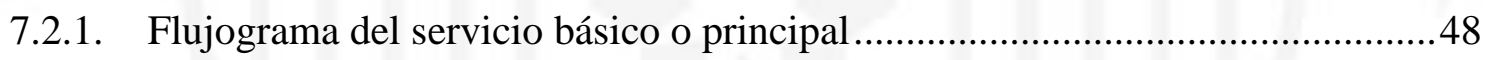

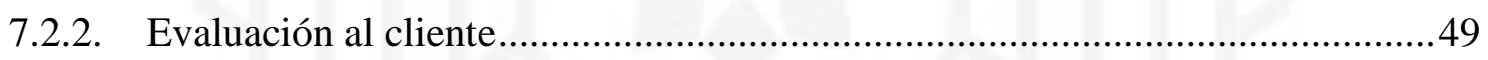

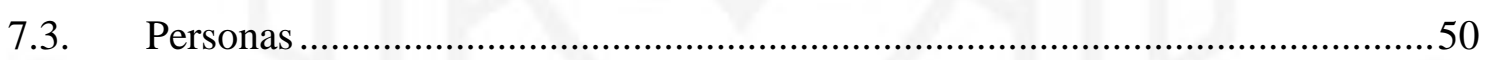

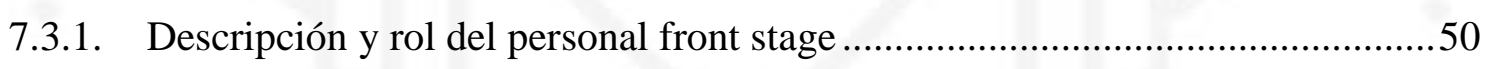

7.3.2. Descripción y rol del personal back stage .....................................................50

7.3.3. Rol del cliente en la producción del servicio.................................................51

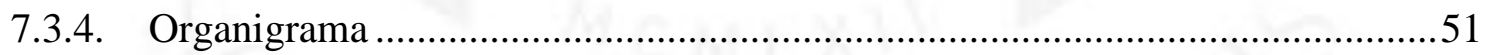

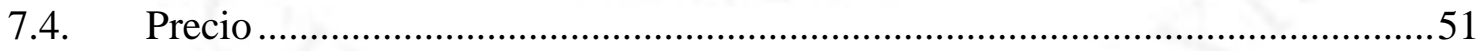

7.4.1. Política de precios criterios de fijación de precios ............................................51

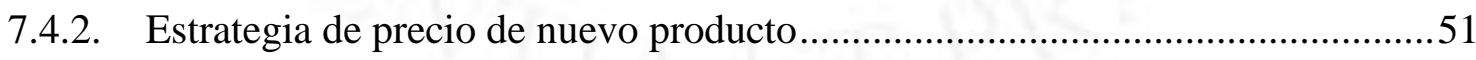

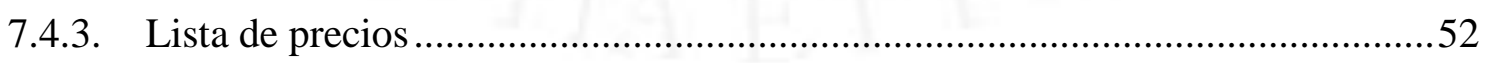

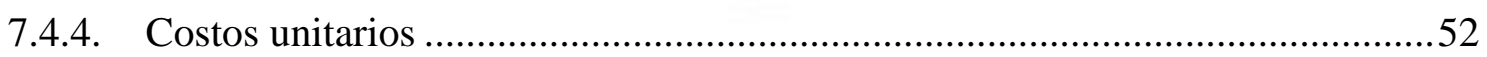

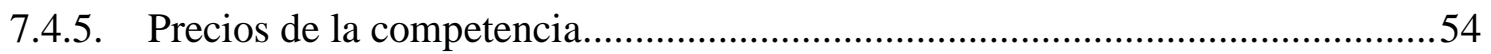

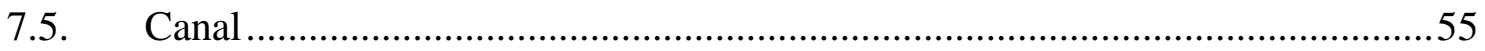

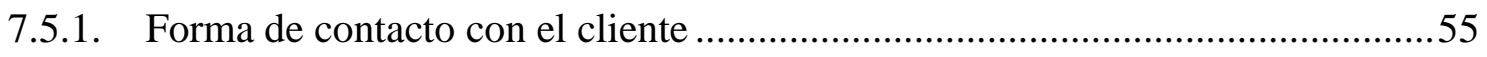

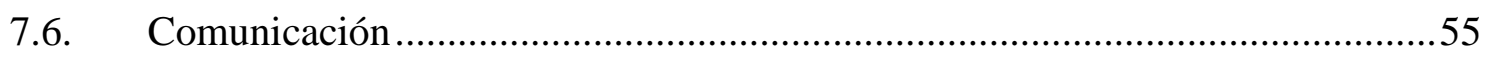

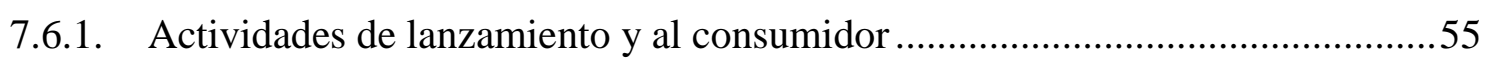




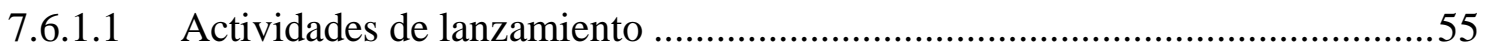

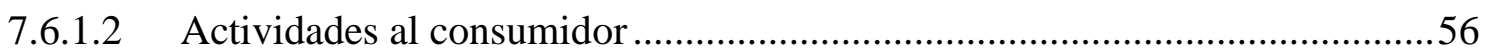

7.6.1.3 Actividades de mantenimiento al consumidor .............................................56

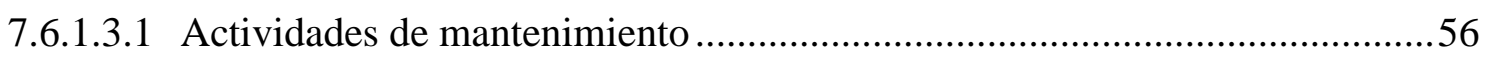

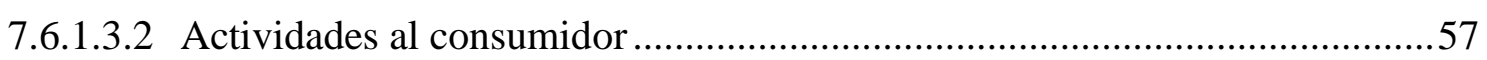

7.6.2. Presupuesto de marketing, por tipo de actividad .............................................57

CAPÍTULO VIII: PROYECCIONES FINANCIERAS ...........................................58

8.1. Pronóstico de ventas y plan de utilidades del primer año.................................58

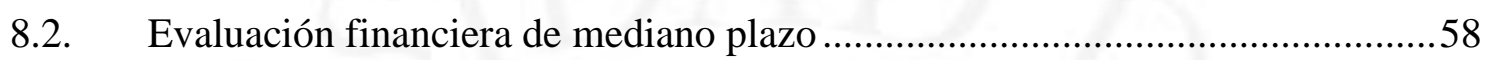

8.3. Análisis del punto de equilibrio (largo plazo) …................................................59

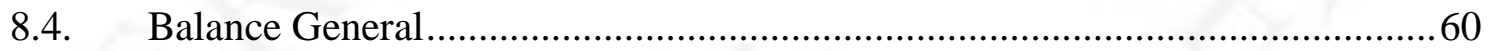

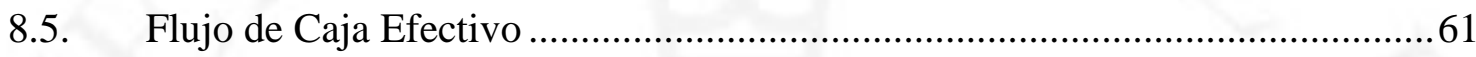

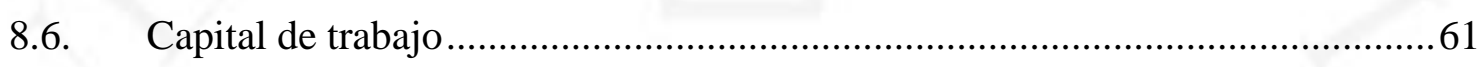

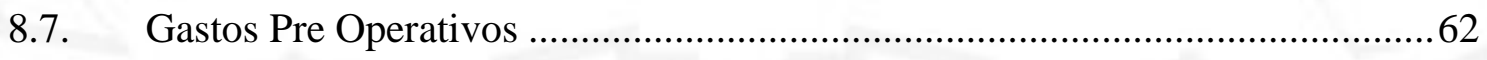

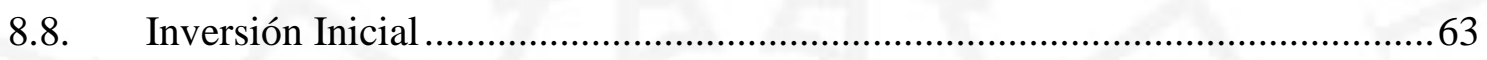

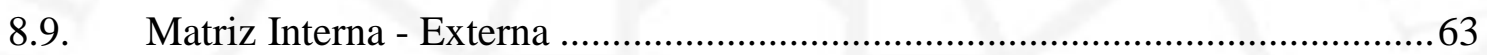

CAPÍTULO IX: CONTROL DEL PLAN DE MARKETING ....................................66

9.1 Criterios de control e indicadores de gestión....................................................66

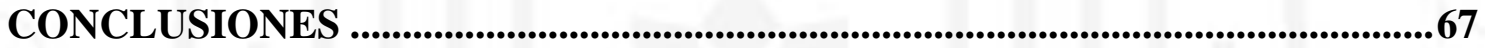

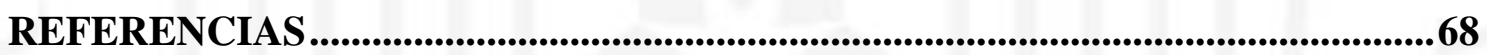

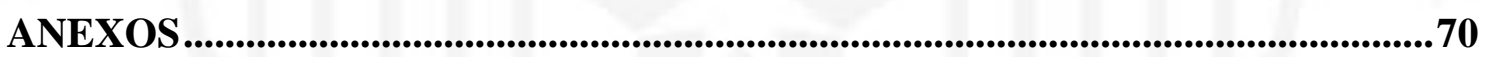




\section{ÍNDICE DE TABLAS}

Tabla 2.1 Identificación de fortalezas y debilidades...................................................

Tabla 2.2 Análisis de ambiente interno VRIO............................................................. 9

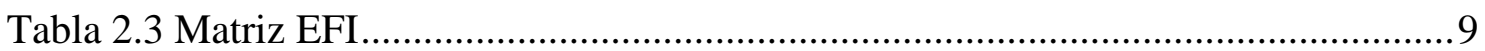

Tabla 2.4 Análisis del macro ambiente........................................................................... 11

Tabla 2.5 Ventas en Perú del sector retail por canal: 2012-2017 ….............................. 14

Tabla 2.6 Participación en el mercado retail por marcas en Perú de 2014 a 2017 ......... 14

Tabla 2.7 Participación en el mercado por marcas en Perú de 2014 a 2017 ................... 15

Tabla 2.8 Análisis de sector de confecciones mediante fuerzas de Porter ..................... 17

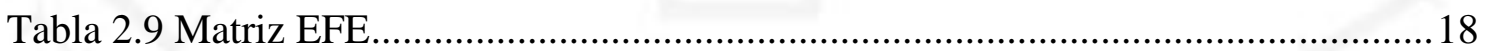

Tabla 3.1 Objetivos de investigación ...................................................................... 19

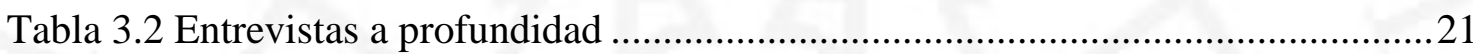

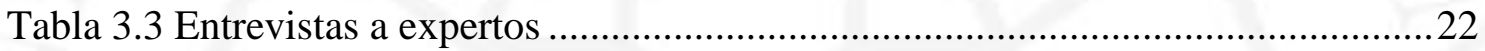

Tabla 4.1 Estimación de demanda del proyecto 2018 (S/.) ..........................................25

Tabla 4.2 Estimación de demanda del proyecto 2019 (S/.) ........................................25

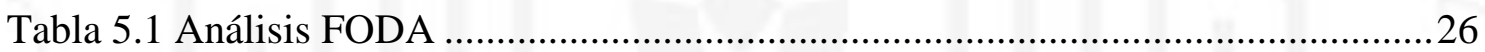

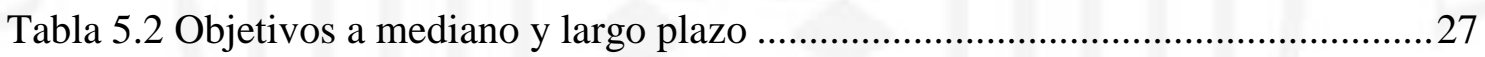

Tabla 5.3 Definición de Mercado Objetivo ................................................................2

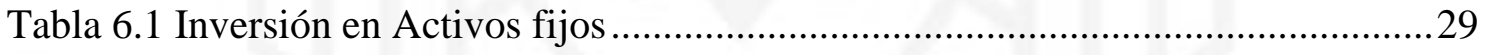

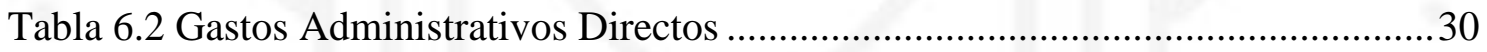

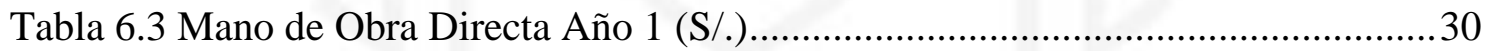

Tabla 6.4 Mano de Obra Directa Año 2 (S/.)................................................................ 31

Tabla 6.5 Mano de Obra Directa Año 3 (S/.)................................................................. 31

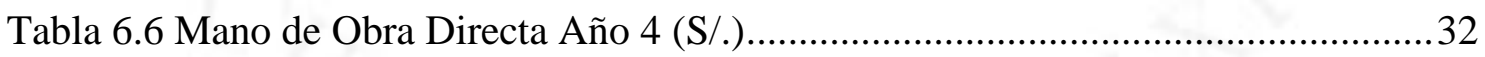

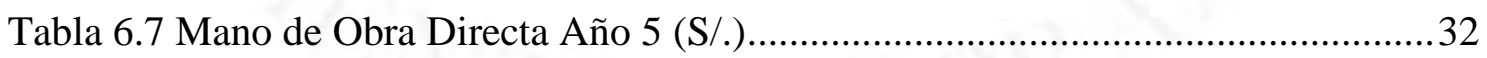

Tabla 6.8 Presupuesto Gastos Administrativos indirectos (S/.)..................................... 33

Tabla 6.9 Presupuesto Gastos Administrativos Total (S/.) ............................................. 33

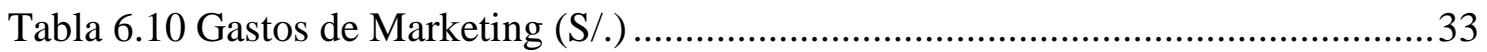

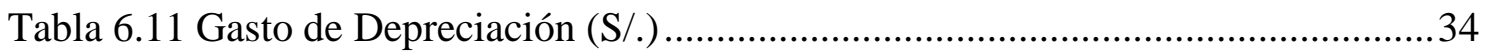

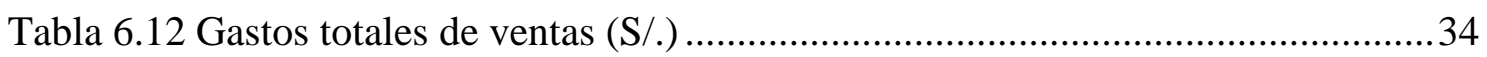

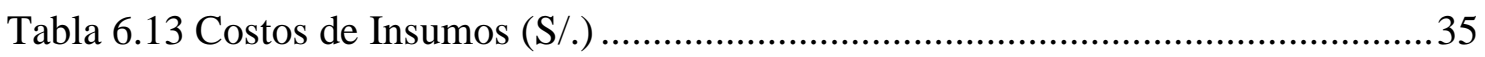

Tabla 6.14 Detalle Mano de Obra Directa Año 1 (S/.) .................................................... 35 


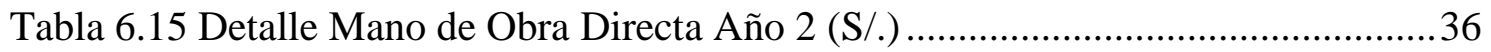

Tabla 6.16 Detalle Mano de Obra Directa Año 3 (S/.) .................................................... 36

Tabla 6.17 Detalle Mano de Obra Directa Año 4 (S/.) ...................................................... 37

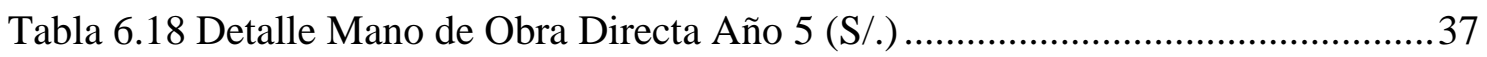

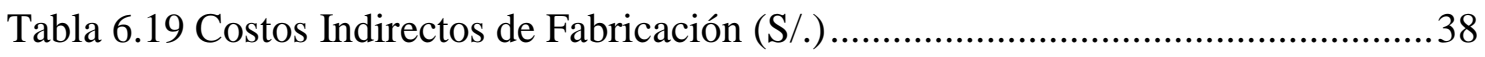

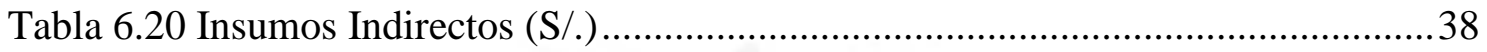

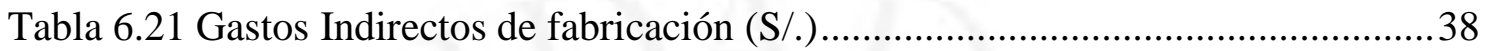

Tabla 6.22 Detalle Mano de Obra Indirecta Año 1 (S/.).................................................. 39

Tabla 6.23 Detalle Mano de Obra Indirecta Año 2 (S/.)............................................... 39

Tabla 6.24 Detalle Mano de Obra Indirecta Año 3 (S/.)............................................... 40

Tabla 6.25 Detalle Mano de Obra Indirecta Año 4 (S/.)............................................... 40

Tabla 6.26 Detalle Mano de Obra Indirecta Año 5 (S/.).............................................. 41

Tabla 6.27 Presupuesto de costo de producción (S/.) ......................................................41

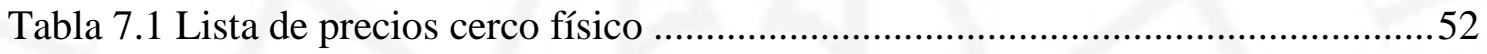

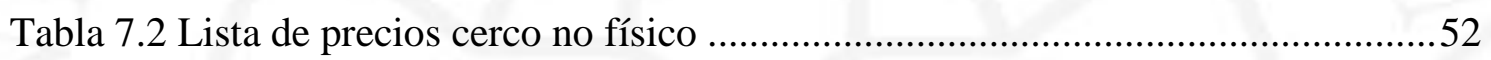

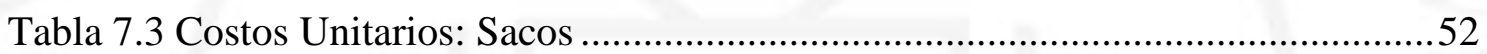

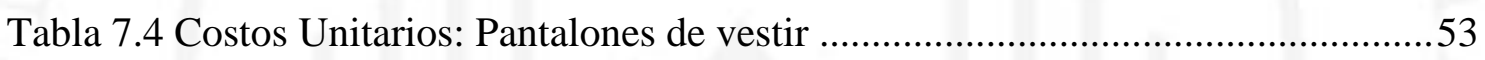

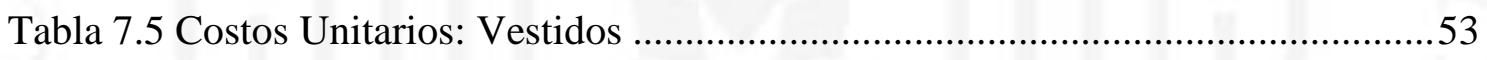

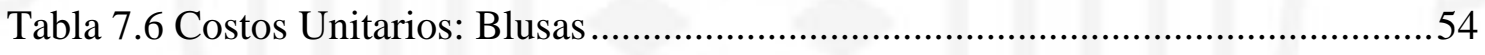

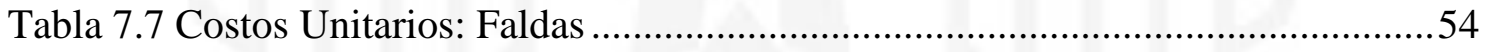

Tabla 7.8 Comparación de Precios: Ayde Co. vs. Competencia .....................................54

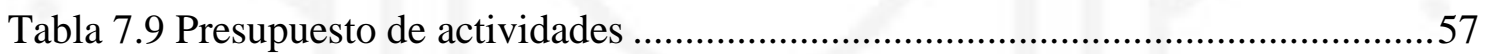

Tabla 8.1 Pronóstico de ventas y plan de utilidades del primer año..............................58

Tabla 8.2 Evaluación financiera a largo plazo - Estado de Ganancias y Pérdidas..........59

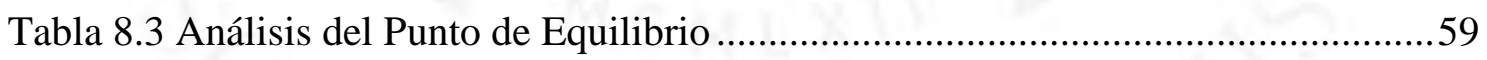

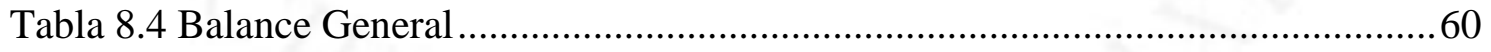

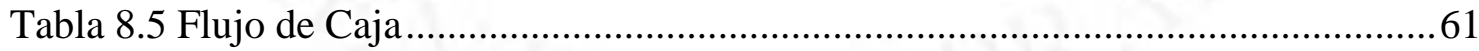

Tabla 8.6 Capital de trabajo - Inversiones en Capital de trabajo ( 3 meses) ....................62

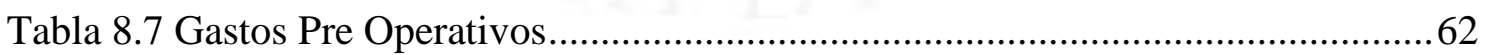

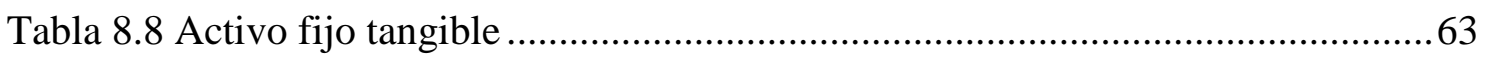

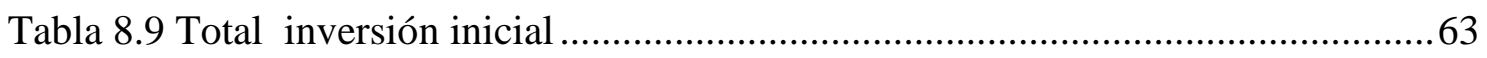

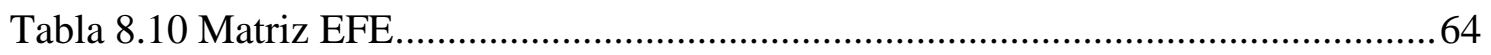

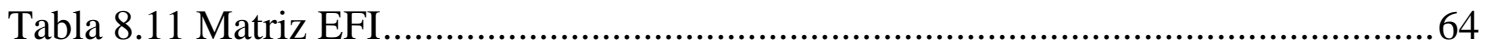

Tabla 9.1 Criterios de Control e Indicadores de Gestión...............................................66 


\section{ÍNDICE DE FIGURAS}

Figura 1.1 Crecimiento de la Población Peruana (Número de Habitantes) ......................3

Figura 1.2 Población económicamente activa ocupada ..............................................

Figura 1.3 Población económicamente activa ocupada ................................................

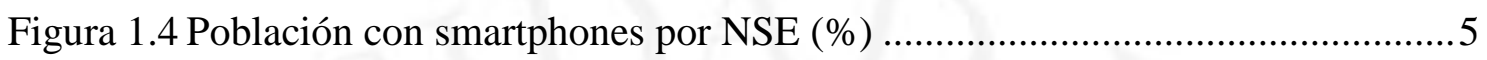

Figura 1.5 Población con smartphones por edad $(\%)$..................................................

Figura 1.6 Modelo Canvas aplicado a idea de Negocio.................................................

Figura 2.1 Clasificación CIIU de la actividad económica ........................................... 16

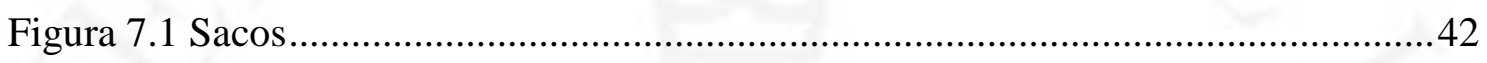

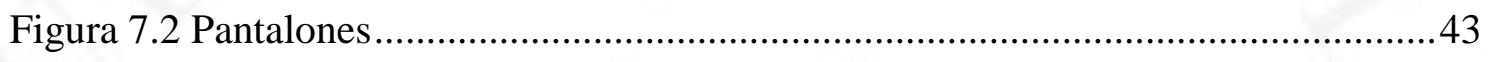

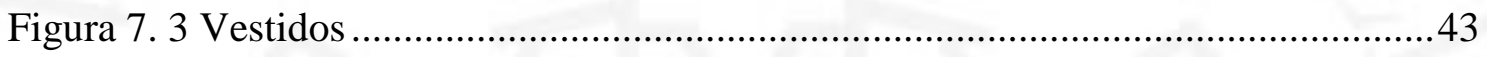

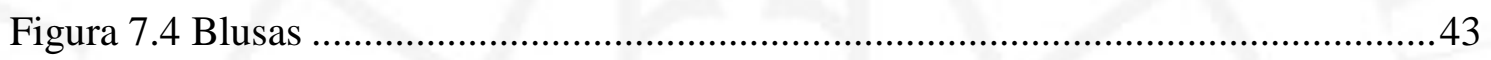

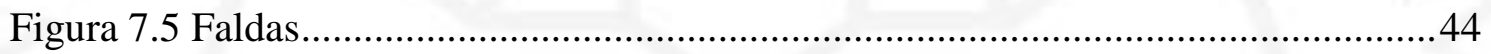

Figura 7.6 Flor de servicio adaptado al modelo de negocio .......................................45

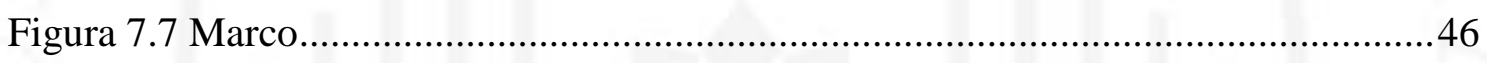

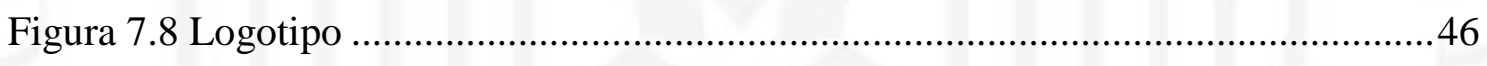

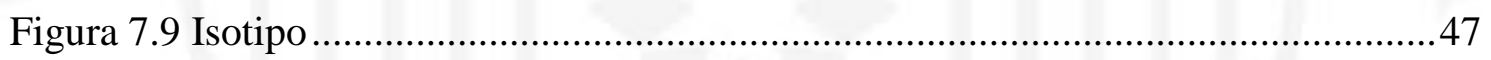

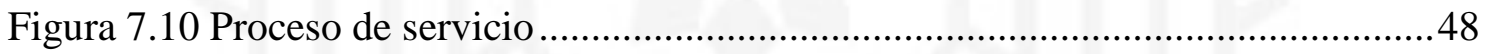

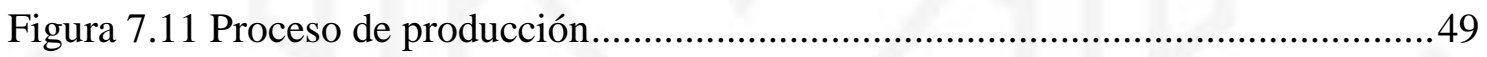

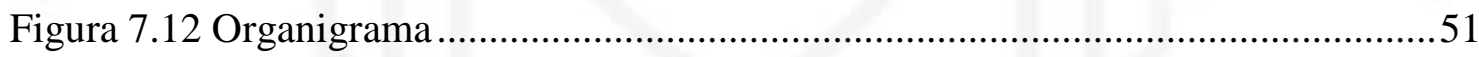

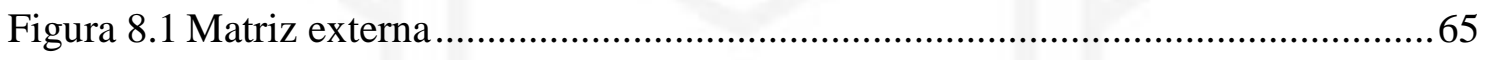




\section{ÍNDICE DE ANEXOS}

ANEXO 1: Guía de entrevistas a profundidad ........................................................ 71

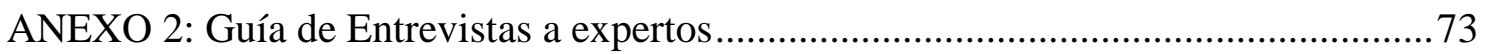

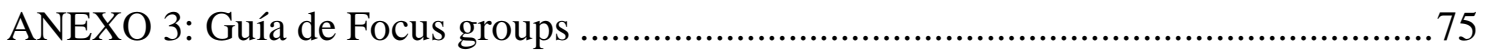

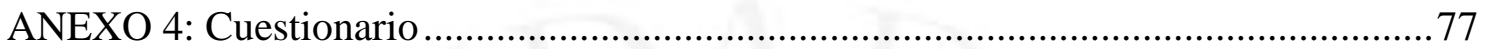

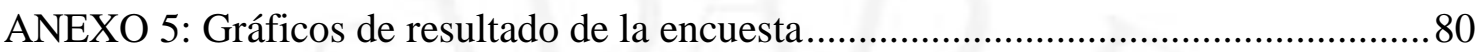




\section{INTRODUCCIÓN}

En el presente trabajo de investigación se presentará una nueva idea de negocio que es la confección de prendas de vestir a medida con servicio diferenciado. Nos referimos a servicio diferenciado por el servicio adicional que ofreceremos a nuestras clientas. El proyecto tiene como objetivo incrementar la demanda, por ello se aplicarán distintas herramientas para medir y validar que el negocio pueda prosperar. A continuación presentaremos factores que justifican la idea de negocio.

Para ello, como primer paso se utilizaron herramientas como el análisis VRIO, factores del macro ambiente y las cinco fuerzas de Porter. Estas herramientas se utilizaron para determinar ventajas competitivas sostenibles, analizar variables del entorno, pero sobre todo del sector. Se debe tener claro el panorama al que se va a enfrentar, ya que se busca un negocio sólido para poder crear un océano azul sostenible en el tiempo.

Se llevó a cabo entrevistas, focus group y encuestas para determinar el grado de aceptación de la idea de negocio. Asimismo, se validaron las características del target para reforzar el diseño del marketing mix. Para ello se tomó una muestra con el objetivo de analizar percepciones, hábito de compra, entre otros. En este escenario se buscó explicar al $100 \%$ el detalle del negocio para tener como resultado aportes de mejora y evaluar el grado de aceptación.

Luego de determinar el público objetivo y sus características, se determinó la demanda proyectando ventas que irán en aumento y con ello el aumento de los márgenes con el objetivo de incrementar ingresos. En base a los resultados se demostró que estamos en capacidad de incrementar nuestras ventas sustentadas en inversión de iniciativas que impulsarán la marca. Como es un negocio que recién empieza proyectamos un aumento de $5 \%$ en la demanda para los primeros 2 años.

Para realizar el plan de marketing se determinaron estrategias fundamentales para generar ventaja competitiva. No solo son estrategias para el producto, también lo fueron para determinar el precio. Por otro lado determinar el precio es importante porque se debe tomar en cuenta la percepción o el monto que está dispuesto el público objetivo a pagar por determinada prenda. 
Para poder implementar el plan de marketing con estrategias es fundamental justificar con el análisis numérico. Se tomó en cuenta que fue necesaria una cotización previa para implementar el negocio logrando que éstos sean los mejores en el mercado para brindar las mejores prendas terminadas para las clientas.

La confección de prendas de vestir tiene dos momentos claves los cuales son: el proceso de venta (servicio) y el proceso de producción. Como proceso de servicio se busca optimizar tiempos y entregar el mejor servicio de parte de las costureras como del personal con contacto directo con el cliente. Se asignarán roles y tareas para todos los involucrado en el proceso de servicio de venta. Es muy importante que el servicio cubra expectativas ya que lo que queremos es generar confianza y lo más importante, la recompra. Respecto al proceso de confección debemos tener en cuenta que los principales procesos de producción son la preparación del molde y la toma de medidas. Con una toma de medidas exacta, no se requerirán mayor número de pruebas, lo cual reducirá el tiempo de entrega.

Se determinó los tipos de prendas que se ofrecerán al target (de acuerdo a las entrevistas), así como sus características y la presentación de la marca. El diseño de la marca y logo guardará relación con la idea de negocio para generar posición de marca en el mediano plazo. Buscamos que la marca sea recordada por nuestras clientas para que la frecuencia de citas vaya en aumento en un mediano plazo.

Definir actividades de comunicación para el cliente aprovechando el canal electrónico que es hoy un medio por el cual se puede llegar en menor tiempo a nuestras clientas. Sin actividades de comunicación será difícil retener a las clientas y será difícil lograr la fidelización, el cual es uno de los principales objetivos de la marca.

Se determinará la sostenibilidad del plan de investigación con el análisis VAN el cual proyectamos que sea positivo para un mejor desarrollo del negocio. Con el resultado se podrá definir la rentabilidad de la idea de negocio y la estimación de la ganancia por cada año que se proyecte el cual nos permitirá crecer sólidos en el mercado.

Por último se definió indicadores de control para monitorear el desarrollo del negocio y alcanzar los objetivos planteados. Los indicadores nos generarán un panorama de cómo va avanzando el negocio el cual esperamos que sea un negocio que vaya en ascenso y genere rentabilidad. 


\section{CAPÍTULO I: IDEA DE NEGOCIO}

\subsection{Descripción y justificación de la oportunidad identificada}

He identificado que hoy en día las mujeres que forman parte del estilo de vida moderna y sofisticada buscan exclusividad, comodidad, ser originales y diferenciarse una de otra. Comprar en una tienda por departamento implica arriesgar encontrar un vestido, un saco, una blusa o cualquier otra prenda del mismo modelo por la calle o en alguna reunión social.

Además, la oferta existente en los grandes almacenes de ropa no se adecúa a las características de la mujer peruana. Las tallas que encontramos en tiendas por departamento son tallas estándar (S, M, L) obligándolas a buscar tiendas especializadas de ropa a medida o modificando las prendas, arriesgando a cambiarlas en su totalidad.

Asimismo, factores económicos como demográficos hicieron posible que el mercado de lujo incrementará en un 6,7\% el 2017 (Gonzales, 2018). A continuación, se sustentará la idea de negocio en primer lugar, con el crecimiento de la población peruana que ha ido en aumento desde 1981 hasta la fecha con una población estimada de 31, 826,018 habitantes (Figura 1.1).

Figura 1.1

Crecimiento de la Población Peruana (Número de Habitantes)

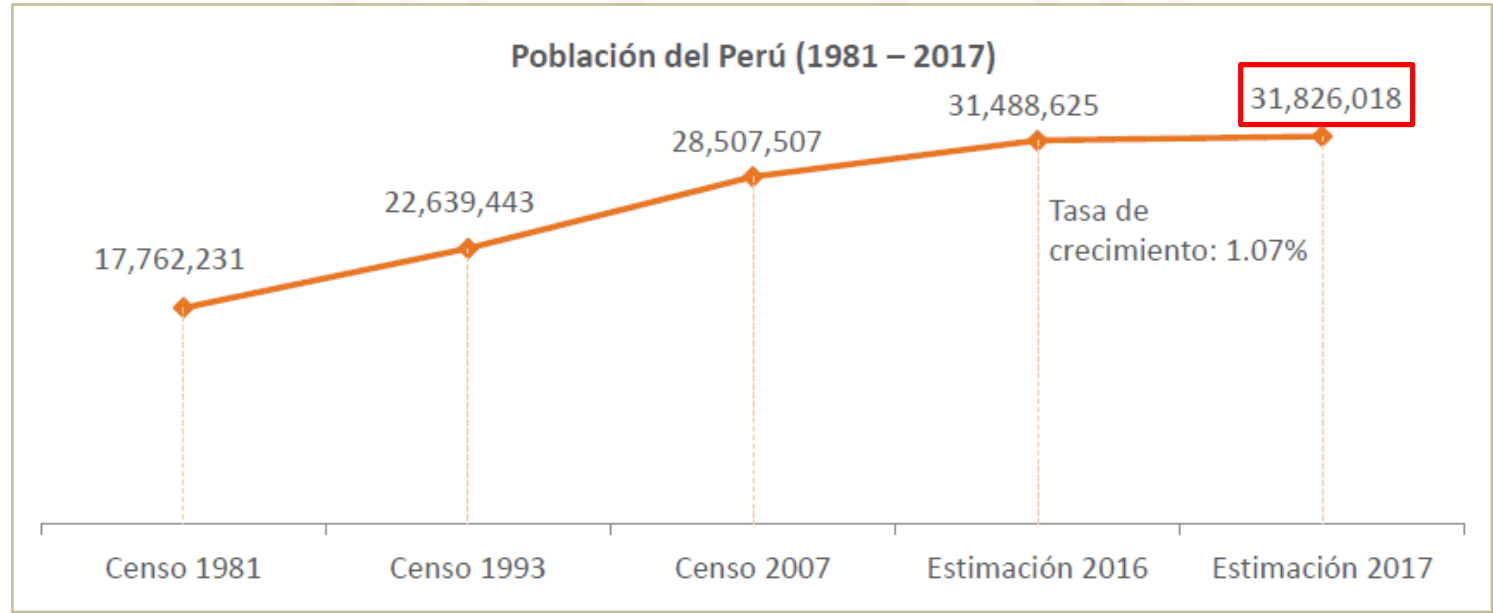

Nota: Se consideran los censos realizados a nivel nacional y las estimaciones para 2016 y 2017. Fuente: Ipsos Apoyo (2017). Estadística Poblacional.

La población limeña está compuesta por un total de 10’212,604 de habitantes, la población femenina representa un 51.2\% (Ipsos Apoyo, 2017); notamos la mayor 
presencia femenina en Lima. Esta es una gran oportunidad ya que el negocio está dirigido a mujeres. Además, el Producto Bruto Interno (PBI) del país creció 3.2\% al cierre del primer trimestre del año 2018 hasta el pasado mes de febrero (Instituto Nacional de Estadística e Informática, 2018).

Figura 1.2

Población económicamente activa ocupada

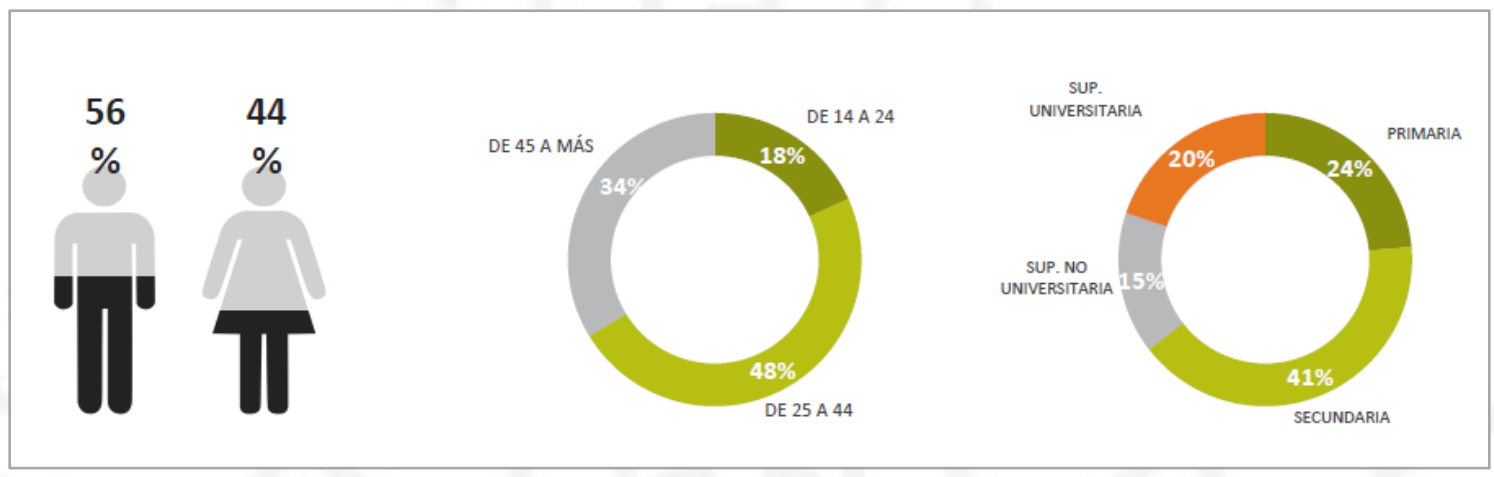

Fuente: Ipsos Apoyo (2017). Estadística Poblacional

Hoy en día las mujeres modernas y sofisticadas se han insertado en el mundo laboral obteniendo así sus propios ingresos (Figura 1.2). Las mujeres ocupan puestos desde trabajadora del hogar hasta puestos de gerencia. Nuestra empresa se enfocará en mujeres profesionales.

Figura 1.3

Estructura del gasto real per cápita según grupo de gasto 2017: Perú (\%)

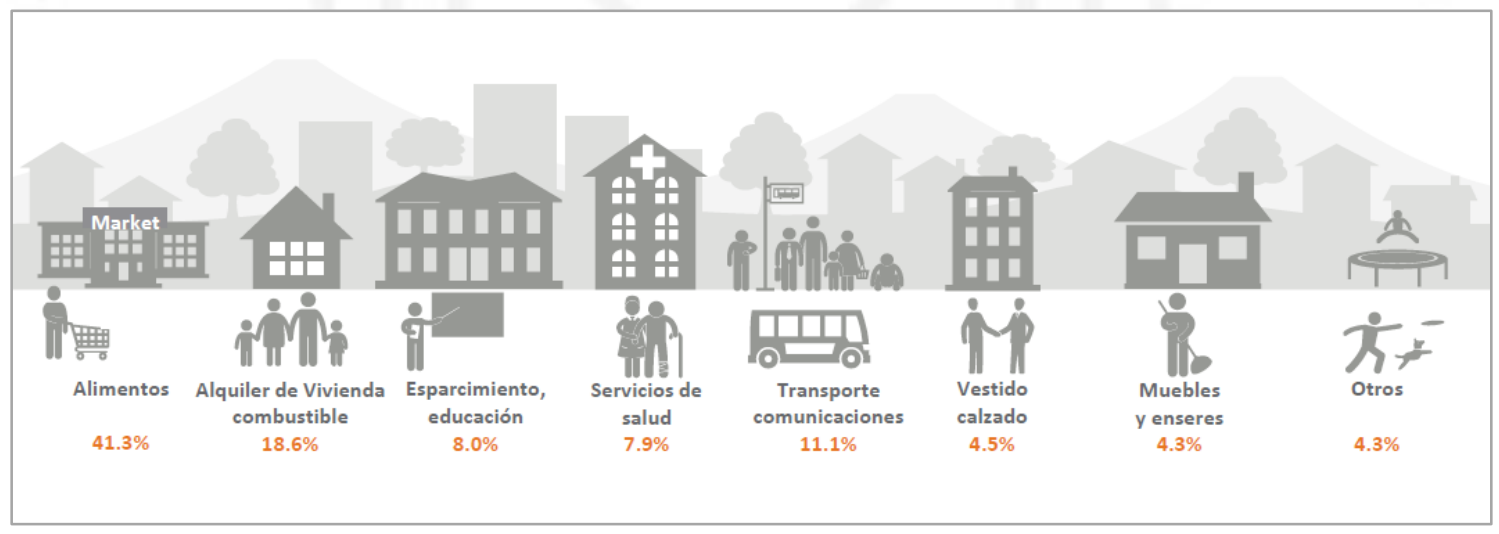

Fuente: Ipsos Apoyo (2017). Estadística Poblacional

Dentro de las categorías en las que el peruano gasta su salario se encuentran: alimentos, alquiler de vivienda y combustible, educación, servicios de salud, transporte y comunicaciones, vestido y calzado, muebles, entre otros (Ipsos Apoyo, 2017). 
Respecto a la comunicación, hoy en día casi todos los peruanos cuentan con un teléfono celular. En este caso, nos enfocaremos a los NSE A y B quienes normalmente cuentan con un smartphone. En el NSE A, el 95\% cuenta con un smartphone y el NSE B, el 79\% (Ipsos Apoyo, 2017) (Figura 1.4). Es importante el uso de un smartphone o teléfono celular pues permite un contacto directo, eficiente y rápido con el cliente, no solo en el contacto inicial, sino también durante el proceso del servicio. Además, el $73 \%$ de jóvenes adultos de 25-39 años hace uso de manera constante de un smartphones. (Figura 1.5).

Figura 1.4

Población con smartphones por NSE (\%)

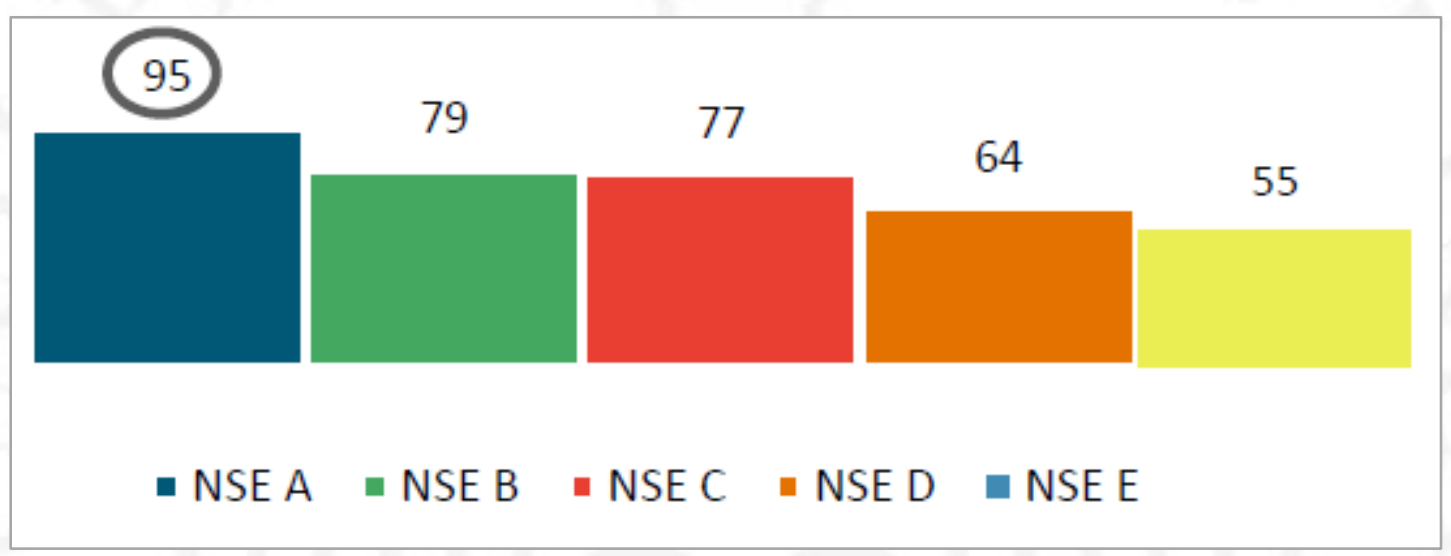

Fuente: Ipsos Apoyo (2017). Uso y actitudes hacia la telefonía móvil.

Figura 1.5

Población con smartphones por edad (\%)

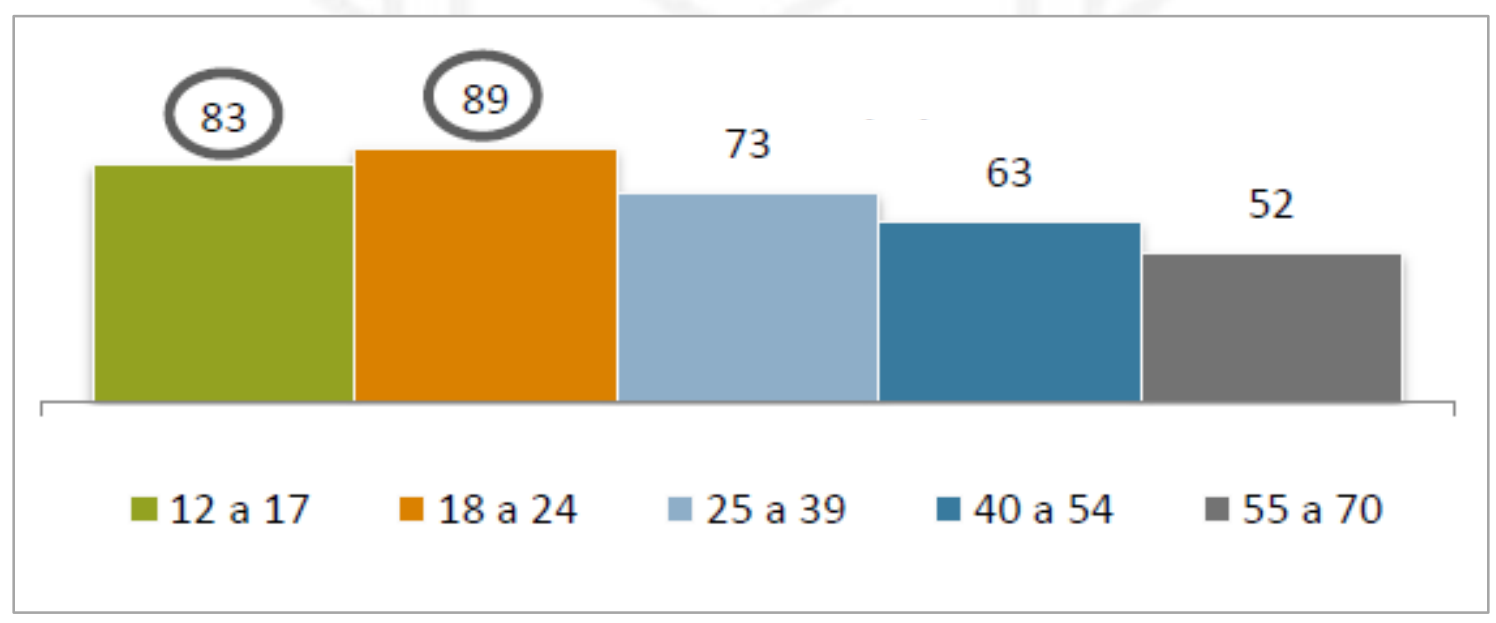

Fuente: Ipsos Apoyo (2017). Uso y actitudes hacia la telefonía móvil. 


\subsection{Definición de la propuesta de valor}

La empresa brindará un servicio de confección, donde nuestras clientas no se verán en la necesidad de movilizarse para la compra de tela o algún otro insumo. Como propuesta de valor diferencial trabajaremos de la mano con un diseñador de moda y adicionalmente ofreceremos una asesoría de imagen completa, acompañada de las más recientes tendencias de moda. Asimismo, ir hasta donde esté la clienta para la elección de la prenda, toma de medidas, prueba de la prenda y entrega a domicilio del producto terminado. Cabe resaltar que el servicio será uno de nuestros principales pilares para brindar la mejor experiencia a nuestras clientas.

Las prendas se confeccionarán con telas de calidad que al ser lavadas no se encogerán ni perderán su color. No solo se confeccionarán prendas de uso diario de trabajo, también se confeccionarán prendas para distintas ocasiones como reuniones sociales, cocktails, bodas, bautizos, cumpleaños, etc. Prendas con las que nuestras clientas se sentirán cómodas y a gusto con lo que llevan puesto, aumentando su autoestima y sacando lo mejor de ellas al vestir una prenda hecha a su medida.

\subsection{Descripción del modelo de negocio}

Somos una empresa conformada por mujeres emprendedoras especializadas en confección de prendas de vestir a medida como sastres, blusas, vestidos para cocktail, vestidos de noche, vestidos de novia, entre otros. Contamos con expertas en costura, diseño y asesoría de imagen. Buscamos la total satisfacción de nuestros clientes brindando nuestros servicios de lunes a sábado con horarios a disposición de las clientas.

Nuestras clientas tendrán la libertad de elegir su diseño mediante imágenes de catálogos, páginas web, aplicaciones y/o creaciones propias. Se le ofrecerá las últimas tendencias por medio de catálogos y muestrarios de telas con el fin de brindar más opciones a la hora de elegir la prenda esperada.

Las citas se darán en casa o el lugar de preferencia de la clienta con previa anticipación con el fin de atender a todas nuestras clientas entregando el mejor servicio y asesoría. La representante de la empresa junto al diseñador serán quienes asistan a casa del cliente o al lugar de cita para la selección del modelo de la prenda, toma de medidas, pruebas de la prenda para definir cambios y entrega final. 


\subsection{Diseño del modelo de negocio mediante el modelo Canvas}

A continuación se muestra el modelo de negocio de acuerdo con el modelo Canvas en base al servicio diferenciado de confección a medida de prendas de vestir.

Figura 1.6

Modelo Canvas aplicado a idea de Negocio

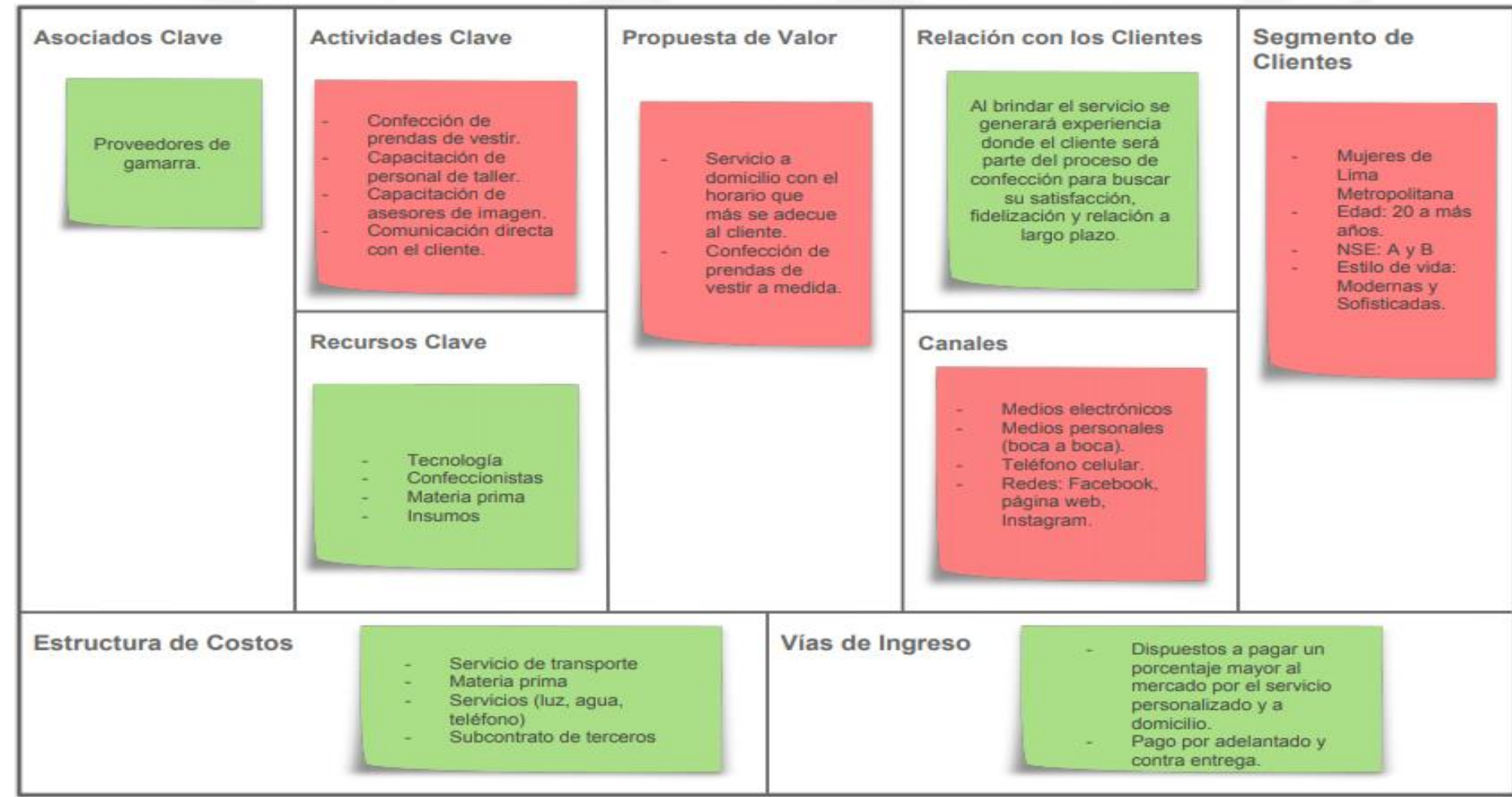

Fuente: Adaptado de Osterwalder y Pigneur (2013). 


\section{CAPÍTULO II: ANÁLISIS DE SITUACIÓN}

\subsection{Análisis del ambiente interno}

\subsubsection{Misión, visión y valores de la empresa}

- Misión:

"Tenemos una responsabilidad con las mujeres peruanas. Queremos hacerlas sentir seguras, empoderadas y modernas".

- Visión:

Empresa líder en confección y servicio personalizado al cliente. Buscamos posicionarnos como la mejor marca para nuestras clientas a nivel nacional.

- Valores:

○ Pasión: Brindamos el mejor servicio apoyándonos con el mejor equipo profesional amante de la moda.

- Responsabilidad: Somos responsables en brindar prendas y servicio de calidad a nuestras clientes.

\subsubsection{Análisis de recursos: fortalezas y debilidades}

Tabla 2.1

Identificación de fortalezas y debilidades

\begin{tabular}{|l|l|}
\hline Fortalezas & Debilidades \\
\hline Experiencia & Capacidad financiera \\
\hline Know - How & Poco conocido por la cliente \\
\hline Logística & Acabados especiales (bordados) \\
\hline Procesos definidos & Management \\
\hline
\end{tabular}

Fuente: Elaboración propia.

\subsubsection{Análisis VRIO}

Con el siguiente análisis VRIO (valioso, raro, inimitables, organizados) identificaremos recursos y capacidades, para finalmente rescatar ventajas competitivas del servicio de confección a medida. 
Tabla 2.2

Análisis de ambiente interno VRIO

\begin{tabular}{|c|c|c|c|c|c|c|}
\hline & RECURSOS & CAPACIDADES & V & $\mathbf{R}$ & I & $\mathbf{0}$ \\
\hline \multirow{4}{*}{ 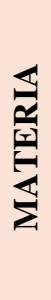 } & Financiero & Generar rentabilidad e inversión. & $\checkmark$ & $\times$ & $x$ & $\checkmark$ \\
\hline & Taller & $\begin{array}{l}\text { Optimizar costos. Producir. Desarrollar actividades } \\
\text { de confección. }\end{array}$ & $\checkmark$ & $\checkmark$ & $x$ & $\checkmark$ \\
\hline & Máquinas de coser & Mejorar calidad, acabado y reducir costos. & $\checkmark$ & $\checkmark$ & $\times$ & $\checkmark$ \\
\hline & Materia Prima & Confeccionar prendas. & $\checkmark$ & $\times$ & $x$ & $\checkmark$ \\
\hline \multirow{4}{*}{ 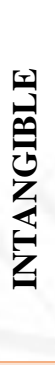 } & Experiencia & $\begin{array}{l}\text { Optimizar procesos, reducir fallas. Evitar } \\
\text { accidentes. Generar valor agregado al cliente. }\end{array}$ & $\checkmark$ & $\checkmark$ & $\checkmark$ & $\checkmark$ \\
\hline & Know - how & $\begin{array}{l}\text { Diferenciar servicio de la competencia. Reducir } \\
\text { tiempo de entrega. }\end{array}$ & $\checkmark$ & $\checkmark$ & $\checkmark$ & $\checkmark$ \\
\hline & Management & $\begin{array}{l}\text { Dirigir eficientemente los procesos y recursos } \\
\text { humanos. }\end{array}$ & $\checkmark$ & $x$ & $\checkmark$ & $\checkmark$ \\
\hline & Innovación & $\begin{array}{l}\text { Visita al cliente a su hogar junto a un diseñador y } \\
\text { ofrecer un servicio adicional de asesoría de imagen. }\end{array}$ & $\checkmark$ & $\checkmark$ & $x$ & $\checkmark$ \\
\hline \multirow{3}{*}{ 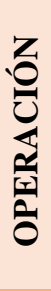 } & Logística & $\begin{array}{l}\text { Tener materiales disponibles cuando se requieran. } \\
\text { Seleccionar proveedores adecuados. }\end{array}$ & $\checkmark$ & $\checkmark$ & $x$ & $\checkmark$ \\
\hline & Procesos definidos & $\begin{array}{l}\text { Estandarizar procesos para reducir tiempos de } \\
\text { entrega. Estandarizar calidad de producto. }\end{array}$ & $\checkmark$ & $\checkmark$ & $\checkmark$ & $\checkmark$ \\
\hline & Producción & $\begin{array}{l}\text { Generar producto final. Satisfacer demanda. } \\
\text { Cumplir con tiempos de entrega. }\end{array}$ & $\checkmark$ & $\times$ & $x$ & $\checkmark$ \\
\hline \multirow{2}{*}{ 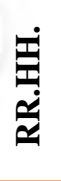 } & Personal de servicio & $\begin{array}{l}\text { Mantener local en condiciones adecuadas. Brindar } \\
\text { buena imagen. }\end{array}$ & $\checkmark$ & $\times$ & $x$ & $\checkmark$ \\
\hline & $\begin{array}{l}\text { Personal con } \\
\text { experiencia }\end{array}$ & $\begin{array}{l}\text { Realizar acabados especiales (ej. Bordado, } \\
\text { pedrería). Diseñador de moda y asesora de imagen. }\end{array}$ & $\checkmark$ & $x$ & $x$ & $\checkmark$ \\
\hline
\end{tabular}

Fuente: Elaboración propia.

El análisis VRIO realizado determinó que la empresa cuenta con ventajas competitivas sostenibles como la experiencia, el know-how y los procesos definidos. Estos recursos presentan las cuatro características de un análisis VRIO.

Como empresa, deberíamos convertir todos nuestros recursos en ventajas competitivas sostenibles para seguir vigentes en el mercado a largo plazo.

Tabla 2.3

Matriz EFI

\section{VALOR}

FORTALEZAS

\begin{tabular}{|l|l|l|l|}
\hline 1. Experiencia & 0.13 & 4 & 0.52 \\
\hline 2. Know How & 0.14 & 4 & 0.56 \\
\hline 3. Logística & 0.11 & 4 & 0.44 \\
\hline
\end{tabular}

(continúa) 
(continuación)

\begin{tabular}{|l|c|c|c|}
\hline 4. Procesos definidos & 0.17 & 4 & 0.68 \\
\hline DEBILIDADES & & & \\
\hline 1. Capacidad financiera & 0.12 & 2.5 & 0.3 \\
\hline 2. Poco reconocimiento (cliente) & 0.09 & 2 & 0.18 \\
\hline 3. Acabados especializados (bordados) & 0.11 & 2.5 & 0.275 \\
\hline 4. Management & 0.13 & 2.5 & 0.325 \\
\cline { 1 - 3 } & 1 & & 3.28 \\
\cline { 2 - 4 } & &
\end{tabular}

Fuente: Elaboración propia.

Conclusiones:

- Como mayor fortaleza contamos con procesos definidos gracias a nuestros casi 30 años de experiencia en el mercado.

- Una debilidad de mayor importancia es el poco reconocimiento de parte del cliente ya que no somos una marca reconocida. 


\subsection{Análisis del macro ambiente}

Tabla 2.4

Análisis del macro ambiente

\begin{tabular}{|c|c|c|c|c|c|}
\hline $\begin{array}{c}\text { FUERZA } \\
\text { MACROAMBIENTAL }\end{array}$ & $\begin{array}{c}\text { VARIABLE DE } \\
\text { FUERZA } \\
\text { MACROAMBIENTAL }\end{array}$ & RESULTADO & $\begin{array}{l}\text { IMPACTO EN SERVICIO } \\
\text { DIFERENCIADO DE } \\
\text { CONFECCIÓN A MEDIDA }\end{array}$ & $\begin{array}{l}\text { OPORTUNIDAD } \\
\text { / AMENAZA }\end{array}$ & FUENTE \\
\hline \multirow{3}{*}{ DEMOGRÁFICAS } & Población de Lima & $\begin{array}{l}\text { Lima cuenta con } \\
10 ’ 212,604 \text { de } \\
\text { habitantes. }\end{array}$ & $\begin{array}{l}\text { El incremento de la población nos } \\
\text { permite oportunidad de negocio en } \\
\text { el rubro. }\end{array}$ & Oportunidad & ( Ipsos Apoyo, 2017) \\
\hline & Género & $\begin{array}{l}\text { En Lima, las mujeres } \\
\text { comprenden una } \\
\text { población de } \\
5,349,758 \text {. }\end{array}$ & $\begin{array}{l}\text { La población limeña en su } \\
\text { mayoría es femenina, el cual } \\
\text { genera mayor demanda. }\end{array}$ & Oportunidad & (Ipsos Apoyo, 2018) \\
\hline & Estilos de Vida & $\begin{array}{l}\text { Las modernas } \\
\text { representan el } 26 \% \text { y } \\
\text { las sofisticadas el } 6 \% \\
\text { de la población peruana }\end{array}$ & $\begin{array}{l}\text { Nuestro público objetivo estará } \\
\text { orientado a los dos estilos de vida. }\end{array}$ & Oportunidad & $\begin{array}{l}\text { (Arellano Marketing, } \\
\text { 2014) }\end{array}$ \\
\hline \multirow[b]{2}{*}{ ECONÓMICAS } & PBI & $\begin{array}{l}\text { El primer trimestre del } \\
2018 \text { el PBI registró un } \\
\text { crecimiento de } 3.2 \%\end{array}$ & $\begin{array}{l}\text { Nuestro target será beneficiado } \\
\text { con mayores oportunidades } \\
\text { laborales incrementando su poder } \\
\text { adquisitivo. }\end{array}$ & Oportunidad & (INEI, 2018) \\
\hline & PEA & $\begin{array}{l}\text { Durante el } 2017 \text { la PEA } \\
\text { en Lima es de } 5,204 \\
\text { millones de personas. } \\
\text { Dividida en } 2,819 \\
\text { mujeres y } 2,385 \\
\text { hombres }\end{array}$ & $\begin{array}{l}\text { El } 28 \% \text { de la PEA tiene empleo } \\
\text { formal esto limita el acceso a } \\
\text { servicios y productos de mejor } \\
\text { calidad o especializados. }\end{array}$ & Amenaza & (Maza, 2018) \\
\hline
\end{tabular}

(continúa) 


\begin{tabular}{|c|c|c|c|c|c|}
\hline $\begin{array}{c}\text { FUERZA } \\
\text { MACROAMBIENTAL }\end{array}$ & $\begin{array}{c}\text { VARIABLE DE } \\
\text { FUERZA } \\
\text { MACROAMBIENTAL }\end{array}$ & RESULTADO & $\begin{array}{l}\text { IMPACTO EN SERVICIO } \\
\text { DIFERENCIADO DE } \\
\text { CONFECCIÓN A MEDIDA }\end{array}$ & $\begin{array}{l}\text { OPORTUNIDAD } \\
\text { / AMENAZA }\end{array}$ & FUENTE \\
\hline ECONÓMICAS & Inflación & $\begin{array}{l}\text { Se proyecta para el } \\
2018 \text { será de } 2.5 \% \\
\text { aproximado. }\end{array}$ & $\begin{array}{l}\text { Los precios de los insumos se } \\
\text { incrementan levemente sin superar } \\
\text { el crecimiento de ingresos } \\
\text { promedio de la PEA }\end{array}$ & Oportunidad & $\begin{array}{l}\text { (BCP se mantiene en } \\
\text { proyección de inflación } \\
\text { en 2,5\% este 2018, 2018) }\end{array}$ \\
\hline SOCIO - CULTURALES & Eventos de moda & $\begin{array}{l}\text { Herramienta importante } \\
\text { que generan negocio en } \\
\text { el rubro. }\end{array}$ & $\begin{array}{l}\text { Tendencias que pueden servir de } \\
\text { influencia para la clienta al decidir } \\
\text { un modelo. }\end{array}$ & Oportunidad & $\begin{array}{l}\text { (LIF Week y la apuesta } \\
\text { de los nuevos } \\
\text { diseñadores, 2018) }\end{array}$ \\
\hline \multirow[t]{2}{*}{ TECNOLÓGICAS } & Redes Sociales & $\begin{array}{l}\text { La población de NSE A } \\
\text { y B acceden a redes } \\
\text { sociales mediante } \\
\text { smartphones }(75 \%)\end{array}$ & $\begin{array}{l}\text { Promoción de la marca, poner en } \\
\text { vitrina a la empresa en donde se } \\
\text { muestran diseños realizados. }\end{array}$ & Oportunidad & (Ipsos Apoyo, 2017) \\
\hline & Telefonía & $\begin{array}{l}\text { Aproximadamente el } \\
70 \% \text { de los hogares } \\
\text { posee un celular. }\end{array}$ & $\begin{array}{l}\text { Se mantiene un contacto directo } \\
\text { con el cliente ya sea vía telefónica } \\
\text { o por mensajería instantánea. }\end{array}$ & Oportunidad & (Ipsos Apoyo, 2017) \\
\hline LEGAL & Formalización & $\begin{array}{l}\text { Tendencia hacia la } \\
\text { formalización }\end{array}$ & $\begin{array}{l}\text { Pasar de la informalidad a la } \\
\text { formalidad para constituirnos } \\
\text { como empresa legal. }\end{array}$ & Oportunidad & $\begin{array}{l}\text { (Hilacha y Trapitos, un } \\
\text { juego ecológico } \\
\text {,2018) }\end{array}$ \\
\hline ECOLÓGICO & Reciclaje & $\begin{array}{l}\text { Los talleres textiles } \\
\text { desechan material el } \\
\text { cual puede ser reusado. }\end{array}$ & $\begin{array}{l}\text { Las mermas textiles se } \\
\text { considerarán ingresos ya que son } \\
\text { adquiridas por empresas que } \\
\text { reutilizan el material. }\end{array}$ & Oportunidad & $\begin{array}{l}\text { (Gobierno crea nuevo } \\
\text { régimen societario: la } \\
\text { SACS, para } \\
\text { emprendedores, 2018) }\end{array}$ \\
\hline
\end{tabular}

Fuente: Elaboración propia 


\subsection{Análisis del micro ambiente}

\subsubsection{Determinación y descripción del entorno específico}

El entorno específico es la confección de prendas de vestir a medida. En Perú, aún contamos con una tasa de informalidad alta, el cual no permite definir contra quien o quienes estamos compitiendo.

El servicio de confección a medida se desarrolla gracias a la mejora en el poder adquisitivo de la mujer peruana que a su vez se sustenta en una prolongada estabilidad económica. La publicidad no se da por medios publicitarios ni otros medios convencionales. La publicidad en su mayoría es por boca a boca.

En su mayoría, quienes se dedican al negocio son mujeres en busca de independencia económica. Sin embargo, la confección hoy en día está certificada como una carrera profesional dirigido tanto para mujeres y hombres.

\subsubsection{Identificación y descripción de los competidores directos}

Nuestras competidoras directas son, al igual que nosotras, mujeres dedicadas a la costura. Algunas de ellas empezaron en talleres y fueron ganando experiencia a través de los años y hoy en día, como trabajadoras independientes, ofrecen el servicio de costura. No podemos cuantificarlas ya que en su mayoría no son formales. Es decir, no emiten factura o recibo por servicios.

Podemos decir que a las que consideramos como competidoras directas no ofrecen el servicio de asesoría de imagen y suelen ser conocidas por no cumplir con los tiempos pactados.

\subsubsection{Cuantificación del entorno específico en unidades y valor de la venta de la industria}

Analizaremos el sector retail ya que el sector de confección a medida aún se encuentra muy fragmentado. Para el 2017, se facturó 102,289 millones de soles en el canal de almacenes. Como muestra la Tabla 2.4, desde el 2012 hasta 2017 hemos percibido un crecimiento, el cual refleja la estabilidad económica del país. 
Tabla 2.5

Ventas en Perú del sector retail por canal: 2012-2017

\begin{tabular}{|c|c|c|c|c|c|c|}
\hline PEN million & $\mathbf{2 0 1 2}$ & $\mathbf{2 0 1 3}$ & $\mathbf{2 0 1 4}$ & $\mathbf{2 0 1 5}$ & $\mathbf{2 0 1 6}$ & $\mathbf{2 0 1 7}$ \\
\hline $\begin{array}{c}\text { Grocery } \\
\text { Retailers }\end{array}$ & $42,764.4$ & $45,108.4$ & $48,114.4$ & $49,971.6$ & $53,567.7$ & $57,775.1$ \\
\hline $\begin{array}{c}\text { Non-Grocery } \\
\text { Specialists }\end{array}$ & $24,369.8$ & $26,884.8$ & $29,468.5$ & $32,263.6$ & $34,825.7$ & $38,317.1$ \\
\hline $\begin{array}{c}\text { Mixed } \\
\text { Retailers }\end{array}$ & $5,019.3$ & $5,516.7$ & $6,249.1$ & $5,614.3$ & $6,018.6$ & $6,197.4$ \\
\hline $\begin{array}{c}\text { Luxury } \\
\text { Retailing }\end{array}$ & 8.2 & 8.0 & 8.0 & - & - & - \\
\hline $\begin{array}{c}\text { Off-price } \\
\text { Retailing }\end{array}$ & - & - & - & - & - & - \\
\hline $\begin{array}{c}\text { Store-based } \\
\text { Retailing }\end{array}$ & $72,153.4$ & $77,509.9$ & $83,831.9$ & $87,849.5$ & $94,412.0$ & $102,289.6$ \\
\hline
\end{tabular}

Nota: No incluye los retails de lujo

Fuente: Euromonitor International (2018).

En cuanto a participación de mercado por marcas en el sector retail (Tabla 2.6) encontramos a "Plaza Vea" con mayor porcentaje de participación desde el año 2014 con $3.2 \%$ hasta el 2017 con $3.9 \%$

Tabla 2.6

Participación en el mercado retail por marcas en Perú de 2014 a 2017

\begin{tabular}{|c|c|c|c|c|c|}
\hline $\begin{array}{l}\text { \% retail value rsp } \\
\text { excl sales tax }\end{array}$ & Company (GBO) & 2014 & 2015 & 2016 & 2017 \\
\hline Plaza Vea & InRetail Peru Corp & 3.5 & 3.8 & 3.9 & 3.9 \\
\hline Tottus & Falabella SACI & 3.3 & 3.1 & 3.3 & 3.3 \\
\hline Metro & Cencosud SA & 3.9 & 3.2 & 3.0 & 3.2 \\
\hline Saga Falabella & Falabella SACI & 3.3 & 3.0 & 3.1 & 2.9 \\
\hline Sodimac & Falabella SACI & 2.3 & 2.1 & 2.0 & 1.9 \\
\hline Ripley & Ripley Corp SA & 2.7 & 2.1 & 2.0 & 1.9 \\
\hline Mifarma & Química Suiza SA & 0.3 & 0.3 & 1.4 & 1.8 \\
\hline Inkafarma & InRetail Peru Corp & 1.7 & 1.8 & 1.8 & 1.7 \\
\hline Maestro Perú & Falabella SACI & 1.7 & 1.8 & 1.7 & 1.6 \\
\hline Hiraoka & Importaciones Hiraoka SA & 1.3 & 1.1 & 1.0 & 1.0 \\
\hline Promart & InRetail Peru Corp & 0.7 & 0.7 & 0.7 & 0.8 \\
\hline La Curacao & Tiendas Efe SA & 0.8 & 0.8 & 0.8 & 0.7 \\
\hline Topi Top & Topy Top SA & 0.6 & 0.6 & 0.6 & 0.6 \\
\hline Oechsle & InRetail Peru Corp & 0.9 & 0.7 & 0.7 & 0.6 \\
\hline Wong & Cencosud SA & 1.0 & 0.6 & 0.6 & 0.6 \\
\hline Celima & Corporación Cerámica SA & 0.8 & 0.7 & 0.6 & 0.6 \\
\hline Tai Loy & Tai Loy SA & 0.6 & 0.5 & 0.6 & 0.6 \\
\hline Vivanda & InRetail Peru Corp & 0.5 & 0.5 & 0.5 & 0.6 \\
\hline Tiendas Efe & Tiendas Efe SA & 0.6 & 0.6 & 0.5 & 0.5 \\
\hline Elektra & Grupo Elektra SAB de CV & 0.6 & 0.5 & 0.5 & 0.5 \\
\hline Others & Others & 68.9 & 71.6 & 70.6 & 70.7 \\
\hline Total & Total & 100.0 & 100.0 & 100 & 100. \\
\hline
\end{tabular}

Fuente: Euromonitor International (2018).

Se observa que en la Tabla 2.7 se analiza toda la data recolectada considerando la participación de marcas y su porcentaje de valor. Considerando tiendas por departamento, 
en primer lugar se encuentra Saga Falabella, seguido de Ripley, Oeschle, Topi Top, entre otros.

Considerar que las primeras 5 empresas de retail también están en el negocio de comercialización de prendas de vestir.

Tabla 2.7

Participación en el mercado por marcas en Perú de 2014 a 2017

\begin{tabular}{|l|l|c|c|c|c|}
$\begin{array}{c}\text { \% retail value } \\
\text { rsp excl sales tax }\end{array}$ & Company (GBO) & 2014 & 2015 & 2016 & 2017 \\
\hline Plaza Vea & InRetail Peru Corp & 3.2 & 3.5 & 3.6 & 3.6 \\
\hline Tottus & Falabella SACI & 3.1 & 2.9 & 3.1 & 3.1 \\
\hline Metro & Cencosud SA & 3.6 & 2.9 & 2.8 & 3.0 \\
\hline Saga Falabella & Falabella SACI & 3.2 & 2.9 & 2.9 & 2.8 \\
\hline Ripley & Ripley Corp SA & 2.5 & 2.1 & 2.1 & 2.0 \\
\hline Topi Top & Topy Top SA & 0.5 & 0.5 & 0.6 & 0.6 \\
\hline Oechsle & InRetail Peru Corp & 0.5 & 0.6 & 0.6 & 0.6 \\
\hline Others & Others & 70.6 & 73.0 & 72.1 & 72.1 \\
\hline
\end{tabular}

Fuente: Euromonitor International (2018).

\subsubsection{Clasificación CIIU de la actividad económica}

A continuación se presentará la clasificación CIIU del servicio diferenciado de confección a medida que más se adecúa a la idea de negocio.

- Sección C: Industrial manufactureras

- División 14: Fabricación de prendas de vestir

- Grupo 141: Fabricación de prendas de vestir, excepto prendas de piel

- Clase 1410: Fabricación de prendas de vestir, excepto prendas de piel 
Figura 2.1

Clasificación CIIU de la actividad económica

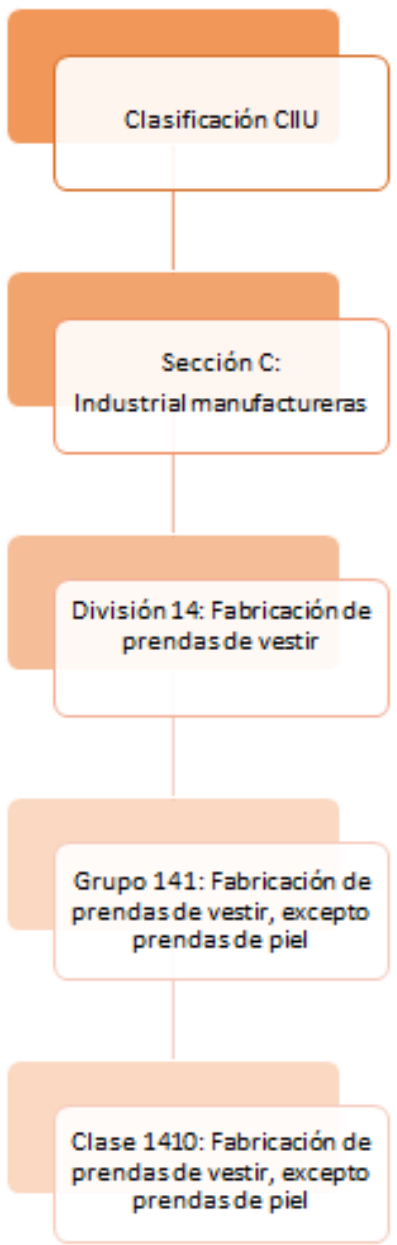

Fuente: Elaboración propia.

\subsubsection{Análisis de las 5 fuerzas de Porter}

A continuación se muestra el análisis del sector mediante las fuerzas de Porter (Porter, 2013).

La industria de confección de prendas de vestir a medida es atractiva gracias al acceso que se tiene con los proveedores, a una creciente demanda y a la oportunidad de ofrecer un servicio diferenciado. Esto nos permite obtener un gran poder de negociación con el cliente. Sin embargo, debemos tener en la mira a futuros competidores, donde el campo está siendo aprovechado por jóvenes emprendedores que buscan ingresos propios satisfaciendo la demanda femenina. Además de ellos, las casas de diseñadores reconocidos a nivel mundial que poco a poco van inaugurando boutiques en Lima. 
Asimismo la amenaza de productos sustitutos es alta gracias al sector retail que mantiene su posicionamiento alrededor del país.

Tabla 2.8

Análisis de sector de confecciones mediante fuerzas de Porter

\begin{tabular}{|c|c|c|}
\hline FUERZA & DESCRIPCIÓN & PODER \\
\hline \multirow{3}{*}{ Rivalidad sectorial existente } & El sector está fragmentado y aún no hay información cuantificable. (-) & \multirow{3}{*}{ Medio } \\
\hline & Existen boutiques, pero son pocos y se ubican en distritos como San Isidro y Miraflores. (+) & \\
\hline & El sector retail cada año va creciendo inaugurando tiendas a nivel nacional. (-) & \\
\hline \multirow{6}{*}{$\begin{array}{l}\text { Amenaza potenciales } \\
\text { competidores }\end{array}$} & Productos chinos que se venden a precios bajos. (-) & \multirow{6}{*}{ Alta } \\
\hline & $\begin{array}{l}\text { Los negocios informales son los principales competidores, aunque aún son pocos quienes se dedican a la confección } \\
\text { a medida. }(+)\end{array}$ & \\
\hline & $\begin{array}{l}\text { En Gamarra podemos encontrar confeccionistas al igual que en Jesús María. Usualmente cercanos a centros } \\
\text { comerciales. (-) }\end{array}$ & \\
\hline & Jóvenes que estudian/estudiaron diseño de modas y confección y ahora emprenden negocio. (-) & \\
\hline & Empresas que venden sus marcas propias por redes sociales. (-) & \\
\hline & La estabilidad económica del país incentiva la creación de nuevas empresas y negocios. (+) & \\
\hline \multirow{3}{*}{$\begin{array}{l}\text { Amenaza de productos } \\
\text { sustitutos }\end{array}$} & El número de retails que existe en Perú cada vez va en aumento y cada vez más cerca del cliente. (-) & \multirow{3}{*}{ Alta } \\
\hline & Ropa que se vende en tiendas por departamento como Saga Falabella, Ripley, H\&M, Oeschle, entre otros. (-) & \\
\hline & Tiendas de diseñador que crean prendas de acuerdo al cuerpo de cliente y requerimientos. (-) & \\
\hline \multirow{3}{*}{$\begin{array}{l}\text { Poder de negociación de } \\
\text { clientes }\end{array}$} & La compra por internet (redes sociales) permite tener más opciones a la hora de seleccionar una prenda. $(+)$ & \multirow{3}{*}{ Alto } \\
\hline & $\begin{array}{l}\text { Si el cliente queda satisfecho con el servicio o producto, se genera un comentario positivo que puede ser transmitido } \\
\text { a su círculo social. (+) }\end{array}$ & \\
\hline & Los clientes son los que eligen el modelo, la tela y demás insumos. $(+)$ & \\
\hline \multirow{3}{*}{$\begin{array}{l}\text { Poder de negociación de } \\
\text { proveedores }\end{array}$} & $\begin{array}{l}\text { Se pueden encontrar variedad de telas en Gamarra. Más de un local se dedica a la venta de telas importadas como } \\
\text { nacionales. (+) }\end{array}$ & \multirow{3}{*}{ Alto } \\
\hline & En el caso de los cierres, existe más de una empresa que se dedica a la producción de cierres como cierres "Rey”. (+) & \\
\hline & $\begin{array}{l}\text { El acceso a la compra de hilos para costura es rápido ya que no solo existe un punto de venta. En su mayoría se ubican } \\
\text { en Gamarra. (+) }\end{array}$ & \\
\hline
\end{tabular}

Fuente: Adaptado de Michael Porter (2013). 
Tabla 2.9

\section{Matriz EFE}

\section{\begin{tabular}{l|l|} 
VALOR & CLASIFICACIÓN
\end{tabular}}

OPORTUNIDADES

\begin{tabular}{|l|l|c|c|}
\hline 1. Mayor población femenina & 0.11 & 3 & 0.33 \\
\hline 2. Orientación del gobierno & 0.09 & 3 & 0.27 \\
\hline 3. Eventos de moda & 0.15 & 4 & 0.6 \\
\hline 4. Redes sociales & 0.17 & 4 & 0.68 \\
\hline A MENAZAS
\end{tabular}

\begin{tabular}{|l|c|c|c|}
\hline 1. Sector retail en aumento & 0.11 & 2 & 0.22 \\
\hline 2. Diseñadores con locales propios & 0.14 & 3 & 0.42 \\
\hline 3. Confeccionistas cerca a zonas empresariales & 0.10 & 2.5 & 0.25 \\
\hline 4. Prendas chinas & 0.13 & 3 & 0.39 \\
\hline
\end{tabular}

Fuente: Elaboración propia.

\section{Conclusiones:}

- El desarrollo de redes sociales nos da una mayor oportunidad para darnos a conocer ante nuestro target y sin incurrir en grandes costos.

- Los diseñadores con atelier propios son una gran amenaza ya que son reconocidos a nivel público. 


\section{CAPÍTULO III: INVESTIGACIÓN DEL CLIENTE}

\subsection{Objetivos de investigación}

En la siguiente tabla se presentarán objetivos que ayudarán a definir el concepto de negocio. Asimismo, identificaremos los procedimientos que se requerirán para cada uno de los objetivos.

Tabla 3.1

Objetivos de investigación

\begin{tabular}{|c|c|c|c|c|c|c|}
\hline \multirow{3}{*}{\multicolumn{2}{|c|}{$\begin{array}{l}\text { OBJETIVOS } \\
\text { GENERALES }\end{array}$}} & \multirow[t]{3}{*}{ OBJETIVOS ESPECÍFICOS } & \multicolumn{4}{|c|}{ PROCEDIMIENTOS } \\
\hline & & & \multicolumn{3}{|c|}{$\begin{array}{c}\text { Fase } \\
\text { Exploratoria. }\end{array}$} & \multirow{2}{*}{$\begin{array}{l}\text { F.D. } \\
\text { EN }\end{array}$} \\
\hline & & & $\mathbf{E E}$ & $\mathbf{E P}$ & FG & \\
\hline & \multirow{2}{*}{$\begin{array}{l}\text { Explorar la } \\
\text { aceptación de mi } \\
\text { público objetivo }\end{array}$} & - $\quad$ Analizar aceptación del concepto. & $\times$ & $\times$ & $\times$ & $x$ \\
\hline & & $\begin{array}{l}\text { Identificar la disposición de comprar } \\
\text { con servicio a domicilio. }\end{array}$ & $x$ & $x$ & $x$ & $x$ \\
\hline & \multirow{2}{*}{$\begin{array}{l}\text { Terminar de } \\
\text { definir mi } \\
\text { concepto de } \\
\text { producto }\end{array}$} & $\begin{array}{l}\text { Explorar su conocimiento sobre } \\
\text { prendas a medida. }\end{array}$ & $x$ & $x$ & $x$ & $x$ \\
\hline & & - Identificar expectativas del cliente. & $x$ & $x$ & $x$ & $x$ \\
\hline \multirow[t]{3}{*}{3.} & \multirow{3}{*}{$\begin{array}{l}\text { Validar las } \\
\text { características de } \\
\text { mi target }\end{array}$} & $\begin{array}{l}\text { - Identificar cuántas veces renuevas el } \\
\text { closet. }\end{array}$ & & $x$ & $\times$ & $x$ \\
\hline & & $\begin{array}{l}\text { - Explorar la importancia respecto al } \\
\text { servicio. }\end{array}$ & $x$ & $x$ & $x$ & $x$ \\
\hline & & $\begin{array}{l}\text { Identificar las mujeres que trabajan } \\
\text { y las amas de casa. }\end{array}$ & & $x$ & $x$ & $x$ \\
\hline & \multirow[t]{4}{*}{$\begin{array}{l}\text { Diseñar mi mkt } \\
\text { mix }\end{array}$} & $\begin{array}{l}\text { - Identificar cuánto están dispuestas a } \\
\text { pagar. }\end{array}$ & $x$ & $x$ & $x$ & $x$ \\
\hline & & $\begin{array}{l}\text { Evaluar el uso que le dan al } \\
\text { Smartphone. }\end{array}$ & & $x$ & $x$ & $x$ \\
\hline & & - Definir estrategias de promoción & & $x$ & $x$ & $x$ \\
\hline & & - $\quad$ Tasa de recompra orgánica. & & $x$ & $\times$ & $x$ \\
\hline \multicolumn{3}{|c|}{$\begin{array}{l}\text { Leyenda: } \\
\text { EE: Entrevistas a expertos } \\
\text { EP: Entrevistas a profundidad al target } \\
\text { FG: Focus group } \\
\text { EN: Encuesta }\end{array}$} & & & & \\
\hline
\end{tabular}

Fuente: Elaboración propia.

\subsection{Metodología de investigación}

\subsubsection{Fase exploratoria}

Para la fase exploratoria se llevó a cabo dos focus group donde las participantes fueron mujeres a partir de 20 años en adelante. 
Además, se realizaron 4 entrevistas a profundidad a mujeres de 20 años a más. Por último, se realizaron 4 entrevistas a costureras con experiencia en el sector.

\subsubsection{Fase descriptiva}

En la fase descriptiva se realizarán 109 encuestas. Malhotra planteó que un mínimo aceptable para pruebas de producto es de 200 encuestas Malhotra (2018). Las encuestas estarán dirigidas a mujeres de 20 años a más que hayan tomado o no el servicio de confección a medida.

\subsection{Principales hallazgos}

\subsubsection{Fase exploratoria}

- Focus group \# 1

* Solicitan la confección de prendas a medida por ocasiones. Puede ser para matrimonios o eventos sociales grandes y para el trabajo.

* Para seleccionar el modelo suelen revisar revistas. Asimismo, toman referencia de presentaciones como El Oscar o los programas de televisión como el de Gisela Valcárcel.

* Les gusta que les sugieran modelos porque consideran que su experiencia les ayuda a conseguir el modelo deseado.

- Consideran que el servicio debe incluir la tela, porque desconocen las variedades de telas que pueden existir, se pueden confundir o las pueden engañar.

No les gusta esperar más de 15 minutos para una prueba por más que les inviten de cortesía alguna bebida o alimento.

* Si se reduce el tiempo de entrega si estarían dispuestas a pagar más porque sienten que sería lo más justo el pago.

Por un tema de seguridad sugieren que el pago sea con tarjeta. Si una prenda les cuesta S/. 500.00 no quieren cargar tanto dinero en la billetera.

* La competencia de modistas tienen puestos o talleres cerca de las zonas empresariales. Las chicas suelen tomar su hora de refrigerio para solicitar algún servicio.

- Focus group \# 2 
* Recurren a Facebook para buscar modistas siempre y cuando tenga buenos comentarios de referencia.

* Por experiencia, sienten que las escuchan pero no las entienden. Existe un problema de comunicación. Puede que las escuchen pero su mente está en otros temas. Frustran a la clienta porque no sabe si transmitió lo que quiere o no.

* Quieren que la modista las conozca, que se tomen un tiempo de hacer encuestas, conversar con la cliente antes de tomar el servicio para que tenga una noción de su personalidad, gustos, entre otros.

Sugieren que la modista sea una experta, con experiencia en el sector porque no les da confianza que sea una confeccionista empírica.

* La modista debe transmitir confianza y sobre todo ser paciente para que la clienta se sienta en la libertad de decir lo que piensa de la prenda que se está preparando y al final se consiga un buen resultado.

- Entrevistas a profundidad

En la siguiente tabla 3.2, podremos identificar los hallazgos que se rescataron de las entrevistas a profundidad.

\section{Tabla 3.2}

Entrevistas a profundidad

\begin{tabular}{|c|c|c|c|c|}
\hline Hallazgos & $\begin{array}{c}\text { Francisca } \\
\text { Gargurevich }\end{array}$ & $\begin{array}{l}\text { Mayra } \\
\text { Arauco }\end{array}$ & $\begin{array}{l}\text { Rocío } \\
\text { Corrales }\end{array}$ & $\begin{array}{c}\text { Diana } \\
\text { Navarrete }\end{array}$ \\
\hline Percepción & \multicolumn{4}{|c|}{ Servicio de confección a medida es muy caro y no todos tienden a solicitarlo. } \\
\hline Experiencia & Buena & Buena & Mala & Buena \\
\hline Motivación & $\begin{array}{l}\text { Lucir un modelo } \\
\text { exclusivo }\end{array}$ & $\begin{array}{l}\text { Dar que hablar en } \\
\text { su círculo social }\end{array}$ & Personalización & $\begin{array}{l}\text { No tendrá que } \\
\text { preocuparse si le } \\
\text { queda bien o no la } \\
\text { prenda. }\end{array}$ \\
\hline
\end{tabular}

Fuente: Elaboración propia.

Todas las entrevistadas coincidieron sobre la percepción del servicio. Sin embargo, teniendo conocimiento del precio recurren a algún confeccionista por el tema de querer ser únicos e inigualables.

Asimismo, se encuentran dispuestas a pagar por el simple hecho de no querer ver una prenda igual a la que están usando.

- Entrevistas a expertos 
En la siguiente matriz, identificaremos los principales hallazgos de las entrevistas a expertos en el sector.

Tabla 3.3

Entrevistas a expertos

\begin{tabular}{|c|c|c|c|c|}
\hline Hallazgos & $\begin{array}{l}\text { Ayde } \\
\text { Cordova }\end{array}$ & $\begin{array}{c}\text { Maco } \\
\text { Calderón }\end{array}$ & $\begin{array}{l}\text { Yuliya } \\
\text { Yulienka }\end{array}$ & $\begin{array}{l}\text { Violeta } \\
\text { Sandoval }\end{array}$ \\
\hline Empresa & \multicolumn{4}{|c|}{ Independiente } \\
\hline $\begin{array}{c}\text { En cuenta para } \\
\text { ingresar al } \\
\text { sector }\end{array}$ & \multicolumn{4}{|c|}{ Calidad de materiales y acabado de prenda final. } \\
\hline Marca propia & $\begin{array}{l}\text { No cuenta con } \\
\text { marca propia. }\end{array}$ & $\begin{array}{c}\text { Cuenta con marca } \\
\text { propia }\end{array}$ & $\begin{array}{c}\text { Cuenta con marca } \\
\text { propia. }\end{array}$ & $\begin{array}{l}\text { No cuenta con } \\
\text { marca propia. }\end{array}$ \\
\hline Clientes & Boca a boca & $\begin{array}{l}\text { Redes sociales y } \\
\text { boca a boca. }\end{array}$ & $\begin{array}{l}\text { Redes sociales y } \\
\text { boca a boca. }\end{array}$ & Boca a boca. \\
\hline Experiencia & \multicolumn{4}{|c|}{ Más de 5 años en el sector } \\
\hline Cobro & \multicolumn{4}{|c|}{$50 \%$ adelantado y el siguiente $50 \%$ contra entrega } \\
\hline
\end{tabular}

Fuente: Elaboración propia.

Los expertos entrevistados son confeccionistas con experiencia de más de 5 años en el sector. La señora Violeta y Ayde iniciaron su negocio hace más de 25 años. En el caso de Maco y Yuliya iniciaron hace 5 años. Los cuatro sostienen que hoy en día las personas no dejarán de priorizar los alimentos y la vestimenta.

Sin embargo, aunque todos emprendieron su propio negocio, son informales. Como ellos, mencionaron en la entrevista que amigos suyos también son informales. Es por esta razón que es difícil identificarlos para cuantificarlos.

Los clientes los consiguen por recomendaciones. Tanto Maco como Yuliya utilizan redes sociales y las dos confeccionistas (Ayde yVioleta), no. Esto se debe porque Ayde y Violeta tienen 50 años de edad y no tienen costumbre de usar por ejemplo Facebook (a pesar de tener ambas una cuenta). Maco y Yuliya son más jóvenes y buscan clientes por redes sociales. Por ello consiguen más clientes que Ayde y Violeta.

\subsubsection{Fase descriptiva}

\section{- Encuestas}

El tamaño de la muestra fue 109 mujeres de 20 años a más edad.

Las encuestas fueron distribuidas online. Si bien las mujeres de 20 a 40 años tienen Smartphone y hacen uso de las redes sociales, las mujeres de 41 en adelante no le dedican 
tiempo a las redes sociales o a revisar su correo. Estos motivos evitaron que logremos conseguir 200 encuestadas.

- Hallazgos:

* El $74.3 \%$ ha solicitado ya el servicio de confección a medida y cuenta con experiencia previa.

Las expectativas frente a este servicio son: buen acabado, calidad de la prenda y tiempo de entrega. Estos atributos fueron los más valorados por las mujeres.

* El 95.4\% de las mujeres consideran importante la nueva propuesta con valor agregado. Muchas veces por tiempo, la ropa no les queda como desean o se imaginan y por comodidad.

* El 71.6\% probablemente estaría dispuesto a tomar el servicio porque valoran mucho el tiempo.

No están al 100\% dispuesta a tomar el servicio porque toman en cuenta el precio que suele ser elevado en este sector.

* Los beneficios que más rescatan las encuestadas es el acabado de la prenda, el tiempo de entrega y el servicio personalizado.

Respecto al precio, están dispuestas a pagar entre $11 \%$ y $20 \%$ más de lo que acostumbran a invertir en ropa.

\subsection{Conclusiones}

Luego de realizar el focus group, como resultado se concluye que el target está dispuesto a tomar el servicio en su casa o en el lugar que les sea conveniente. Esto debido que se considera el tiempo como factor importante.

Según las entrevistas a profundidad al target, se concluye que el público objetivo tiene conocimiento respecto a la confección de prendas a medida por experiencia previa.

En base a la fase exploratoria se destaca la necesidad de las mujeres por querer ser entendidas. No basta con escuchar necesitan que el confeccionista sea proactivo por ello la importancia del servicio y la selección de personal capacitado.

Respecto al precio, el público objetivo está dispuesto a pagar montos mayores de los que paga por alguna prenda de retail porque se valora el tener un modelo único y a medida. 


\section{CAPÍTULO IV: ESTIMACIÓN Y PRONÓSTICO DE LA DEMANDA}

\subsection{Estimación de la demanda}

Se establecerá la demanda a través de un objetivo de crecimiento. Partiendo de un ingreso de S/. 125,000 anuales (2018) esperamos incrementar nuestros ingresos hasta S/.135,000 anuales (2019) mediante nuestro servicio y actividades de marketing que darán como resultado un aumento proporcional de clientes. Además, se considera que el porcentaje de distribución será constante a lo largo de los años

Como se observa en la tabla 4.1, durante el 2018 se generarán ingresos de S/. 25,000 tomando en cuenta el incremento de ventas en meses como enero, mayo, julio, noviembre y diciembre. El porcentaje que se presenta en la estimación de la demanda del proyecto representan el aumento o disminución de la demanda a lo largo del 2018. Por otro lado, nos proyectamos a generar ingresos de S/.135, 000 sustentados en refuerzos de marketing y un plan de servicio al cliente enfocado en atención personalizada. Al igual que el cálculo de los ingresos del 2018 se proyectaron los ingresos para el 2019 considerando el incremento de pedidos en los meses ya mencionados. 


\section{Tabla 4.1}

Estimación de demanda del proyecto 2018 (S/.)

\begin{tabular}{|c|c|c|c|c|c|c|c|c|c|c|c|c|c|}
\hline & Ene & Feb & Mar & Abr & May & Jun & Jul & Ago & Set & Oct & Nov & Dic & Total \\
\hline$\%$ & $13 \%$ & $1 \%$ & $7 \%$ & $6 \%$ & $9 \%$ & $4 \%$ & $16 \%$ & $8 \%$ & $4 \%$ & $4 \%$ & $12 \%$ & $16 \%$ & $100 \%$ \\
\hline S/. & 16,000 & 1,000 & 8,800 & 7,700 & 11,500 & 5,000 & 20,000 & 10,000 & 5,000 & 5,000 & 15,000 & 20,000 & 125,000 \\
\hline
\end{tabular}

Fuente: Elaboración propia.

Tabla 4.2

Estimación de demanda del proyecto 2019 (S/.)

\begin{tabular}{|c|c|c|c|c|c|c|c|c|c|c|c|c|c|}
\multicolumn{2}{|c|}{ Ene } & Feb & Mar & Abr & May & Jun & Jul & \multicolumn{2}{c|}{ Ago } & Sep \\
\hline $\begin{array}{c}\% \\
\text { distribución }\end{array}$ & $5.0 \%$ & $5.0 \%$ & $13.0 \%$ & $5.0 \%$ & $5.0 \%$ & $5.0 \%$ & $17.0 \%$ & $5.0 \%$ & $5.0 \%$ & $5.0 \%$ & $13.0 \%$ & $17.0 \%$ & $100.0 \%$ \\
\hline Año 1 & $6,750.00$ & $6,750.00$ & $17,550.00$ & $6,750.00$ & $6,750.00$ & $6,750.00$ & $22,950.00$ & $6,750.00$ & $6,750.00$ & $6,750.00$ & $17,550.00$ & $22,950.00$ & $135,000.00$ \\
\hline Año 2 & $7,087.50$ & $7,087.50$ & $18,427.50$ & $7,087.50$ & $7,087.50$ & $7,087.50$ & $24,097.50$ & $7,087.50$ & $7,087.50$ & $7,087.50$ & $18,427.50$ & $24,097.50$ & $141,750.00$ \\
\hline Año 3 & $7,441.90$ & $7,441.90$ & $19,348.94$ & $7,441.90$ & $7,441.90$ & $7,441.90$ & $25,302.46$ & $7,441.90$ & $7,441.90$ & $7,441.90$ & $19,348.94$ & $25,302.46$ & $148,838.00$ \\
\hline Año 4 & $7,888.40$ & $7,888.40$ & $20,509.84$ & $7,888.40$ & $7,888.40$ & $7,888.40$ & $26,820.56$ & $7,888.40$ & $7,888.40$ & $7,888.40$ & $20,509.84$ & $26,820.56$ & $157,768.00$ \\
\hline Año 5 & $8,361.70$ & $8,361.70$ & $21,740.42$ & $8,361.70$ & $8,361.70$ & $8,361.70$ & $28,429.78$ & $8,361.70$ & $8,361.70$ & $8,361.70$ & $21,740.42$ & $28,429.78$ & $167,234.00$ \\
\hline
\end{tabular}

Fuente: Elaboración propia. 


\section{CAPÍTULO V: PLANEACIÓN ESTRATÉGICA DE MARKETING}

\subsection{Análisis FODA}

Realizaremos un análisis FODA para crear estrategias concretas del resultado del análisis interno y externo.

Tabla 5.1

Análisis FODA

\section{FORTALEZAS}

Factores Internos

Factores Externos

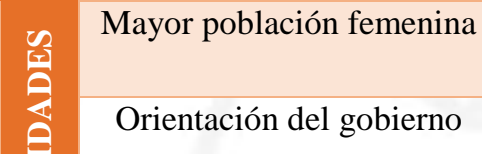

Eventos de moda

Redes Sociales

Sector retail en aumento

Diseñadores con locales propios

Confeccionistas cerca a zonas empresariales

Prendas chinas
Experiencia

Know - How

Logística

Procesos definidos

Desarrollo de producto.

Con el know how estamos en la capacidad de crear prendas que los clientes observan en eventos de moda y adaptarlos a su cuerpo y medidas.
DEBILIDADES

Capacidad financiera

Poco conocido por la cliente

Acabados especiales (bordados)

Management

Penetración de mercado:

Utilizaremos las redes sociales para aumentar nuestra participación de mercado y darnos a conocer con nuestra nueva propuesta al target.

$$
\begin{aligned}
& \text { Desarrollo de Producto: Con } \\
& \text { nuestra experiencia en el sector } \\
& \text { podremos minimizar el impacto } \\
& \text { del crecimiento del sector retail } \\
& \text { con prendas similares pero a } \\
& \text { medida de cada cliente. }
\end{aligned}
$$

Subcontratación: Contrataremos a personal especializado en acabados como bordado o pedrería para contrarrestar la competencia de diseñadores independientes.

Fuente: Elaboración propia.

\subsection{Fundamentación de la ventaja competitiva}

De acuerdo a lo que hemos observado, nuestra ventaja competitiva es brindar asesoría de imagen acompañada del servicio de confección a medida en el domicilio de la clienta o cualquier lugar de su preferencia.

La competencia aún no cuenta con este servicio adicional; ya que solo ofrecen servicios de confección, que si bien es a domicilio no cuenta con la asesoría en moda respectiva. 


\subsection{Objetivos de marketing}

Con la definición de objetivos tenemos como fin trazarnos resultados alcanzables a mediano y largo plazo.

Tabla 5.2

Objetivos a mediano y largo plazo

\begin{tabular}{|c|c|c|c|c|c|c|}
\hline OBJETIVOS & $\begin{array}{l}\text { INDICADOR } \\
\text { UTILIZADO }\end{array}$ & 1er año & 2 do año & 3er año & 4to año & 5 to año \\
\hline $\begin{array}{l}\text { 1. Incrementar } \\
\text { ventas }\end{array}$ & $\begin{array}{l}\text { Ventas respecto al } \\
\text { año anterior. }\end{array}$ & & $5 \%$ & $5 \%$ & $6 \%$ & $6 \%$ \\
\hline $\begin{array}{l}\text { 2. Alcanzar } \\
\text { participación de } \\
\text { mercado }\end{array}$ & $\begin{array}{l}\text { Porcentaje de } \\
\text { unidades vendidas en } \\
\text { el mercado }\end{array}$ & & $3 \%$ & $3 \%$ & $3 \%$ & $4 \%$ \\
\hline 3. Rentabilidad & $\begin{array}{l}\text { Margen bruto en } \\
\text { soles respecto al año } \\
\text { anterior. }\end{array}$ & & $4 \%$ & $4 \%$ & $5 \%$ & $6 \%$ \\
\hline $\begin{array}{l}\text { 4. Reducir los } \\
\text { reprocesos de costura }\end{array}$ & $\begin{array}{l}\text { Volumen de prendas } \\
\text { respecto al volumen } \\
\text { programado. }\end{array}$ & $3 \%$ & $3 \%$ & $4 \%$ & $5 \%$ & $5 \%$ \\
\hline $\begin{array}{l}\text { 5. Interacción en } \\
\text { redes sociales }\end{array}$ & $\begin{array}{l}\text { Clientes que } \\
\text { comentan/publican } \\
\text { en el fan page }\end{array}$ & $10 \%$ & $10 \%$ & $15 \%$ & $15 \%$ & $20 \%$ \\
\hline
\end{tabular}

Fuente: Elaboración propia.

\subsection{Mercado objetivo}

En el siguiente cuadro se mostrará las distintas características de nuestro público objetivo detallando cada una de ellas.

Tabla 5.3

Definición de Mercado Objetivo

\begin{tabular}{|c|c|c|}
\hline \multicolumn{3}{|c|}{ MERCADO OBJETIVO } \\
\hline Geográfico & Zona & Lima Moderna \\
\hline \multirow{3}{*}{ Demográfico } & Edad & 25 a 50 años \\
\hline & Género & Mujeres \\
\hline & NSE & A y B \\
\hline \multirow{4}{*}{ Psicográfico } & \multirow{4}{*}{ Estilo de Vida } & $\begin{array}{l}\text { Se maquillan, se arreglan y buscan el reconocimiento de } \\
\text { la sociedad }\end{array}$ \\
\hline & & Valoran mucho la imagen personal \\
\hline & & Son innovadores en el consumo y cazadores de tendencias \\
\hline & & Mujeres que trabajan o estudian. \\
\hline \multirow{4}{*}{ Conductual } & \multirow{2}{*}{ Beneficios buscados } & Buscan vestirse de acuerdo a la temporada. \\
\hline & & Quieren sentirse cómodas con las prendas que visten. \\
\hline & \multirow{2}{*}{$\begin{array}{l}\text { Roles en la decisión de } \\
\text { compra }\end{array}$} & Compradoras \\
\hline & & Consumidoras \\
\hline
\end{tabular}

Fuente: Elaboración propia. 


\subsection{Posicionamiento}

A continuación se presentará la declaración de posicionamiento de la idea de negocio:

"Ayde Co" brinda a las mujeres la mejor experiencia y comodidad al vestir prendas confeccionadas a medida, logrando que se sientan únicas y hermosas."

\subsection{Estrategia genérica}

Tomaremos la estrategia de nicho por diferenciación según Porter. Con esta estrategia buscamos la creación de intimidad con el cliente. Según el focus group realizado, las mujeres a la que nos dirigimos valoran la relación que se logre con la confeccionista.

Buscaremos desarrollar relaciones a largo plazo desde el primer contacto con la clienta. Es decir, desde el primer contacto hasta la entrega final de la prenda. La clienta podrá monitorear el proceso, mantenerse en contacto con la confeccionista por cualquier medio para así poder tener la libertad de dar sus opiniones y obtener un buen resultado con la prenda final.

\subsection{Estrategias competitivas}

Para la idea de negocio, tomaremos la estrategia de empresa retadora para atacar empresas del mismo rubro y del mismo tamaño. Nuestra estrategia será ofrecer el mejor servicio y sobre todo experiencia ( Kotler y Keller, 2016).

Uno de los problemas de la competencia es la entrega a tiempo y la atención al cliente. Como empresa, contamos con las mejores máquinas e insumos para la confección y acabado de prendas para así posicionarnos como una marca confiable.

\subsection{Estrategias de crecimiento}

Desde los primeros días en que se inicie legalmente el negocio utilizaremos una estrategia de penetración. Consistirá en promocionarnos por las redes sociales para no incurrir en gastos fuertes como anuncios en TV, radio o paneles.

Mediante las redes sociales se publicarán a las clientas satisfechas y testimonio de cada una de ellas al tomar el servicio de confección. Así, por ejemplo, podremos viralizar el fan page y muchas mujeres podrán tener conocimiento del servicio que ofrecemos. 


\section{CAPÍTULO VI: IMPLEMENTACIÓN}

\subsection{Análisis de inversiones iniciales}

\subsubsection{Inversiones en activos fijos}

Consideramos estos activos como fijos ya que el negocio está en marcha y los elementos mencionados en la tabla 6.1 son básicamente lo esencial para empezar el negocio. Las laptops se utilizarán como medio de comunicación entre la cliente y nosotros. La cliente podrá agendar citas, escribirnos desde cualquier red social y nosotros atenderlas en el corto tiempo posible.

Los muebles e implementos como mesa para cortes, estante de telas, maniquí y demás forman parte del proceso de producción. Sin los mencionados activos no podremos brindar los mejores acabados y servicio.

Tabla 6.1

Inversión en Activos fijos

\begin{tabular}{|l|r|r|r|}
\hline \multicolumn{1}{|c|}{ ACTIVO FIJO } & CANTIDAD & \multicolumn{1}{c|}{ MONTO } & TOTAL (S/.) \\
\hline Laptop & 2 & $1,900.00$ & $3,800.00$ \\
\hline Impresora & 1 & 199.00 & 199.00 \\
\hline Estante de telas & 4 & 269.90 & $1,079.60$ \\
\hline Máquina de coser & 1 & 950.00 & 950.00 \\
\hline Máquina remalladora & 1 & $3,450.00$ & $3,450.00$ \\
\hline Mesa para cortes & 1 & 400.00 & 400.00 \\
\hline Plancha & 1 & 160.00 & 160.00 \\
\hline Colgadores & 1 & 80.00 & 80.00 \\
\hline Sillas & 2 & 150.00 & 300.00 \\
\hline Maniquí & 1 & 100.00 & 100.00 \\
\hline Espejo & 1 & 100.00 & 100.00 \\
\hline & & TOTAL (S/.) & $\mathbf{1 0 , 6 1 8 . 6 0}$ \\
\hline
\end{tabular}

Fuente: Elaboración propia.

\subsection{Análisis de los gastos operativos}

\subsubsection{Gastos Administrativos}

Los gastos administrativos se construirán en base de los gastos administrativos directos los cuales se componen del alquiler del taller. El siguiente punto importante es la mano 
de obra directa a quien tenemos como Gerente General. La posición del titular de la empresa será quien tenga contacto directo con el cliente, busque clientes, concrete citas.

Finalmente tenemos los gastos administrativos indirectos el cual se conforma por laptops, impresora y silla que al mismo tiempo en un largo plazo de 5 años acumulan una depreciación anual. Que su resultado y la suma con los gastos administrativos directos e indirectos dan el total en gastos administrativos para la idea de negocio.

Tabla 6.2

Gastos Administrativos Directos

Fuente: Elaboración propia.

\begin{tabular}{|c|c|c|c|c|c|}
\hline Activos & AÑ̃ 1 & AÑO 2 & AÑ̃ 3 & AÑO 4 & AÑ̃ 5 \\
\hline Alquiler & $1,200.00$ & $1,200.00$ & $1,200.00$ & $1,200.00$ & $1,200.00$ \\
\hline TOTAL & $\mathbf{1 , 2 0 0 . 0 0}$ & $\mathbf{1 , 2 0 0 . 0 0}$ & $\mathbf{1 , 2 0 0 . 0 0}$ & $\mathbf{1 , 2 0 0 . 0 0}$ & $\mathbf{1 , 2 0 0 . 0 0}$ \\
\hline
\end{tabular}

Tabla 6.3

Mano de Obra Directa Año 1 (S/.)

\begin{tabular}{|c|c|c|c|c|c|c|c|c|c|c|c|c|c|}
\hline Detalle & Ene & Feb & Mar & Abr & May & Jun & Jul & Ago & Sep & Oct & Nov & Dic & TOTAL \\
\hline Gerente General & $2,300.00$ & $2,300.00$ & $2,300.00$ & $2,300.00$ & $2,300.00$ & $2,300.00$ & $2,300.00$ & $2,300.00$ & $2,300.00$ & $2,300.00$ & $2,300.00$ & $2,300.00$ & $27,600.00$ \\
\hline Total & $2,300.00$ & $2,300.00$ & $2,300.00$ & $2,300.00$ & $2,300.00$ & $2,300.00$ & $2,300.00$ & $2,300.00$ & $2,300.00$ & $2,300.00$ & $2,300.00$ & $2,300.00$ & $27,600.00$ \\
\hline Gratificaciones & 383.33 & 383.33 & 383.33 & 383.33 & 383.33 & 383.33 & 383.33 & 383.33 & 383.33 & 383.33 & 383.33 & 383.33 & $4,600.00$ \\
\hline Total & $2,683.33$ & $2,683.33$ & $2,683.33$ & $2,683.33$ & $2,683.33$ & $2,683.33$ & $2,683.33$ & $2,683.33$ & $2,683.33$ & $2,683.33$ & $2,683.33$ & $2,683.33$ & $32,200.00$ \\
\hline CTS & 223.61 & 223.61 & 223.61 & 223.61 & 223.61 & 223.61 & 223.61 & 223.61 & 223.61 & 223.61 & 223.61 & 223.61 & $2,683.33$ \\
\hline ESSALUD & 241.50 & 241.50 & 241.50 & 241.50 & 241.50 & 241.50 & 241.50 & 241.50 & 241.50 & 241.50 & 241.50 & 241.50 & $2,898.00$ \\
\hline $\begin{array}{l}\text { Costo salarial } \\
\text { mensual }\end{array}$ & $3,148.44$ & $3,148.44$ & $3,148.44$ & $3,148.44$ & 3,1 & .44 & 3,1 & 44 & 3.44 & 3,1 & 3.44 & 8.44 & 37 \\
\hline
\end{tabular}

Fuente: Elaboración propia. 
Tabla 6.4

Mano de Obra Directa Año 2 (S/.)

\begin{tabular}{|l|c|c|c|c|c|c|c|c|c|c|c|c|c|c|}
\hline & Ene & Feb & Mar & Abr & May & Jun & Jul & Ago & Sep & Oct & Nov & Dic & TOTAL \\
\hline Gerente General & $2,300.00$ & $2,300.00$ & $2,300.00$ & $2,300.00$ & $2,300.00$ & $2,300.00$ & $2,300.00$ & $2,300.00$ & $2,300.00$ & $2,300.00$ & $2,300.00$ & $2,300.00$ & $27,600.00$ \\
\hline Total & $\mathbf{2 , 3 0 0 . 0 0}$ & $\mathbf{2 , 3 0 0 . 0 0}$ & $\mathbf{2 , 3 0 0 . 0 0}$ & $\mathbf{2 , 3 0 0 . 0 0}$ & $\mathbf{2 , 3 0 0 . 0 0}$ & $\mathbf{2 , 3 0 0 . 0 0}$ & $\mathbf{2 , 3 0 0 . 0 0}$ & $\mathbf{2 , 3 0 0 . 0 0}$ & $\mathbf{2 , 3 0 0 . 0 0}$ & $\mathbf{2 , 3 0 0 . 0 0}$ & $\mathbf{2 , 3 0 0 . 0 0}$ & $\mathbf{2 , 3 0 0 . 0 0}$ & $\mathbf{2 7 , 6 0 0 . 0 0}$ \\
\hline Gratificaciones & 383.33 & 383.33 & 383.33 & 383.33 & 383.33 & 383.33 & 383.33 & 383.33 & 383.33 & 383.33 & 383.33 & 383.33 & $4,600.00$ \\
\hline Total & $2,683.33$ & $2,683.33$ & $2,683.33$ & $2,683.33$ & $2,683.33$ & $2,683.33$ & $2,683.33$ & $2,683.33$ & $2,683.33$ & $2,683.33$ & $2,683.33$ & $2,683.33$ & $32,200.00$ \\
\hline CTS & 223.61 & 223.61 & 223.61 & 223.61 & 223.61 & 223.61 & 223.61 & 223.61 & 223.61 & 223.61 & 223.61 & 223.61 & $2,683.33$ \\
\hline ESSALUD & 241.50 & 241.50 & 241.50 & 241.50 & 241.50 & 241.50 & 241.50 & 241.50 & 241.50 & 241.50 & 241.50 & 241.50 & $2,898.00$ \\
\hline $\begin{array}{l}\text { Costo salarial } \\
\text { mensual }\end{array}$ & $\mathbf{3 , 1 4 8 . 4 4}$ & $\mathbf{3 , 1 4 8 . 4 4}$ & $\mathbf{3 , 1 4 8 . 4 4}$ & $\mathbf{3 , 1 4 8 . 4 4}$ & $\mathbf{3 , 1 4 8 . 4 4}$ & $\mathbf{3 , 1 4 8 . 4 4}$ & $\mathbf{3 , 1 4 8 . 4 4}$ & $\mathbf{3 , 1 4 8 . 4 4}$ & $\mathbf{3 , 1 4 8 . 4 4}$ & $\mathbf{3 , 1 4 8 . 4 4}$ & $\mathbf{3 , 1 4 8 . 4 4}$ & $\mathbf{3 , 1 4 8 . 4 4}$ & $\mathbf{3 7 , 7 8 1 . 3 3}$ \\
\hline
\end{tabular}

Fuente: Elaboración propia.

\section{Tabla 6.5}

Mano de Obra Directa Año 3 (S/.)

\begin{tabular}{|l|c|c|c|c|c|c|c|c|c|c|c|c|c|}
\hline & Ene & \multicolumn{2}{|c}{ Feb } & Mar & Abr & May & Jun & Jul & \multicolumn{2}{c|}{ Ago } & Sep & Oct & Nov \\
\hline Gerente General & $2,300.00$ & $2,300.00$ & $2,300.00$ & $2,300.00$ & $2,300.00$ & $2,300.00$ & $2,300.00$ & $2,300.00$ & $2,300.00$ & $2,300.00$ & $2,300.00$ & $2,300.00$ & $27,600.00$ \\
\hline Total & $\mathbf{2 , 3 0 0 . 0 0}$ & $\mathbf{2 , 3 0 0 . 0 0}$ & $\mathbf{2 , 3 0 0 . 0 0}$ & $\mathbf{2 , 3 0 0 . 0 0}$ & $\mathbf{2 , 3 0 0 . 0 0}$ & $\mathbf{2 , 3 0 0 . 0 0}$ & $\mathbf{2 , 3 0 0 . 0 0}$ & $\mathbf{2 , 3 0 0 . 0 0}$ & $\mathbf{2 , 3 0 0 . 0 0}$ & $\mathbf{2 , 3 0 0 . 0 0}$ & $\mathbf{2 , 3 0 0 . 0 0}$ & $\mathbf{2 , 3 0 0 . 0 0}$ & $\mathbf{2 7 , 6 0 0 . 0 0}$ \\
\hline Gratificaciones & 383.33 & 383.33 & 383.33 & 383.33 & 383.33 & 383.33 & 383.33 & 383.33 & 383.33 & 383.33 & 383.33 & 383.33 & $4,600.00$ \\
\hline Total & $2,683.33$ & $2,683.33$ & $2,683.33$ & $2,683.33$ & $2,683.33$ & $2,683.33$ & $2,683.33$ & $2,683.33$ & $2,683.33$ & $2,683.33$ & $2,683.33$ & $2,683.33$ & $32,200.00$ \\
\hline CTS & 223.61 & 223.61 & 223.61 & 223.61 & 223.61 & 223.61 & 223.61 & 223.61 & 223.61 & 223.61 & 223.61 & 223.61 & $2,683.33$ \\
\hline ESSALUD & 241.50 & 241.50 & 241.50 & 241.50 & 241.50 & 241.50 & 241.50 & 241.50 & 241.50 & 241.50 & 241.50 & 241.50 & $2,898.00$ \\
\hline $\begin{array}{l}\text { Costo salarial } \\
\text { mensual }\end{array}$ & $\mathbf{3 , 1 4 8 . 4 4}$ & $\mathbf{3 , 1 4 8 . 4 4}$ & $\mathbf{3 , 1 4 8 . 4 4}$ & $\mathbf{3 , 1 4 8 . 4 4}$ & $\mathbf{3 , 1 4 8 . 4 4}$ & $\mathbf{3 , 1 4 8 . 4 4}$ & $\mathbf{3 , 1 4 8 . 4 4}$ & $\mathbf{3 , 1 4 8 . 4 4}$ & $\mathbf{3 , 1 4 8 . 4 4}$ & $\mathbf{3 , 1 4 8 . 4 4}$ & $\mathbf{3 , 1 4 8 . 4 4}$ & $\mathbf{3 , 1 4 8 . 4 4}$ & $\mathbf{3 7 , 7 8 1 . 3 3}$ \\
\hline
\end{tabular}

Fuente: Elaboración propia. 


\section{Tabla 6.6}

Mano de Obra Directa Año 4 (S/.)

\begin{tabular}{|c|c|c|c|c|c|c|c|c|c|c|c|c|c|}
\hline & Ene & Feb & Mar & Abr & May & Jun & Jul & Ago & Sep & Oct & Nov & Dic & TOTAL \\
\hline Gerente General & $2,500.00$ & $2,500.00$ & $2,500.00$ & $2,500.00$ & $2,500.00$ & $2,500.00$ & $2,500.00$ & $2,500.00$ & $2,500.00$ & $2,500.00$ & $2,500.00$ & $2,500.00$ & $30,000.00$ \\
\hline Total &, 500.00 & $2,500.00$ & $2,500.00$ & $2,500.00$ & $2,500.00$ & $2,500.00$ & $2,500.00$ & $2,500.00$ & $2,500.00$ & $2,500.00$ & $2,500.00$ & $2,500.00$ & $30,000.00$ \\
\hline Gratific & 416.67 & 416.67 & 416.67 & 416.67 & 416.67 & 416.67 & 416.67 & 416.67 & 416.67 & 416.67 & 416.67 & 416.67 & $5,000.00$ \\
\hline Total & $2,916.67$ & $2,916.67$ & $2,916.67$ & $2,916.67$ & $2,916.67$ & $2,916.67$ & $2,916.67$ & $2,916.67$ & $2,916.67$ & $2,916.67$ & $2,916.67$ & $2,916.67$ & $35,000.00$ \\
\hline CTS & 243.06 & 243.06 & 243.06 & 243.06 & 243.06 & 243.06 & 243.06 & 243.06 & 243.06 & 243.06 & 243.06 & 243.06 & $2,916.67$ \\
\hline ESSALUD & 252.50 & 252.50 & 252.50 & 252.50 & 252.50 & 252.50 & 252.50 & 252.50 & 252.50 & 252.50 & 252.50 & 252.50 & $3,150.00$ \\
\hline $\begin{array}{l}\text { Costo salarial } \\
\text { mensual }\end{array}$ & 422.22 &, 422.22 & $3,422.22$ & ,422.22 & $3,422.22$ & $3,422.22$ & $3,422.22$ & $3,422.22$ & $3,422.22$ & $3,422.22$ & $3,422.22$ & $3,422.22$ & $41,066.67$ \\
\hline
\end{tabular}

Fuente: Elaboración propia.

Tabla 6.7

Mano de Obra Directa Año 5 (S/.)

\begin{tabular}{|c|c|c|c|c|c|c|c|c|c|c|c|c|c|}
\hline & Ene & Feb & Mar & Abr & May & Jun & Jul & Ago & Sep & Oct & Nov & Dic & TOTAL \\
\hline Gerente General & $2,500.00$ & $2,500.00$ & $2,500.00$ & $2,500.00$ & $2,500.00$ & $2,500.00$ & $2,500.00$ & $2,500.00$ & $2,500.00$ & $2,500.00$ & $2,500.00$ & $2,500.00$ & $30,000.00$ \\
\hline Total & $2,500.00$ & $2,500.00$ & $2,500.00$ & $2,500.00$ & $2,500.00$ & $2,500.00$ & $2,500.00$ & $2,500.00$ & $2,500.00$ & $2,500.00$ & $2,500.00$ & $2,500.00$ & $30,000.00$ \\
\hline Gratificaciones & 416.67 & 416.67 & 416.67 & 416.67 & 416.67 & 416.67 & 416.67 & 416.67 & 416.67 & 416.67 & 416.67 & 416.67 & $5,000.00$ \\
\hline Total & $2,916.67$ & $2,916.67$ & $2,916.67$ & $2,916.67$ & $2,916.67$ & $2,916.67$ & $2,916.67$ & $2,916.67$ & $2,916.67$ & $2,916.67$ & $2,916.67$ & $2,916.67$ & $35,000.00$ \\
\hline CTS & 243.06 & 243.06 & 243.06 & 243.06 & 243.06 & 243.06 & 243.06 & 243.06 & 243.06 & 243.06 & 243.06 & 243.06 & $2,916.67$ \\
\hline ESSALUD & 252.50 & 252.50 & 252.50 & 252.50 & 252.50 & 252.50 & 252.50 & 252.50 & 252.50 & 252.50 & 252.50 & 252.50 & $3,150.00$ \\
\hline $\begin{array}{l}\text { Costo salarial } \\
\text { mensual }\end{array}$ & $3,422.22$ & $3,422.22$ & $3,422.22$ & $3,422.22$ & $3,422.22$ & $3,422.22$ & $3,422.22$ & $3,422.22$ & $3,422.22$ & $3,422.22$ & $3,422.22$ & $3,422.22$ & $41,066.67$ \\
\hline
\end{tabular}

Fuente: Elaboración propia. 
Tabla 6.8

Presupuesto Gastos Administrativos indirectos (S/.)

\begin{tabular}{|l|c|c|c|c|c|}
\hline \multicolumn{7}{|c|}{ AÑ̃ 1 } & AÑ̃ 2 & AÑ̃ 3 & AÑ̃ 4 & AÑ̃ 5 \\
\hline DEPRECIACION & 760.00 & 760.00 & 760.00 & 760.00 & 760.00 \\
\hline Laptop & 39.80 & 39.80 & 39.80 & 39.80 & 39.80 \\
\hline Impresora & 60.00 & 60.00 & 60.00 & 60.00 & 60.00 \\
\hline Sillas & $\mathbf{8 5 9 . 8 0}$ & $\mathbf{8 5 9 . 8 0}$ & $\mathbf{8 5 9 . 8 0}$ & $\mathbf{8 5 9 . 8 0}$ & $\mathbf{8 5 9 . 8 0}$ \\
\hline TOTAL DEPRECIACIÓN & & & & \\
\hline AMORTIZACION INTANGIBLE & & & & & \\
\hline AMORTIZACION ANUAL & 832.86 & 832.86 & 832.86 & 832.86 & 832.86 \\
\hline TOTAL AMORTIZACIÓN & 832.86 & 832.86 & 832.86 & 832.86 & 832.86 \\
\hline
\end{tabular}

Fuente: Elaboración propia.

Tabla 6.9

Presupuesto Gastos Administrativos Total (S/.)

\begin{tabular}{|l|c|c|c|c|c|}
\hline & AÑO 1 & AÑO 2 & AÑO 3 & AÑO 4 & AÑO 5 \\
\hline Gastos administrativos directos & $1,200.00$ & $1,200.00$ & $1,200.00$ & $1,200.00$ & $1,200.00$ \\
\hline Mano de obra administrativa & $37,781.33$ & $37,781.33$ & $37,781.33$ & $41,066.67$ & $41,066.67$ \\
\hline Gastos administrativos indirectos & $1,692.66$ & $1,692.66$ & $1,692.66$ & $1,692.66$ & $1,692.66$ \\
\hline TOTAL & $\mathbf{4 0 , 6 7 3 . 9 9}$ & $\mathbf{4 0 , 6 7 3 . 9 9}$ & $\mathbf{4 0 , 6 7 3 . 9 9}$ & $\mathbf{4 3 , 9 5 9 . 3 2}$ & $\mathbf{4 3 , 9 5 9 . 3 2}$ \\
\hline
\end{tabular}

Fuente: Elaboración propia.

\subsubsection{Gastos de Venta}

Nuestros gastos de venta se verán conformados por el gasto de venta directo y los gastos de venta indirectos por 5 años ya que no contamos con mano de obra de venta.

Como gasto de venta directo tenemos todos nuestros gastos de marketing. Empezando por la actividad de lanzamiento que se llevará a cabo para la marca. Asimismo, se desarrollará una página web para que las clientas puedas tener un book con todos nuestros trabajos, servicios adicionales e incluso reservar citas.

Tabla 6.10

Gastos de Marketing (S/.)

\begin{tabular}{|l|c|c|c|c|c|c|}
\hline & $\begin{array}{c}\text { Costo } \\
\text { mensual }\end{array}$ & AÑ̃ 1 & AÑ̃ 2 & AÑ̃ 3 & AÑO 4 & AÑ̃ 5 \\
\hline Iniciativa Mkt & 135.00 & $1,620.00$ & $1,701.00$ & $1,786.05$ & $1,875.35$ & $1,969.12$ \\
\hline & & & & & \multicolumn{3}{c}{ (continúa) }
\end{tabular}


(continuación)

\begin{tabular}{|l|c|c|c|c|c|c|}
\hline $\begin{array}{l}\text { Página Web (dominio } \\
\text { + hosting) anual }\end{array}$ & 22.50 & 270.00 & 283.50 & 283.50 & 283.50 & 283.50 \\
\hline Página Web (desarrollo) & 250.00 & $3,000.00$ & $3,150.00$ & $3,150.00$ & $3,150.00$ & $3,150.00$ \\
\hline Anuncios en redes & 150.00 & $1,800.00$ & $1,890.00$ & $1,890.00$ & $1,890.00$ & $1,890.00$ \\
\hline TOTAL & $\mathbf{5 5 7 . 5 0}$ & $\mathbf{6 , 6 9 0 . 0 0}$ & $\mathbf{7 , 0 2 4 . 5 0}$ & $\mathbf{7 , 1 0 9 . 5 5}$ & $\mathbf{7 , 1 9 8 . 8 5}$ & $\mathbf{7 , 2 9 2 . 6 2}$ \\
\hline
\end{tabular}

Fuente: Elaboración propia.

El gasto de venta indirecta se refleja en la depreciación anual de los colgadores, maniquí y espejo los cuales forman parte de la etapa de servicio al cliente y de la producción.

Tabla 6.11

Gasto de Depreciación (S/.)

\begin{tabular}{|l|c|c|c|c|c|c|}
\hline \multicolumn{1}{l|}{} & AÑO 1 & AÑO 2 & AÑO 3 & AÑO 4 & AÑO 5 \\
\hline Colgadores & 16.00 & 16.00 & 16.00 & 16.00 & 16.00 \\
\hline Maniquí & 20.00 & 20.00 & 20.00 & 20.00 & 20.00 \\
\hline Espejo & 20.00 & 20.00 & 20.00 & 20.00 & 20.00 \\
\hline TOTAL & $\mathbf{5 6 . 0 0}$ & $\mathbf{5 6 . 0 0}$ & $\mathbf{5 6 . 0 0}$ & $\mathbf{5 6 . 0 0}$ & $\mathbf{5 6 . 0 0}$ \\
\hline
\end{tabular}

Fuente: Elaboración propia.

Como resultado obtenemos el gasto de venta total confirmado por la sumatoria de ambos cálculo previos. Con una proyección a largo plazo vemos que nuestros gastos irán en aumentos ya sea por el aumento de nuestra demanda o por el aumento de recursos que necesitemos para el proceso de servicio y producción.

Tabla 6.12

Gastos totales de ventas (S/.)

\begin{tabular}{|l|c|c|c|c|c|}
\hline Gastos de ventas directos & AÑ 1 & AÑO 2 & AÑO 3 & AÑO 4 & A ̃̃O 5 \\
\hline Mano de obra de venta & $6,690.00$ & $7,024.50$ & $7,109.55$ & $7,198.85$ & $7,292.62$ \\
\hline Gastos de ventas indirectos & - & - & - & - & - \\
\hline TOTAL & 56.00 & 56.00 & 56.00 & 56.00 & 56.00 \\
\hline
\end{tabular}

Fuente: Elaboración propia.

\subsubsection{Costos de Producción}

Para los costos de producción contamos con los materiales, la mano de obra directa que en nuestra idea de negocio son las costureras y los costos indirectos de fabricación. 


\section{Tabla 6.13}

Costos de Insumos (S/.)

Fuente: Elaboración propia.

Tabla 6.14

Detalle Mano de Obra Directa Año 1 (S/.)

\begin{tabular}{|l|c|c|c|c|c|}
\multicolumn{1}{l|}{} & AÑO 1 & AÑ 2 & AÑ 3 & AÑ 4 & A ÑO 5 \\
\hline Hilo & 168.00 & 176.00 & 185.00 & 196.00 & 208.00 \\
\hline Telas & $13,500.00$ & $14,175.00$ & $14,884.00$ & $15,777.00$ & $16,723.00$ \\
\hline Aguja & 75.00 & 79.00 & 83.00 & 88.00 & 93.00 \\
\hline Alfileres & 330.00 & 347.00 & 364.00 & 386.00 & 409.00 \\
\hline Tijera & 400.00 & 420.00 & 441.00 & 467.00 & 496.00 \\
\hline Piquetera & 16.00 & 17.00 & 18.00 & 19.00 & 20.00 \\
\hline Regla & 105.00 & 110.00 & 116.00 & 123.00 & 130.00 \\
\hline Papel de molde & 116.00 & 121.00 & 127.00 & 135.00 & 143.00 \\
\hline Tiza & 30.00 & 32.00 & 33.00 & 35.00 & 37.00 \\
\hline TOTAL & $\mathbf{1 4 , 7 3 9 . 5 0}$ & $\mathbf{1 5 , 4 7 6 . 4 8}$ & $\mathbf{1 6 , 2 5 0 . 3 0}$ & $\mathbf{1 7 , 2 2 5 . 3 2}$ & $\mathbf{1 8 , 2 5 8 . 8 4}$ \\
\hline
\end{tabular}

\begin{tabular}{|c|c|c|c|c|c|c|c|c|c|c|c|c|c|}
\hline & Ene & Feb & Mar & Abr & May & Jun & Jul & Ago & Sep & Oct & Nov & Dic & TOTAL \\
\hline Costurera & 500.00 & 500.00 & 500.00 & 500.00 & 500.00 & 500.00 & 500.00 & 500.00 & 500.00 & 500.00 & 500.00 & 500.00 & $6,000.00$ \\
\hline Total & 500.00 & 500.00 & 500.00 & 500.00 & 500.00 & 500.00 & 500.00 & 500.00 & 500.00 & 500.00 & 500.00 & 500.00 & $6,000.00$ \\
\hline Gratifi & 83.33 & 83.33 & 83.33 & 83.33 & 83.33 & 83.33 & & & & 83.33 & 83.33 & & $1,000.00$ \\
\hline Total & 583.33 & 583.33 & 583.33 & 583.33 & 583.33 & 583.33 & 583.33 & 583.33 & 583.33 & 583.33 & 583.33 & 583.33 & $7,000.00$ \\
\hline CTS & 48.61 & 48.61 & 48.61 & 48.61 & 48.61 & 48.61 & 48.61 & 48.61 & 48.61 & 48.61 & 48.61 & 48.61 & 583.33 \\
\hline ESSALUD & 52.50 & 52.50 & 52.50 & 52.50 & 52.50 & 52.50 & 52.50 & 52.50 & 52.50 & 52.50 & 52.50 & 52.50 & 630.00 \\
\hline Costo salarial mensual & 684.44 & 684.44 & 684.44 & 684.44 & 684.44 & 684.44 & 684.44 & 684.44 & 684.44 & 684.44 & 684.44 & 684.44 & $8,213.33$ \\
\hline
\end{tabular}

Fuente: Elaboración propia. 


\section{Tabla 6.15}

Detalle Mano de Obra Directa Año 2 (S/.)

\begin{tabular}{|l|c|c|c|c|c|c|c|c|c|c|c|c|c|c|}
\multicolumn{1}{c}{} & Ene & Feb & Mar & Abr & \multicolumn{1}{c}{ May } & Jun & Jul & Ago & Sep & Oct & Nov & Dic & TOTAL \\
\hline Costurera & 500.00 & 500.00 & 500.00 & 500.00 & 500.00 & 500.00 & 500.00 & 500.00 & 500.00 & 500.00 & 500.00 & 500.00 & $6,000.00$ \\
\hline Total & $\mathbf{5 0 0 . 0 0}$ & $\mathbf{5 0 0 . 0 0}$ & $\mathbf{5 0 0 . 0 0}$ & $\mathbf{5 0 0 . 0 0}$ & $\mathbf{5 0 0 . 0 0}$ & $\mathbf{5 0 0 . 0 0}$ & $\mathbf{5 0 0 . 0 0}$ & $\mathbf{5 0 0 . 0 0}$ & $\mathbf{5 0 0 . 0 0}$ & $\mathbf{5 0 0 . 0 0}$ & $\mathbf{5 0 0 . 0 0}$ & $\mathbf{5 0 0 . 0 0}$ & $\mathbf{6 , 0 0 0 . 0 0}$ \\
\hline Gratificaciones & 83.33 & 83.33 & 83.33 & 83.33 & 83.33 & 83.33 & 83.33 & 83.33 & 83.33 & 83.33 & 83.33 & 83.33 & $1,000.00$ \\
\hline Total & 583.33 & 583.33 & 583.33 & 583.33 & 583.33 & 583.33 & 583.33 & 583.33 & 583.33 & 583.33 & 583.33 & 583.33 & $7,000.00$ \\
\hline CTS & 48.61 & 48.61 & 48.61 & 48.61 & 48.61 & 48.61 & 48.61 & 48.61 & 48.61 & 48.61 & 48.61 & 48.61 & 583.33 \\
\hline ESSALUD & 52.50 & 52.50 & 52.50 & 52.50 & 52.50 & 52.50 & 52.50 & 52.50 & 52.50 & 52.50 & 52.50 & 52.50 & 630.00 \\
\hline Costo salarial mensual & $\mathbf{6 8 4 . 4 4}$ & $\mathbf{6 8 4 . 4 4}$ & $\mathbf{6 8 4 . 4 4}$ & $\mathbf{6 8 4 . 4 4}$ & $\mathbf{6 8 4 . 4 4}$ & $\mathbf{6 8 4 . 4 4}$ & $\mathbf{6 8 4 . 4 4}$ & $\mathbf{6 8 4 . 4 4}$ & $\mathbf{6 8 4 . 4 4}$ & $\mathbf{6 8 4 . 4 4}$ & $\mathbf{6 8 4 . 4 4}$ & $\mathbf{6 8 4 . 4 4}$ & $\mathbf{8 , 2 1 3 . 3 3}$ \\
\hline
\end{tabular}

Fuente: Elaboración propia.

Tabla 6.16

Detalle Mano de Obra Directa Año 3 (S/.)

\begin{tabular}{|c|c|c|c|c|c|c|c|c|c|c|c|c|c|}
\hline & Ene & Feb & Mar & Abr & May & Jun & Jul & Ago & Sep & Oct & Nov & Dic & TOTAL \\
\hline Costurera & 500.00 & 500.00 & 500.00 & 500.00 & 500.00 & 500.00 & 500.00 & 500.00 & 500.00 & 500.00 & 500.00 & 500.00 & $6,000.00$ \\
\hline Total & 500.00 & 500.00 & 500.00 & 500.00 & 500.00 & 500.00 & 500.00 & 500.00 & 500.00 & 500.00 & 500.00 & 500.00 & $6,000.00$ \\
\hline Gratifi & 83.33 & 83.33 & 83.33 & 83.33 & 83.33 & 83.33 & 83.33 & 83.33 & 83.33 & 83.33 & 83.33 & 83.33 & $1,000.00$ \\
\hline Total & 583.33 & 583.33 & 583.33 & 583.33 & 583.33 & 583.33 & 583.33 & 583.33 & 583.33 & 583.33 & 583.33 & 583.33 & $7,000.00$ \\
\hline CTS & 48.61 & 48.61 & 48.61 & 48.61 & 48.61 & 48.61 & 48.61 & 48.61 & 48.61 & 48.61 & 48.61 & 48.61 & 583.33 \\
\hline ESSALUD & 52.50 & 52.50 & 52.50 & 52.50 & 52.50 & 52.50 & 52.50 & 52.50 & 52.50 & 52.50 & 52.50 & 52.50 & 630.00 \\
\hline Costo salarial mensual & 684.44 & 684.44 & 684.44 & 684.44 & 684.44 & 684.44 & 684.44 & 684.44 & 684.44 & 684.44 & 684.44 & 684.44 & $8,213.33$ \\
\hline
\end{tabular}

Fuente: Elaboración propia. 
Tabla 6.17

Detalle Mano de Obra Directa Año 4 (S/.)

\begin{tabular}{|c|c|c|c|c|c|c|c|c|c|c|c|c|c|}
\hline & Ene & Feb & Mar & Abr & May & Jun & Jul & Ago & Sep & Oct & Nov & Dic & TOTAL \\
\hline Costurera & $1,000.00$ & $1,000.00$ & $1,000.00$ & $1,000.00$ & $1,000.00$ & $1,000.00$ & $1,000.00$ & $1,000.00$ & $1,000.00$ & $1,000.00$ & $1,000.00$ & $1,000.00$ & $12,000.00$ \\
\hline Total & $1,000.00$ & $1,000.00$ & $1,000.00$ & $\mathbf{1 , 0 0 0 . 0 0}$ & $1,000.00$ & $1,000.00$ & $1,000.00$ & $1,000.00$ & $1,000.00$ & $1,000.00$ & $\mathbf{1 , 0 0 0 . 0 0}$ & $\mathbf{1 , 0 0 0 . 0 0}$ & $12,000.00$ \\
\hline Gratificaciones & 166.66 & 166.66 & 166.66 & 166.66 & 166.66 & 166.66 & 166.66 & 166.66 & 166.66 & 166.66 & 166.66 & 166.66 & $2,000.00$ \\
\hline Total & $1,166.66$ & $1,166.66$ & $1,166.66$ & $1,166.66$ & $1,166.66$ & $1,166.66$ & $1,166.66$ & $1,166.66$ & $1,166.66$ & $1,166.66$ & $1,166.66$ & $1,166.66$ & $14,000.00$ \\
\hline CTS & 97.22 & 97.22 & 97.22 & 97.22 & 97.22 & 97.22 & 97.22 & 97.22 & 97.22 & 97.22 & 97.22 & 97.22 & $1,166.66$ \\
\hline ESSALUD & 105.00 & 105.00 & 105.00 & 105.00 & 105.00 & 105.00 & 105.00 & 105.00 & 105.00 & 105.00 & 105.00 & 105.00 & $1,260.00$ \\
\hline $\begin{array}{l}\text { Costo salarial } \\
\text { mensual }\end{array}$ & $1,368.88$ & 1,368.88 & $1,368.88$ & 1,368.88 & $1,368.88$ & $1,368.88$ & 1,368.88 & 1,368.88 & $1,368.88$ & 1,368.88 & $1,368.88$ & 1,368.88 & $16,426.66$ \\
\hline
\end{tabular}

Fuente: Elaboración propia

Tabla 6.18

Detalle Mano de Obra Directa Año 5 (S/.)

\begin{tabular}{|c|c|c|c|c|c|c|c|c|c|c|c|c|c|}
\hline & Ene & Feb & Mar & Abr & May & Jun & Jul & Ago & Sep & Oct & Nov & Dic & TOTAL \\
\hline Costurera & $1,000.00$ & $1,000.00$ & $1,000.00$ & $1,000.00$ & $1,000.00$ & $1,000.00$ & $1,000.00$ & $1,000.00$ & $1,000.00$ & $1,000.00$ & $1,000.00$ & $1,000.00$ & $12,000.00$ \\
\hline Total & $1,000.00$ & $1,000.00$ & $1,000.00$ & $1,000.00$ & $1,000.00$ & $1,000.00$ & $1,000.00$ & $1,000.00$ & $1,000.00$ & $1,000.00$ & $1,000.00$ & $1,000.00$ & $12,000.00$ \\
\hline Gratificaciones & 166.66 & 166.66 & 166.66 & 166.66 & 166.66 & 166.66 & 166.66 & 166.66 & 166.66 & 166.66 & 166.66 & 166.66 & $2,000.00$ \\
\hline Total & $1,166.66$ & $1,166.66$ & $1,166.66$ & $1,166.66$ & $1,166.66$ & $1,166.66$ & $1,166.66$ & $1,166.66$ & $1,166.66$ & $1,166.66$ & $1,166.66$ & $1,166.66$ & $14,000.00$ \\
\hline CTS & 97.22 & 97.22 & 97.22 & 97.22 & 97.22 & 97.22 & 97.22 & 97.22 & 97.22 & 97.22 & 97.22 & 97.22 & $1,166.66$ \\
\hline ESSALUD & 105.00 & 105.00 & 105.00 & 105.00 & 105.00 & 105.00 & 105.00 & 105.00 & 105.00 & 105.00 & 105.00 & 105.00 & $1,260.00$ \\
\hline $\begin{array}{l}\text { Costo salarial } \\
\text { mensual }\end{array}$ & 1,368.88 & 1,368.88 & 1,368.88 & 1,368.88 & $1,368.88$ & 1,368.88 & 1,368.88 & 1,368.88 & $1,368.88$ & 1,368.88 & 1,368.88 & 1,368.88 & $16,426.66$ \\
\hline
\end{tabular}

Fuente: Elaboración propia. 
Tabla 6.19

Costos Indirectos de Fabricación (S/.)

\begin{tabular}{|l|c|c|c|c|c|}
\hline \multicolumn{1}{|c|}{} & AÑ̃ 1 & AÑNO 2 & AÑO 3 & AÑO 4 & AÑ̃ 5 \\
\hline Insumos indirectos & 192.00 & 192.00 & 192.00 & 192.00 & 192.00 \\
\hline Gastos Indirectos de fabricación & $6,487.92$ & $6,593.52$ & $6,701.23$ & $6,811.10$ & $6,923.16$ \\
\hline Mano de Obra Indirecta & $52,565.33$ & $52,565.33$ & $52,565.33$ & $67,349.33$ & $67,349.33$ \\
\hline TOTAL & $\mathbf{5 9 , 2 4 5 . 2 5}$ & $\mathbf{5 9 , 3 5 0 . 8 5}$ & $\mathbf{5 9 , 4 5 8 . 5 7}$ & $\mathbf{7 4 , 3 5 2 . 4 3}$ & $\mathbf{7 4 , 4 6 4 . 5 0}$ \\
\hline
\end{tabular}

Fuente: Elaboración propia.

Tabla 6.20

Insumos Indirectos (S/.)

\begin{tabular}{|l|c|c|c|c|c|c|c|}
\hline & AÑ̃ 0 & AÑ̃ 1 & AÑ̃ 2 & AÑ̃ 3 & AÑ 4 & AÑ 5 \\
\hline Escoba & 6 & 24 & 24 & 24 & 24 & 24 \\
\hline Limpia Piso (1,960 ml.) & 6 & 72 & 72 & 72 & 72 & 72 \\
\hline Trapeador & 8 & 96 & 96 & 96 & 96 & 96 \\
\hline $\begin{array}{l}\text { Articulos de limpieza } \\
\text { (ambientador) }\end{array}$ & 9 & 18 & 18 & 18 & 18 & 18 \\
\hline & TOTAL & 29 & 192 & 192 & 192 & 192 & 192 \\
\hline
\end{tabular}

Fuente: Elaboración propia.

Tabla 6.21

Gastos Indirectos de fabricación (S/.)

\begin{tabular}{|l|c|c|c|c|c|}
\hline & AÑ 1 & AÑ 2 & AÑ 3 & AÑ 4 & AÑ 5 \\
\hline Estante de telas & 215.92 & 215.92 & 215.92 & 215.92 & 215.92 \\
\hline Máquina de coser & 190 & 190 & 190 & 190 & 190 \\
\hline Máquina remalladora & 690 & 690 & 690 & 690 & 690 \\
\hline Mesa para cortes & 80 & 80 & 80 & 80 & 80 \\
\hline Plancha & 32 & 32 & 32 & 32 & 32 \\
\hline TOTAL & $1,207.92$ & $1,207.92$ & $1,207.92$ & $1,207.92$ & $1,207.92$ \\
\hline OTROS GASTOS & & & & & \\
\hline Luz & $2,040.00$ & $2,080.80$ & $2,122.42$ & $2,164.86$ & $2,208.16$ \\
\hline Agua & 840 & 856.8 & 873.94 & 891.41 & 909.24 \\
\hline Teléfono + Internet & $2,400.00$ & $2,448.00$ & $2,496.96$ & $2,546.90$ & $2,597.84$ \\
\hline TOTAL & $5,280.00$ & $5,385.60$ & $5,493.31$ & $5,603.18$ & $5,715.24$ \\
\hline TOTAL & $6,487.92$ & $6,593.52$ & $6,701.23$ & $6,811.10$ & $6,923.16$ \\
\hline DEPREC+AMORT+GASTOS & & & & & \\
\hline
\end{tabular}

Fuente: Elaboración propia. 


\section{Tabla 6.22}

Detalle Mano de Obra Indirecta Año 1 (S/.)

\begin{tabular}{|l|c|c|c|c|c|c|c|c|c|c|c|c|c|}
\multicolumn{1}{|c}{} & Ene & Feb & Mar & Abr & May & Jun & Jul & Ago & Sep & Oct & Nov & Dic & TOTAL \\
\hline Asesora de Imagen & 300 & 300 & 300 & 300 & 300 & 300 & 300 & 300 & 300 & 300 & 300 & 300 & $\mathbf{3 , 6 0 0 . 0 0}$ \\
\hline Modista & $1,600.00$ & $1,600.00$ & $1,600.00$ & $1,600.00$ & $1,600.00$ & $1,600.00$ & $1,600.00$ & $1,600.00$ & $1,600.00$ & $1,600.00$ & $1,600.00$ & $1,600.00$ & $19,200.00$ \\
\hline Diseñador & $1,300.00$ & $1,300.00$ & $1,300.00$ & $1,300.00$ & $1,300.00$ & $1,300.00$ & $1,300.00$ & $1,300.00$ & $1,300.00$ & $1,300.00$ & $1,300.00$ & $1,300.00$ & $15,600.00$ \\
\hline Total & $\mathbf{3 , 2 0 0 . 0 0}$ & $\mathbf{3 , 2 0 0 . 0 0}$ & $\mathbf{3 , 2 0 0 . 0 0}$ & $\mathbf{3 , 2 0 0 . 0 0}$ & $\mathbf{3 , 2 0 0 . 0 0}$ & $\mathbf{3 , 2 0 0 . 0 0}$ & $\mathbf{3 , 2 0 0 . 0 0}$ & $\mathbf{3 , 2 0 0 . 0 0}$ & $\mathbf{3 , 2 0 0 . 0 0}$ & $\mathbf{3 , 2 0 0 . 0 0}$ & $\mathbf{3 , 2 0 0 . 0 0}$ & $\mathbf{3 , 2 0 0 . 0 0}$ & $\mathbf{3 8 , 4 0 0 . 0 0}$ \\
\hline Gratificaciones & 533.33 & 533.33 & 533.33 & 533.33 & 533.33 & 533.33 & 533.33 & 533.33 & 533.33 & 533.33 & 533.33 & 533.33 & $6,400.00$ \\
\hline Total & $3,733.33$ & $3,733.33$ & $3,733.33$ & $3,733.33$ & $3,733.33$ & $3,733.33$ & $3,733.33$ & $3,733.33$ & $3,733.33$ & $3,733.33$ & $3,733.33$ & $3,733.33$ & $44,800.00$ \\
\hline CTS & 311.11 & 311.11 & 311.11 & 311.11 & 311.11 & 311.11 & 311.11 & 311.11 & 311.11 & 311.11 & 311.11 & 311.11 & $3,733.33$ \\
\hline ESSALUD & 336 & 336 & 336 & 336 & 336 & 336 & 336 & 336 & 336 & 336 & 336 & 336 & $4,032.00$ \\
\hline Costo salarial mensual & $\mathbf{4 , 3 8 0 . 4 4}$ & $\mathbf{4 , 3 8 0 . 4 4}$ & $\mathbf{4 , 3 8 0 . 4 4}$ & $\mathbf{4 , 3 8 0 . 4 4}$ & $\mathbf{4 , 3 8 0 . 4 4}$ & $\mathbf{4 , 3 8 0 . 4 4}$ & $\mathbf{4 , 3 8 0 . 4 4}$ & $\mathbf{4 , 3 8 0 . 4 4}$ & $\mathbf{4 , 3 8 0 . 4 4}$ & $\mathbf{4 , 3 8 0 . 4 4}$ & $\mathbf{4 , 3 8 0 . 4 4}$ & $\mathbf{4 , 3 8 0 . 4 4}$ & $\mathbf{5 2 , 5 6 5 . 3 3}$ \\
\hline
\end{tabular}

Fuente: Elaboración propia.

\section{Tabla 6.23}

Detalle Mano de Obra Indirecta Año 2 (S/.)

\begin{tabular}{|l|c|c|c|c|c|c|c|c|c|c|c|c|c|}
\multicolumn{1}{|c|}{} & Ene & Feb & Mar & Abr & May & Jun & Jul & Ago & Sep & Oct & Nov & Dic & TOTAL \\
\hline Asesora de Imagen & 300 & 300 & 300 & 300 & 300 & 300 & 300 & 300 & 300 & 300 & 300 & 300 & $\mathbf{3 , 6 0 0 . 0 0}$ \\
\hline Modista & $1,600.00$ & $1,600.00$ & $1,600.00$ & $1,600.00$ & $1,600.00$ & $1,600.00$ & $1,600.00$ & $1,600.00$ & $1,600.00$ & $1,600.00$ & $1,600.00$ & $1,600.00$ & $19,200.00$ \\
\hline Diseñador & $1,300.00$ & $1,300.00$ & $1,300.00$ & $1,300.00$ & $1,300.00$ & $1,300.00$ & $1,300.00$ & $1,300.00$ & $1,300.00$ & $1,300.00$ & $1,300.00$ & $1,300.00$ & $15,600.00$ \\
\hline Total & $\mathbf{3 , 2 0 0 . 0 0}$ & $\mathbf{3 , 2 0 0 . 0 0}$ & $\mathbf{3 , 2 0 0 . 0 0}$ & $\mathbf{3 , 2 0 0 . 0 0}$ & $\mathbf{3 , 2 0 0 . 0 0}$ & $\mathbf{3 , 2 0 0 . 0 0}$ & $\mathbf{3 , 2 0 0 . 0 0}$ & $\mathbf{3 , 2 0 0 . 0 0}$ & $\mathbf{3 , 2 0 0 . 0 0}$ & $\mathbf{3 , 2 0 0 . 0 0}$ & $\mathbf{3 , 2 0 0 . 0 0}$ & $\mathbf{3 , 2 0 0 . 0 0}$ & $\mathbf{3 8 , 4 0 0 . 0 0}$ \\
\hline Gratificaciones & 533.33 & 533.33 & 533.33 & 533.33 & 533.33 & 533.33 & 533.33 & 533.33 & 533.33 & 533.33 & 533.33 & 533.33 & $6,400.00$ \\
\hline Total & $3,733.33$ & $3,733.33$ & $3,733.33$ & $3,733.33$ & $3,733.33$ & $3,733.33$ & $3,733.33$ & $3,733.33$ & $3,733.33$ & $3,733.33$ & $3,733.33$ & $3,733.33$ & $44,800.00$ \\
\hline CTS & 311.11 & 311.11 & 311.11 & 311.11 & 311.11 & 311.11 & 311.11 & 311.11 & 311.11 & 311.11 & 311.11 & 311.11 & $3,733.33$ \\
\hline ESSALUD & 336 & 336 & 336 & 336 & 336 & 336 & 336 & 336 & 336 & 336 & 336 & 336 & $4,032.00$ \\
\hline Costo salarial mensual & $\mathbf{4 , 3 8 0 . 4 4}$ & $\mathbf{4 , 3 8 0 . 4 4}$ & $\mathbf{4 , 3 8 0 . 4 4}$ & $\mathbf{4 , 3 8 0 . 4 4}$ & $\mathbf{4 , 3 8 0 . 4 4}$ & $\mathbf{4 , 3 8 0 . 4 4}$ & $\mathbf{4 , 3 8 0 . 4 4}$ & $\mathbf{4 , 3 8 0 . 4 4}$ & $\mathbf{4 , 3 8 0 . 4 4}$ & $\mathbf{4 , 3 8 0 . 4 4}$ & $\mathbf{4 , 3 8 0 . 4 4}$ & $\mathbf{4 , 3 8 0 . 4 4}$ & $\mathbf{5 2 , 5 6 5 . 3 3}$ \\
\hline
\end{tabular}

Fuente: Elaboración propia. 
Tabla 6.24

Detalle Mano de Obra Indirecta Año 3 (S/.)

\begin{tabular}{|c|c|c|c|c|c|c|c|c|c|c|c|c|c|}
\hline & Ene & Feb & Mar & Abr & May & Jun & Jul & Ago & Sep & Oct & Nov & Dic & TOTAL \\
\hline Asesora de Imagen & 300 & 300 & 300 & 300 & 300 & 300 & 300 & 300 & 300 & 300 & 300 & 300 & $3,600.00$ \\
\hline Modista & $1,600.00$ & $1,600.00$ & $1,600.00$ & $1,600.00$ & $1,600.00$ & $1,600.00$ & $1,600.00$ & $1,600.00$ & $1,600.00$ & $1,600.00$ & $1,600.00$ & $1,600.00$ & $19,200.00$ \\
\hline Diseñador & $1,300.00$ & $1,300.00$ & $1,300.00$ & $1,300.00$ & $1,300.00$ & $1,300.00$ & $1,300.00$ & $1,300.00$ & $1,300.00$ & $1,300.00$ & $1,300.00$ & $1,300.00$ & $15,600.00$ \\
\hline Total & $3,200.00$ & $3,200.00$ & $3,200.00$ & $3,200.00$ & $3,200.00$ & $3,200.00$ & $3,200.00$ & $3,200.00$ & $3,200.00$ & $3,200.00$ & $3,200.00$ & $3,200.00$ & $38,400.00$ \\
\hline Gratificaciones & 533.33 & 533.33 & 533.33 & 533.33 & 533.33 & 533.33 & 533.33 & 533.33 & 533.33 & 533.33 & 533.33 & 533.33 & $6,400.00$ \\
\hline Total & $3,733.33$ & $3,733.33$ & $3,733.33$ & $3,733.33$ & $3,733.33$ & $3,733.33$ & $3,733.33$ & $3,733.33$ & $3,733.33$ & $3,733.33$ & $3,733.33$ & $3,733.33$ & $44,800.00$ \\
\hline CTS & 311.11 & 311.11 & 311.11 & 311.11 & 311.11 & 311.11 & 311.11 & 311.11 & 311.11 & 311.11 & 311.11 & 311.11 & $3,733.33$ \\
\hline ESSALUD & 336 & 336 & 336 & 336 & 336 & 336 & 336 & 336 & 336 & 336 & 336 & 336 & $4,032.00$ \\
\hline Costo salarial mensual & $4,380.44$ & $4,380.44$ & $4,380.44$ & $4,380.44$ & $4,380.44$ & $4,380.44$ & $4,380.44$ & $4,380.44$ & $4,380.44$ & $4,380.44$ & $4,380.44$ & $4,380.44$ & $52,565.33$ \\
\hline
\end{tabular}

Fuente: Elaboración propia.

Tabla 6.25

Detalle Mano de Obra Indirecta Año 4 (S/.)

\begin{tabular}{|c|c|c|c|c|c|c|c|c|c|c|c|c|c|}
\hline & Ene & Feb & Mar & Abr & May & Jun & Jul & Ago & Sep & Oct & Nov & Dic & TOTAL \\
\hline Asesora de Imagen & 900 & 900 & 900 & 900 & 900 & 900 & 900 & 900 & 900 & 900 & 900 & 900 & $9,900.00$ \\
\hline Modista & $1,800.00$ & $1,800.00$ & $1,800.00$ & $1,800.00$ & $1,800.00$ & $1,800.00$ & $1,800.00$ & $1,800.00$ & $1,800.00$ & $1,800.00$ & $1,800.00$ & $1,800.00$ & $21,600.00$ \\
\hline Diseñador & $1,400.00$ & $1,400.00$ & $1,400.00$ & $1,400.00$ & $1,400.00$ & $1,400.00$ & $1,400.00$ & $1,400.00$ & $1,400.00$ & $1,400.00$ & $1,400.00$ & $1,400.00$ & $16,800.00$ \\
\hline Total & $4,100.00$ & $4,100.00$ & $4,100.00$ & $4,100.00$ & $4,100.00$ & $4,100.00$ & $4,100.00$ & $4,100.00$ & $4,100.00$ & $4,100.00$ & $4,100.00$ & $4,100.00$ & $49,200.00$ \\
\hline Gratificaciones & 683.33 & 683.33 & 683.33 & 683.33 & 683.33 & 683.33 & 683.33 & 683.33 & 683.33 & 683.33 & 683.33 & 683.33 & $8,200.00$ \\
\hline Total & $4,783.33$ & $4,783.33$ & $4,783.33$ & $4,783.33$ & $4,783.33$ & $4,783.33$ & $4,783.33$ & $4,783.33$ & $4,783.33$ & $4,783.33$ & $4,783.33$ & $4,783.33$ & $57,400.00$ \\
\hline CTS & 398.61 & 398.61 & 398.61 & 398.61 & 398.61 & 398.61 & 398.61 & 398.61 & 398.61 & 398.61 & 398.61 & 398.61 & $4,783.33$ \\
\hline ESSALUD & 430.5 & 430.5 & 430.5 & 430.5 & 430.5 & 430.5 & 430.5 & 430.5 & 430.5 & 430.5 & 430.5 & 430.5 & $5,166.00$ \\
\hline Costo salarial mensual & $5,612.44$ & $5,612.44$ & $5,612.44$ & $5,612.44$ & $5,612.44$ & $5,612.44$ & $5,612.44$ & $5,612.44$ & $5,612.44$ & $5,612.44$ & $5,612.44$ & $5,612.44$ & $67,349.33$ \\
\hline
\end{tabular}

$\pm$ 


\section{Tabla 6.26}

Detalle Mano de Obra Indirecta Año 5 (S/.)

\begin{tabular}{|c|c|c|c|c|c|c|c|c|c|c|c|c|c|}
\hline & Ene & $\mathrm{Feb}$ & Mar & Abr & May & Jun & Jul & Ago & Sep & Oct & Nov & Dic & TOTAL \\
\hline Asesora de Imagen & 900 & 900 & 900 & 900 & 900 & 900 & 900 & 900 & 900 & 900 & 900 & 900 & 9,900.00 \\
\hline Modista & $1,800.00$ & $1,800.00$ & $1,800.00$ & $1,800.00$ & $1,800.00$ & $1,800.00$ & $1,800.00$ & $1,800.00$ & $1,800.00$ & $1,800.00$ & $1,800.00$ & $1,800.00$ & $21,600.00$ \\
\hline Diseñador & $1,400.00$ & $1,400.00$ & $1,400.00$ & $1,400.00$ & $1,400.00$ & $1,400.00$ & $1,400.00$ & $1,400.00$ & $1,400.00$ & $1,400.00$ & $1,400.00$ & $1,400.00$ & $16,800.00$ \\
\hline Total & $4,100.00$ & $4,100.00$ & $4,100.00$ & $4,100.00$ & $4,100.00$ & $4,100.00$ & $4,100.00$ & $4,100.00$ & $4,100.00$ & $4,100.00$ & $4,100.00$ & $4,100.00$ & $49,200.00$ \\
\hline Gratificaciones & 683.33 & 683.33 & 683.33 & 683.33 & 683.33 & 683.33 & 683.33 & 683.33 & 683.33 & 683.33 & 683.33 & 683.33 & $8,200.00$ \\
\hline Total & $4,783.33$ & $4,783.33$ & $4,783.33$ & $4,783.33$ & $4,783.33$ & $4,783.33$ & $4,783.33$ & $4,783.33$ & $4,783.33$ & $4,783.33$ & $4,783.33$ & $4,783.33$ & $57,400.00$ \\
\hline CTS & 398.61 & 398.61 & 398.61 & 398.61 & 398.61 & 398.61 & 398.61 & 398.61 & 398.61 & 398.61 & 398.61 & 398.61 & $4,783.33$ \\
\hline ESSALUD & 430.5 & 430.5 & 430.5 & 430.5 & 430.5 & 430.5 & 430.5 & 430.5 & 430.5 & 430.5 & 430.5 & 430.5 & $5,166.00$ \\
\hline Costo salarial mensual & $5,612.44$ & $5,612.44$ & $5,612.44$ & $5,612.44$ & $5,612.44$ & $5,612.44$ & $5,612.44$ & $5,612.44$ & $5,612.44$ & $5,612.44$ & $5,612.44$ & $5,612.44$ & $67,349.33$ \\
\hline
\end{tabular}

Fuente: Elaboración propia.

Tabla 6.27

Presupuesto de costo de producción (S/.)

\begin{tabular}{|l|c|c|c|c|c|}
\hline & AÑO 1 & AÑO 2 & AÑ̃ 3 & AÑ̃ 4 & AÑ̃ 5 \\
\hline Materiales insumos & $14,739.50$ & $15,476.48$ & $16,250.30$ & $17,225.32$ & $18,258.84$ \\
\hline Mano de Obra Directa & $8,213.33$ & $8,213.33$ & $8,213.33$ & $16,426.67$ & $16,426.67$ \\
\hline Costos Indirectos de Fabricación & $59,245.25$ & $59,350.85$ & $59,458.57$ & $74,352.43$ & $74,464.50$ \\
\hline TOTAL & $\mathbf{8 2 , 1 9 8 . 0 9}$ & $\mathbf{8 3 , 0 4 0 . 6 6}$ & $\mathbf{8 3 , 9 2 2 . 2 0}$ & $\mathbf{1 0 8 , 0 0 4 . 4 1}$ & $\mathbf{1 0 9 , 1 5 0 . 0 0}$ \\
\hline
\end{tabular}

Fuente: Elaboración propia. 


\section{CAPÍTULO VII: MARKETING MIX}

\subsection{Servicio}

\subsubsection{Descripción del servicio}

Los prendas que se confeccionarán serán: sacos, pantalones de vestir, vestidos, blusas y faldas. Estas serán diseñadas por un diseñador de modas que graficará por medio de un bosquejo cómo será la prenda según el modelo que se requiera.

La toma del pedido y la toma de medidas será en el lugar donde programe la clienta. Buscamos la mayor comodidad de la clienta por ello quienes escogen el lugar de encuentro de desarrollo de la prenda son las clientas.

Todas las prendas serán confeccionadas en máquinas rectas de coser y máquinas remalladoras. Dichas prendas serán modelos únicos con el fin de que la clienta se sienta satisfecha con la prenda y que no tenga opción de encontrar la misma prenda en otra persona.

\subsubsection{Descripción e ilustración del tangible (producto híbrido)}

A continuación presentaremos cada una de ellas.

- Sacos: Los sacos se confeccionarán en base a telas como drill. Paño, alpaca, lanillas o polystel.

Figura 7.1

Sacos

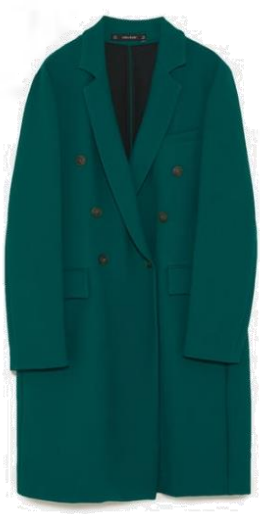

Fuente: Zara (2018). 
- Pantalones: Drill, polystel, chalis, paño o jean.

Figura 7.2

Pantalones

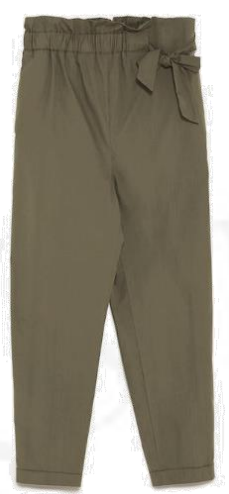

Fuente: Zara (2018).

- Vestidos: gaza, chalis, seda, organza, seda shantú, razo, broderie, encaje o licrada

Figura 7. 3

Vestidos

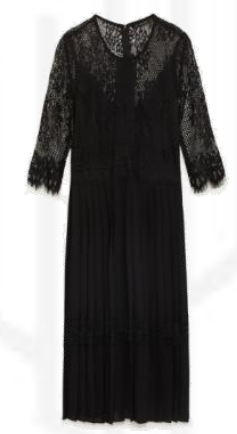

Fuente: Zara (2018).

- Blusas: gaza, seda, broderie, chalis, nanzu o popelina.

\section{Figura 7.4}

Blusas

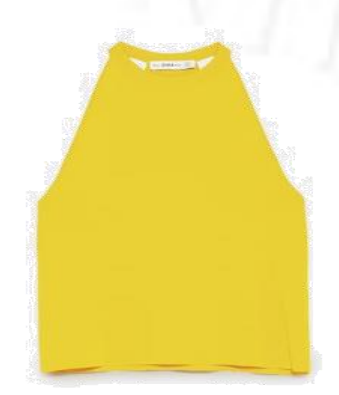

Fuente: Zara (2018). 
- Falda: corduroi, drill, paño o polystel.

Figura 7.5

Faldas

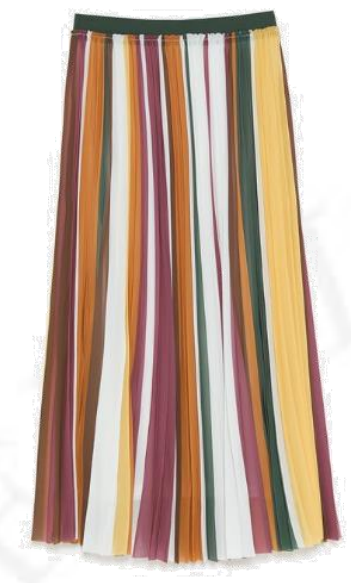

Fuente: Zara (2018).

\subsubsection{Descripción del (los) servicio(s) secundario(s)}

Como servicio secundario ofreceremos un servicio de asesoría de imagen el cual se tomará a petición del cliente.

Dentro del paquete que se ofrece al tomar el servicio de asesoría de imagen incluyen los siguientes puntos:

- Dos horas de Personal Shopper.

- Análisis de cuerpo y paleta de colores más tips para vestir.

- Revisión de armario.

- Outfits armados.

\subsubsection{Descripción de la Flor de servicios complementarios de facilitación}

- Información

○ Dirección de oficina y taller: Jr. Independencia 433 Dpto. 106 - Breña.

○ Horario: Lunes a Domingo de 8:00 am - 6:00 p.m. (El horario puede ser modificado si el servicio lo requiere).

- Condiciones de servicio: Una vez tomado el pedido y que la cliente cancele cuando este ya esté en la fase de producción se cobrará una penalidad por gastos incurridos hasta la fecha y por trabajo. 
- Confirmación de reservaciones: Las reservas se deben confirmar con 24 horas de anticipación.

- Recibos y facturas: Se entregará boleta de venta y factura en caso la clienta lo solicite.

- Toma de pedido

- Solicitudes: Servicio con previa cita.

- Ingreso de pedidos: Se solicitan citas por medio de la página web o Whatssap.

- Facturación

- Cotizaciones en la primera visita.

- Pago

- Autoservicio: Se contará con POS para pagos con tarjetas de débito y crédito.

- Pago directo a destinatario: No solo aceptamos pagos con tarjetas, aceptamos dinero en efectivo.

Figura 7.6

Flor de servicio adaptado al modelo de negocio

Información

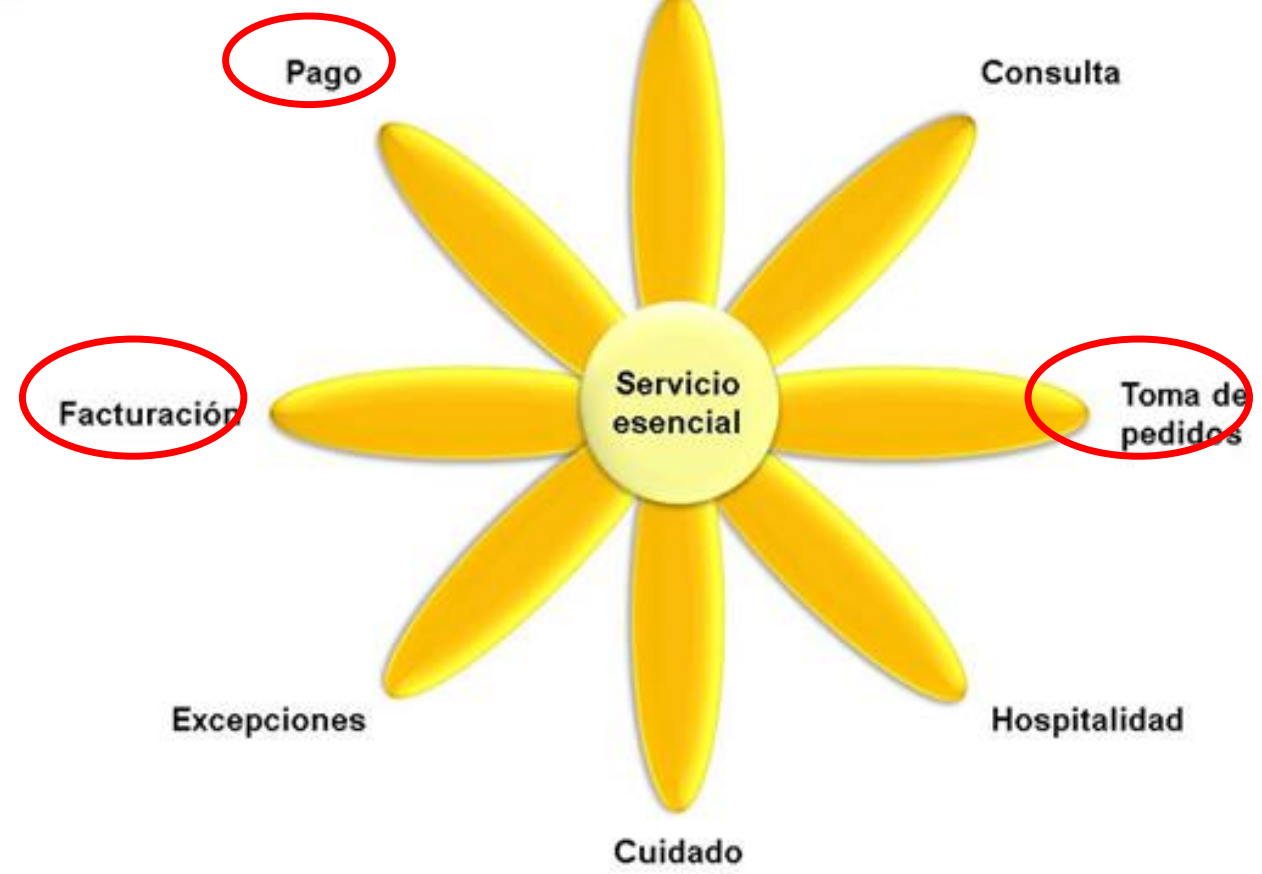

Fuente: Adaptado de Lovelock, C., y Wirtz, J. (2015). 


\subsubsection{La marca}

Descripción de la marca (nombre de marca, logotipo, otro)

- Marca: “Ayde Co.”

Figura 7.7

Marca

\section{Ayde Co.}

Fuente: Elaboración propia.

Como empresa creemos que cada mujer es única. Es por ello que el mensaje de la marca refleja una realidad al confeccionar modelos exclusivos para cada cliente y preferencias.

- Logotipo:

Para el logotipo, se quiere una esencia de modernidad ya que este reflejaría que contamos siempre con prendas en tendencia o a gusto de la clienta.

Figura 7.8

Logotipo

\section{Ayde Co.}

Fuente: Elaboración propia.

- Isotipo:

El isotipo como referencia a nuestro público objetivo para transmitir que las mujeres forman parte de nuestro público objetivo. 
Figura 7.9

Isotipo

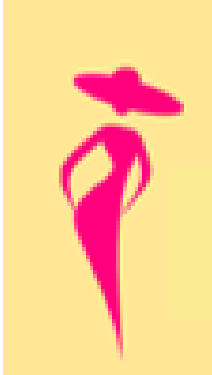

Fuente: Elaboración propia. 


\subsection{Procesos}

\subsubsection{Flujograma del servicio básico o principal}

Figura 7.10

Proceso de servicio

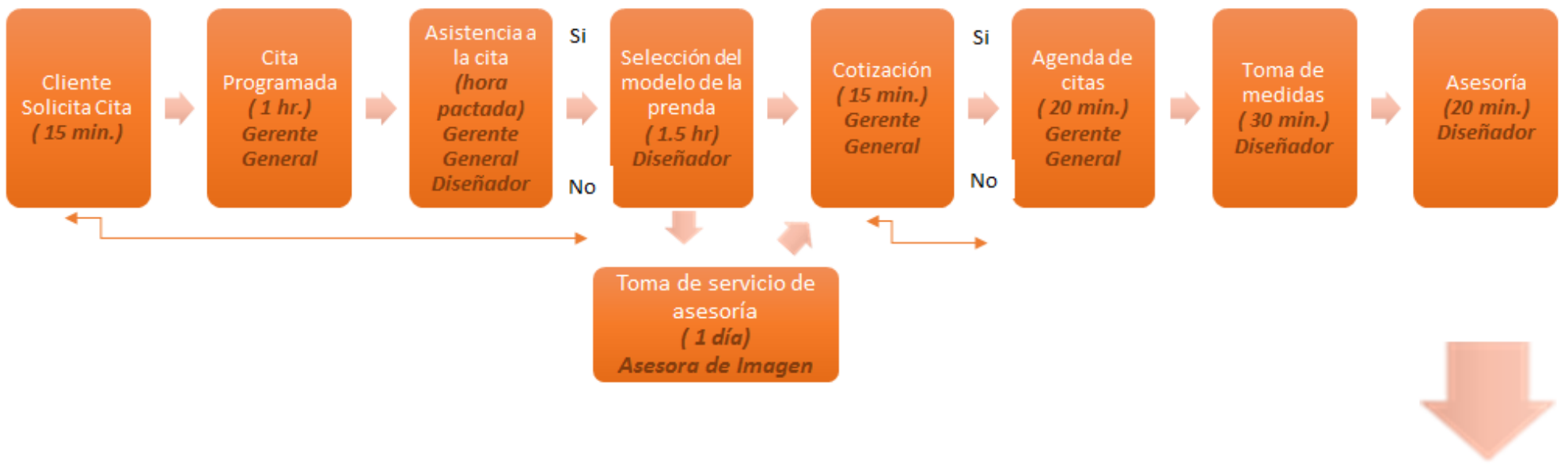

Fuente: Elaboración propia.

to 
Figura 7.11

Proceso de Producción

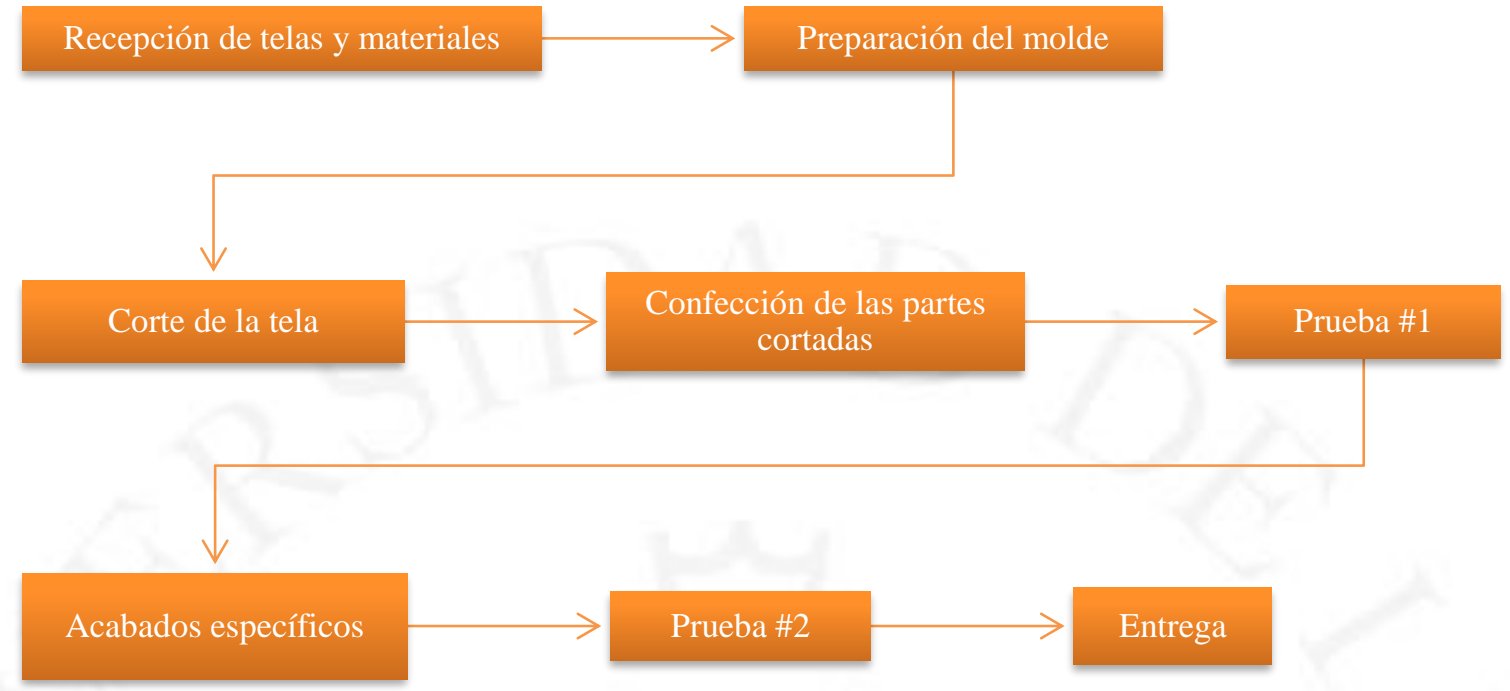

Fuente: Elaboración propia.

\subsubsection{Evaluación al cliente}

Una vez que se haya dado por finalizado el servicio y concluya con la entrega de la prenda se realizará una evaluación que estará a cargo del Gerente General. La evaluación tiene como propósito identificar nuestras fortalezas y oportunidades de mejora. Cabe decir que esta herramienta es de importante consideración ya que lo que se busca es retener al cliente con el mejor servicio prometido desde el primer contacto.

La evaluación contará con 5 puntos: tangible, confiabilidad, respuesta, certidumbre y empatía. Bajo cada punto se encontrarán los temas a tocar en el cuestionario.

\section{Modelo SERVQUAL}

1. Tangibles

- Local presentable / moderno.

- Presentación de los representantes (imagen).

- Revistas de actuales de moda, equipos o herramientas en buenas condiciones.

2. Confiabilidad

- Cumplimiento de horarios

- Cumplimiento de entrega prenda en el tiempo pactado.

- Entrega de un servicio homogéneo a las clientas. 


\section{Respuesta}

- Tiempo de respuesta a las solicitudes de atención.

- Equipo siempre a disposición del cliente.

4. Certidumbre

- Servicio confiable.

- Equipo con amplio conocimiento del negocio.

- Seguridad del cumplimiento del pedido.

- Atención de calidad, equipo dedicado al servicio.

5. Empatía

- Servicio personalizado.

- Horarios flexibles para la atención de las clientas.

- Entender lo que la cliente está buscando.

\subsection{Personas}

\subsubsection{Descripción y rol del personal front stage}

Representante principal y diseñador de modas:

Ambos llegarán al lugar pactado por la clienta. La representante hará una introducción sobre la marca, mostrará el catálogo de trabajos previos para que la clienta potencial tenga una noción de las prendas ya realizadas. Además será quien realice la cotización del pedido.

El diseñador de modas será quien bosqueje el modelo de la prenda solicitada por la clienta. No solo se encargará de dibujar un prospecto de su futura prenda, también brindará asesoría respecto al diseño, colores y telas adecuadas para cada clienta.

\subsubsection{Descripción y rol del personal back stage}

La costurera es quien confeccionará la prenda. En caso haya más de un pedido, trabajará de la mano con otra costurera (presta servicios por horas) para evitar atrasos y se cumplan los tiempos pactados. 


\subsubsection{Rol del cliente en la producción del servicio}

El rol del cliente es escoger su modelo de prenda. Una vez que se defina el modelo se tendrá que programar dos citas para la toma de pruebas obligatoria. En ese proceso del servicio al cliente podrá modificar las prendas hasta que quede a su gusto.

\subsubsection{Organigrama}

Figura 7.12

Organigrama

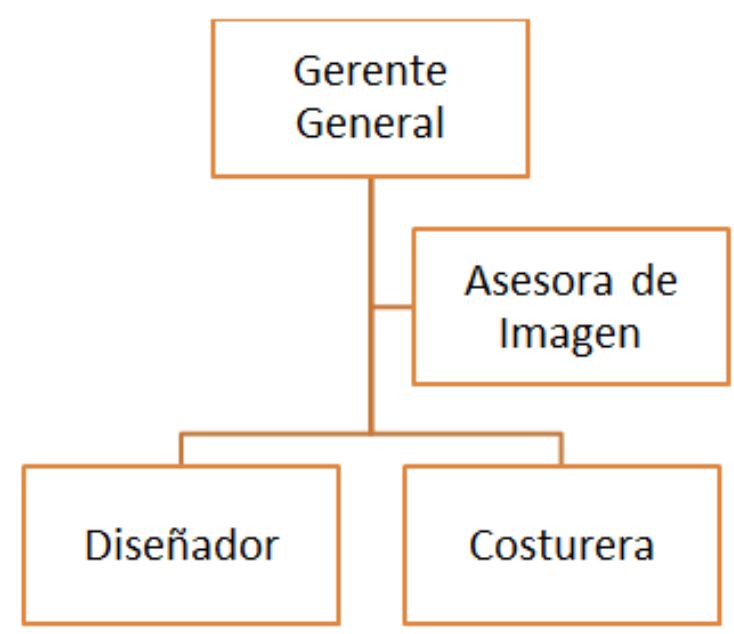

Fuente: Elaboración propia.

\subsection{Precio}

\subsubsection{Política de precios criterios de fijación de precios}

El criterio que se utilizará será el de valor percibido que podemos tomar como referencia del focus group y de las encuestas realizadas a nuestro target.

\subsubsection{Estrategia de precio de nuevo producto}

La estrategia que utilizaremos será de penetración ya que ingresaremos al mercado con un servicio diferenciado y atractivo para el público objetivo. El gasto en el que incurrimos en llevarlo hasta la cliente será valorado. 


\subsubsection{Lista de precios}

Los precios variarán de acuerdo al modelo de la prendas y de las medidas de la clienta para poder satisfacer sus expectativas. Estos precios se basan en cercos físicos ya que nosotros vamos hasta la ubicación que el cliente lo requiera. En caso de clientes frecuentes se aplicarán precios de cercos no físicos. Se le aplicará un pequeño descuento para los clientes frecuentes como parte del programa de fidelización.

A continuación mostraremos precios basados en cercos físicos de referencia para el público objetivo.

Tabla 7.1

Lista de precios cerco físico

\begin{tabular}{|c|c|}
\hline PRENDAS & MONTO CON IGV \\
\hline Pantalones de vestir & S/.180.00 \\
\hline Vestidos & S/.200 a más aprox. \\
\hline Blusas & S/. 100.00 \\
\hline Faldas & S/. 120.00 \\
\hline Sacos & S/. 300.00 \\
\hline
\end{tabular}

Fuente: Elaboración propia.

Tabla 7.2

Lista de precios cerco no físico

\begin{tabular}{|c|c|c|}
\hline PRENDAS & PRECIO & $\begin{array}{c}\text { DESCUENTO } \\
5 \%\end{array}$ \\
\hline Pantalones de vestir & S/. 180 & S/. 171 \\
\hline Vestidos & S/.250 & S/. 238 \\
\hline Blusas & S/. 100 & S/. 95 \\
\hline Faldas & S/. 120 & S/. 114 \\
\hline Sacos & S/. 300 & S/. 285 \\
\hline
\end{tabular}

Fuente: Elaboración propia.

\subsubsection{Costos unitarios}

A continuación mostraremos los costos unitarios por cada tipo de prenda.

- $\operatorname{Sacos}$

\section{Tabla 7.3}

Costos Unitarios: Sacos

\begin{tabular}{|c|c|c|}
\hline $\begin{array}{c}\text { MATERIA } \\
\text { PRIMA }\end{array}$ & CANTIDAd & \multicolumn{1}{c}{ MONTO } \\
\hline Hilo & Unidades & S/. 2.50 \\
\hline & & (continúa) \\
\hline
\end{tabular}


(continuación)

\begin{tabular}{|l|c|rr|}
\hline Tela polistel & $2 \mathrm{mt}$ & S/. & 105.00 \\
\hline Aguja & unidades & S/. & 0.50 \\
\hline Alfileres & unidades & S/. & 1.50 \\
\hline Tijera & unidades & S/. & 15.00 \\
\hline Piquetera & unidades & S/. & 2.00 \\
\hline Regla & unidades & S/. & 2.00 \\
\hline Papel de molde & unidades & S/. & 0.70 \\
\hline Tiza & unidades & S/. & 1.00 \\
\hline & MOD & S/. & 20.00 \\
\hline
\end{tabular}

Fuente: Elaboración propia.

- Pantalones de vestir

Tabla 7.4

Costos Unitarios: Pantalones de vestir

\begin{tabular}{|l|c|rr|}
\multicolumn{1}{|c}{ MATERIA } & CANTIDAD & \multicolumn{2}{c|}{ MONTO } \\
\hline Hilo & unidades & S/. & 2.50 \\
\hline Tela Drill & $2 \mathrm{mts}$ & S/. & 36.00 \\
\hline Aguja & unidades & S/. & 0.50 \\
\hline Alfileres & unidades & S/. & 1.50 \\
\hline Tijera & unidades & S/. & 15.00 \\
\hline Piquetera & unidades & S/. & 2.00 \\
\hline Regla & unidades & S/. & 2.00 \\
\hline Papel de molde & unidades & S/. & 0.70 \\
\hline Tiza & unidades & S/. & 1.00 \\
\hline & MOD & S/. & 20.00 \\
\hline
\end{tabular}

Fuente: Elaboración propia.

\section{- Vestidos}

Tabla 7.5

Costos Unitarios: Vestidos

\begin{tabular}{|l|l|rr|}
\multicolumn{1}{c|}{$\begin{array}{c}\text { MATERIA } \\
\text { PRIMA }\end{array}$} & CANTIDAD & \multicolumn{2}{c|}{ MONTO } \\
\hline Hilo & unidades & S/. & 2.50 \\
\hline Tela Chalis & $2.5 \mathrm{mts}$ & S/. & 35.00 \\
\hline Aguja & unidades & S/. & 0.50 \\
\hline Alfileres & unidades & S/. & 1.50 \\
\hline Tijera & unidades & S/. & 15.00 \\
\hline Piquetera & unidades & S/. & 2.00 \\
\hline Regla & unidades & S/. & 2.00 \\
\hline Papel de molde & unidades & S/. & 0.70 \\
\hline Tiza & unidades & S/. & 1.00 \\
\hline & MOD & S/. & 20.00 \\
\hline & TOTAL & S/. & $\mathbf{8 0 . 2 0}$ \\
\hline
\end{tabular}

Fuente: Elaboración propia. 
- Blusas

Tabla 7.6

Costos Unitarios: Blusas

\begin{tabular}{|c|c|c|}
\hline $\begin{array}{l}\text { MATERIA } \\
\text { PRIMA }\end{array}$ & CANTIDAD & MONTO \\
\hline Hilo & Unidades & S/. $\quad 2.50$ \\
\hline Tela Chalis & $1 / 2 \mathrm{mt}$ & S/. $\quad 7.00$ \\
\hline Aguja & Unidades & S/. $\quad 0.50$ \\
\hline Alfileres & Unidades & S/. 1.50 \\
\hline Tijera & Unidades & S/. 15.00 \\
\hline Piquetera & Unidades & S/. $\quad 2.00$ \\
\hline Regla & Unidades & S/. $\quad 2.00$ \\
\hline Papel de molde & Unidades & S/. $\quad 0.70$ \\
\hline \multirow[t]{3}{*}{ Tiza } & Unidades & S/. 1.00 \\
\hline & MOD & S/. $\quad 20.00$ \\
\hline & TOTAL & S/. 52.20 \\
\hline
\end{tabular}

Fuente: Elaboración propia.

- Faldas

Tabla 7.7:

Costos Unitarios: Faldas

\begin{tabular}{|l|l|rr|}
\multicolumn{1}{|c|}{ MATERIA } & \multicolumn{1}{c|}{ CANTIDAD } & \multicolumn{2}{c|}{ MONTO } \\
\hline Hilo & Unidades & S/. & 2.50 \\
\hline Tela Drill & $1.5 \mathrm{mt}$. & S/. & 27.00 \\
\hline Aguja & unidades & S/. & 0.50 \\
\hline Alfileres & unidades & S/. & 1.50 \\
\hline Tijera & unidades & S/. & 15.00 \\
\hline Piquetera & unidades & S/. & 2.00 \\
\hline Regla & unidades & S/. & 2.00 \\
\hline Papel de molde & unidades & S/. & 0.70 \\
\hline Tiza & unidades & S/. & 1.00 \\
\hline & MOD & S/. & 20.00 \\
\hline
\end{tabular}

Fuente: Elaboración propia.

\subsubsection{Precios de la competencia}

Respecto a la competencia, compararemos precios con los que ofrece una trabajadora independiente. Se comparte el mismo target y el rango de edades.

Tabla 7.8

Comparación de Precios: Ayde Co. vs. Competencia 


\begin{tabular}{|l|r|r|r|}
\multicolumn{1}{c}{ PRENDAS } & $\begin{array}{r}\text { COMPETENCIA } \\
\text { (INDEPENDIENTES) }\end{array}$ & AYDE CO. & \multicolumn{1}{c|}{ DIFERENCIA } \\
\hline Pantalones de vestir & S/. 100.00 & S/.120 & 20 \\
\hline Vestidos & S/.200 y S/.500 & S/.150 y S/. 600 & Aprox: S/. 100 \\
\hline Blusas & S/. 65.00 & S/. 80.00 & S/. 15 \\
\hline Faldas & S/. 80.00 & S/. 70.00 & S/. 10 \\
\hline Sacos & S/. 200.00 & S/. 250.00 & S/. 50 \\
\hline
\end{tabular}

Fuente: Elaboración propia.

\subsection{Canal}

\subsubsection{Forma de contacto con el cliente}

"Ayde Co." presenta una distribución directa porque producimos y entregamos directamente al consumidor final. Esto quiere decir que no utilizamos intermediarios.

El cliente se contacta con nosotros, realiza su pedido y nosotros como empresa nos encargamos de llevar al punto donde el cliente prefiera.

- Ubicación y dirección del local

La distribución será por medio de venta directa. Contaremos con un taller en el distrito de Breña.

$\mathrm{Al}$ momento que la clienta se contacte con nosotros, nos dirigiremos al punto de referencia que nos indiquen.

La dirección será en: Jirón independencia 433 Dpto. 106 - Breña.

- Horarios de atención:

De Lunes a Domingo de 8:00 am - 6:00 p.m. (El horario puede ser modificado si el servicio lo requiere)

\subsection{Comunicación}

\subsubsection{Actividades de lanzamiento y al consumidor}

\subsubsection{Actividades de lanzamiento}

- Actividad 1:

Para la campaña de lanzamiento se creará un "fan page” en Facebook. El fin de la campaña es mantener en intriga al público objetivo con el servicio diferenciado que 
ofreceremos. Solo se mostrará la marca junto al logo y día a día se creará publicaciones para que el target interactúe o pregunte sobre la idea de negocio.

Esta campaña de intriga se dará durante menos de 15 días porque puede causar rechazo tanta espera.

\subsubsection{Actividades al consumidor}

\section{- Actividad 1:}

Se repartirán tarjetas de invitación al círculo más cercano para la inauguración y lanzamientos de la marca "Ayde Co.".

El lugar será en la dirección del taller el cual será ambientado para recibir a las clientas potenciales.

En este evento se presentará la marca, se repartirán tarjetas de presentación para las asistentes y se hará in brindis por la inauguración.

\subsubsection{Actividades de mantenimiento al consumidor}

\subsection{Actividades de mantenimiento}

Crearemos cuentas en "Instagram" y "Pinterest" con el fin de publicar periódicamente los diseños que se han ido trabajando con las clientas. Incluirá fotos del proceso de confección para que se pueda tener en mente cómo es que trabajamos en "Ayde Co.”.

Además de redes sociales como herramientas de mantenimiento o fidelización a las clientas trabajaremos las siguientes propuestas:

- Email marketing: Es importante hacer recordar a nuestras clientas que estamos pendientes de sus sugerencias y de lo importante que son el negocio. Adicional a ello podrán tener descuentos personales u algún incentivo.

- Llevar a cabo acciones promocionales a través de códigos QR.

- Conectar a las clientas con la marca por reusar lo máximo posible los recursos que sobra.

- Realizar showrooms cada cierto tiempo al año para que las clientas puedan conocer directamente el taller y a su vez comprar prendas en descuento. 


\subsection{Actividades al consumidor}

- Actividad 1

Con una base de datos de todas las clientas, hacer llegar a las clientas un regalo con la marca "Ayde Co.”. El regalo será un kit de manicure ya que nos dirigimos a mujeres modernas y sofisticadas. Contaremos con 200 kits para repartirlos durante los primeros meses. En caso se requieran de más kits, se comprarán. Este obsequio se les hará llegar el día de su cumpleaños.

- $\quad$ Actividad 2

Invertir en anuncios de Facebook e Instagram. Durante el primer año invertir S/. 1,800.00 soles para publicitar en Facebook e Instagram. Luego del primer año y de analizar si la marca ha llegado a un número considerable de clientas, invertir más de 150 soles (mensual) para que los anuncios aparezcan por más tiempo durante el día.

\subsubsection{Presupuesto de marketing, por tipo de actividad}

Presupuestaremos por cada tipo de actividad que se llevarán a cabo.

Tabla 7.9

Presupuesto de actividades

\begin{tabular}{|c|c|c|c|c|}
\hline ACTIVIDAD & GASTOS & CANTIDAD & PRECIO & TOTAL \\
\hline \multirow{4}{*}{ Lanzamiento } & 100 kits para regalo & 200 & S/. 5.00 & S/. $1,000.00$ \\
\hline & Tarjetas de invitación & 1,000 & S/. 300.00 & S/. 300.00 \\
\hline & Espumante & 5 & S/. 60.00 & S/. 300.00 \\
\hline & Copas descartables & 50 & S/. 20.00 & S/. 20.00 \\
\hline \multicolumn{4}{|c|}{ TOTAL ACTIVIDADES DE LANZAMIENTO } & S/. 1,620 \\
\hline \multirow{2}{*}{$\begin{array}{c}\text { Al } \\
\text { Consumidor }\end{array}$} & $\begin{array}{l}\text { Anuncios mensuales en } \\
\text { Facebook }\end{array}$ & 12 & S/. 150.00 & S/. 1,800.00 \\
\hline & Página Web & 1 & S/. 3,000 & $3,270.00$ \\
\hline
\end{tabular}

Fuente: Elaboración propia. 


\section{CAPÍTULO VIII: PROYECCIONES FINANCIERAS}

\subsection{Pronóstico de ventas y plan de utilidades del primer año}

Se estimarán las ventas en base a las estacionalidades del negocio. Los meses de marzo, julio, noviembre y diciembre suelen ser altos debido a eventos que suelen darse en esos meses como matrimonios, graduaciones y celebración por año nuevo. Como se observa en la tabla 8.1 el margen operativo en ciertos meses es negativo debido a la estacionalidad y los gastos que son fijos mes a mes.

Tabla 8.1

Pronóstico de ventas y plan de utilidades del primer año

\begin{tabular}{|c|c|c|c|c|c|c|c|c|c|c|c|c|c|}
\hline & Ene. & Feb. & Mar. & Abr. & May. & Jun. & Jul. & Ago. & Set. & Oct. & Nov. & Dic. & Total \\
\hline Venta Neta S/. & $6,750.00$ & $6,750.00$ & $17,550.00$ & $6,750.00$ & $6,750.00$ & $6,750.00$ & $22,950.00$ & $6,750.00$ & $6,750.00$ & $6,750.00$ & $17,550.00$ & $22,950.00$ & $135,000.00$ \\
\hline Costos Variable & & & 605000 & $6,850.00$ & $6,850.00$ & & & & & & & & \\
\hline . & 10000 & -10000 & $10,700.00$ & -100.00 & م000 & -100.00 & $16,100.00$ & -100.00 & -100.00 & -100.00 & $10,700.00$ & $16,100.00$ & \\
\hline & & & & & & & & & & & & & \\
\hline & & & & & & & & & & & & & \\
\hline Margen Operativo & $-4,052.00$ & $-4,052.00$ & $6,748.00$ & $-4,052.00$ & $-4,052.00$ & $-4,052.00$ & $12,148.00$ & $-4,052.00$ & $-4,052.00$ & $-4,052.00$ & $6,748.00$ & $12,148.00$ & $5,382.00$ \\
\hline
\end{tabular}

Fuente: Elaboración propia.

\subsection{Evaluación financiera de mediano plazo}

El siguiente flujo presenta los resultados obtenidos del plan operacional para finalmente obtener el VAN del proyecto. 
Tabla 8.2

Evaluación financiera a largo plazo - Estado de Ganancias y Pérdidas

\begin{tabular}{|c|c|c|c|c|c|}
\hline & AÑO 1 & AÑO 2 & AÑO 3 & AÑO 4 & AÑO 5 \\
\hline Ventas netas & $135,000.00$ & $141,750.00$ & $148,838.00$ & $157,768.00$ & $167,234.00$ \\
\hline (Costo de ventas) & $82,198.00$ & $83,041.00$ & $83,922.00$ & $108,004.00$ & $109,150.00$ \\
\hline Utilidad Bruta & $52,802.00$ & $58,709.00$ & $64,915.00$ & $49,763.00$ & $58,084.00$ \\
\hline (Gastos Administrativos) & $40,674.00$ & $40,674.00$ & $40,674.00$ & $43,959.00$ & $43,959.00$ \\
\hline (Gasto de Ventas) & $6,746.00$ & $7,081.00$ & $7,166.00$ & $7,255.00$ & $7,349.00$ \\
\hline Utilidad Operativa & $5,382.00$ & $10,955.00$ & $17,076.00$ & $-1,451.00$ & $6,776.00$ \\
\hline (Gastos Financieros) & - & - & - & - & - \\
\hline Ingreso Financiero & 367.00 & 437.00 & 546.00 & 699.00 & 721.00 \\
\hline Utilidad antes impuestos & $5,749.00$ & $11,391.00$ & $17,622.00$ & -752.00 & $7,497.00$ \\
\hline (Impuestos a la Renta) & $1,725.00$ & $3,417.00$ & $5,286.00$ & - & $2,249.00$ \\
\hline Utilidad Neta & $4,024.00$ & 7,974.00 & $12,335.00$ & -752.00 & $5,248.00$ \\
\hline Depreciación & $2,124.00$ & $2,124.00$ & $2,124.00$ & $2,124.00$ & $2,124.00$ \\
\hline Amortización Intangibles & 833.00 & 833.00 & 833.00 & 833.00 & 833.00 \\
\hline VALOR * $(1-\mathrm{T})$ & & & & & $56,199.00$ \\
\hline FCE & $6,981.00$ & $10,931.00$ & $15,292.00$ & $2,204.00$ & $64,403.00$ \\
\hline INVERSION & 51,455 & & & & \\
\hline COSTO DE OPORTUNIDAD & $15 \%$ & & & & \\
\hline VAN ECONOMICO & 6,214 & & & & \\
\hline
\end{tabular}

Fuente: Elaboración propia.

\subsection{Análisis del punto de equilibrio (largo plazo)}

Para hallar el punto de equilibrio requerimos de las ventas netas en soles como ventas netas en unidades, de los costos de producción y de los gastos incurridos.

Tabla 8.3

Análisis del Punto de Equilibrio

\begin{tabular}{|l|c|c|c|c|c|c|}
\hline & AÑO 1 & AÑO 2 & AÑO 3 & AÑO 4 & AÑ̃ 5 \\
\hline Ventas Netas S/. & $135,000.00$ & $141,750.00$ & $148,838.00$ & $\begin{array}{c}157,768.0 \\
0\end{array}$ & $167,234.00$ \\
\hline Ventas Netas UND & 90 & 95 & 99 & 105 & 111 \\
\hline Costos Insumos & $14,740.00$ & $15,476.00$ & $16,250.00$ & $17,225.00$ & $18,259.00$ \\
\hline Mano de Obra Directa & $8,213.00$ & $8,213.00$ & $8,213.00$ & $16,427.00$ & $16,427.00$ \\
\hline Costo Indirecto de Fabricación & $59,245.00$ & $59,351.00$ & $59,459.00$ & $74,352.00$ & $74,464.00$ \\
\hline $\begin{array}{l}\text { Punto de Equilibrio: Producción } \\
\text { de Unidades }\end{array}$ & 50 & 51 & 51 & 68 & 68 \\
\hline Gastos Administrativos directos & $1,200.00$ & $1,200.00$ & $1,200.00$ & $1,200.00$ & $1,200.00$ \\
\hline Mano de Obra Administrativa & $37,781.00$ & $37,781.00$ & $37,781.00$ & $41,067.00$ & $41,067.00$ \\
\hline
\end{tabular}

(continúa) 
(continuación)

\begin{tabular}{|l|c|c|c|c|c|}
\hline $\begin{array}{l}\text { Gastos Administrativos } \\
\text { indirectos }\end{array}$ & $1,693.00$ & $1,693.00$ & $1,693.00$ & $1,693.00$ & $1,693.00$ \\
\hline Gastos de Ventas Directos & $6,690.00$ & $7,025.00$ & $7,110.00$ & $7,199.00$ & $7,293.00$ \\
\hline Mano de Obra de Ventas & 0.00 & 0.00 & 0.00 & 0.00 & 0.00 \\
\hline Gastos de Ventas Indirectos & 56.00 & 56.00 & 56.00 & 56.00 & 56.00 \\
\hline $\begin{array}{l}\text { Punto de Equilibrio: } \\
\text { Operativo en Unidades }\end{array}$ & 86 & 86 & 86 & 106 & 106 \\
\hline Gastos Financieros & 0.00 & 0.00 & 0.00 & 0.00 & 0.00 \\
\hline Ingresos financieros & 367.00 & 437.00 & 546.00 & 699.00 & 721.00 \\
\hline $\begin{array}{l}\text { Punto de Equilibrio: } \\
\text { Financiero en Unidades }\end{array}$ & 86 & 86 & 86 & 106 & 106 \\
\hline Impuesto a la Renta & $1,725.00$ & $3,417.00$ & $5,286.00$ & 0.00 & $2,249.00$ \\
\hline $\begin{array}{l}\text { Punto de Equilibrio: } \\
\text { Neto en Unidades }\end{array}$ & 87 & 89 & 90 & 106 & 108 \\
\hline
\end{tabular}

Fuente: Elaboración propia.

\subsection{Balance General}

Para el siguiente cuando mostramos el balance general del proyecto.

Tabla 8.4

Balance General

\begin{tabular}{|l|r|r|r|r|r|r|r|}
\hline \multicolumn{2}{|c|}{ AÑ̃ 0 } & AÑO 1 & AÑO 2 & AÑ 3 & AÑ 4 & AÑ 5 \\
\hline ACTIVO CORRIENTE & & & & & \\
\hline Caja & $36,672.60$ & $43,653.23$ & $54,583.77$ & $69,875.47$ & $72,079.96$ & $80,284.21$ \\
\hline Total & $36,672.60$ & $43,653.23$ & $54,583.77$ & $69,875.47$ & $72,079.96$ & $80,284.21$ \\
\hline ACTIVO NO CORRIENTE & & & & & & \\
\hline Activo Fijo & $10,618.60$ & $10,618.60$ & $10,618.60$ & $10,618.60$ & $10,618.60$ & $10,618.60$ \\
\hline Depreciación & 0 & $2,123.72$ & $4,247.44$ & $6,371.16$ & $8,494.88$ & $10,618.60$ \\
\hline Activo Intangible & $4,164.29$ & $4,164.29$ & $4,164.29$ & $4,164.29$ & $4,164.29$ & $4,164.29$ \\
\hline Amortización & 0 & 832.86 & $1,665.71$ & $2,498.57$ & $3,331.43$ & $4,164.29$ \\
\hline Total & $14,782.89$ & $11,826.31$ & $8,869.73$ & $5,913.15$ & $2,956.58$ & 0 \\
\hline TOTAL ACTIVO & $\mathbf{5 1 , 4 5 5 . 4 9}$ & $\mathbf{5 5 , 4 7 9 . 5 4}$ & $\mathbf{6 3 , 4 5 3 . 5 1}$ & $\mathbf{7 5 , 7 8 8 . 6 3}$ & $\mathbf{7 5 , 0 3 6 . 5 4}$ & $\mathbf{8 0 , 2 8 4 . 2 1}$ \\
\hline
\end{tabular}

\begin{tabular}{|l|l|l|l|l|l|l|}
\hline PASIVO & 0 & 0 & 0 & 0 & 0 & 0 \\
\hline Impuesto a la Renta & 0 & 0 & 0 & 0 & 0 & 0 \\
\hline Total Pasivo & &
\end{tabular}

\begin{tabular}{|l|r|r|r|r|r|r|}
\hline PATRIMINIO & $51,455.49$ & $51,455.49$ & $51,455.49$ & $51,455.49$ & $51,455.49$ & $51,455.49$ \\
\hline Capital & 0 & 0 & $4,024.05$ & $11,998.02$ & $24,333.14$ & $23,581.05$ \\
\hline Utilidades Retenidas & 0 & $4,024.05$ & $7,973.97$ & $12,335.12$ & -752.09 & $5,247.67$ \\
\hline Utilidades Ejercicio & $51,455.49$ & $55,479.54$ & $63,453.51$ & $75,788.63$ & $75,036.54$ & $80,284.21$ \\
\hline Total Patrimonio & $\mathbf{5 1 , 4 5 5 . 4 9}$ & $\mathbf{5 5 , 4 7 9 . 5 4}$ & $\mathbf{6 3 , 4 5 3 . 5 1}$ & $\mathbf{7 5 , 7 8 8 . 6 3}$ & $\mathbf{7 5 , 0 3 6 . 5 4}$ & $\mathbf{8 0 , 2 8 4 . 2 1}$ \\
\hline $\begin{array}{l}\text { TOTAL: PASIVO + } \\
\text { PATRIMONIO }\end{array}$ & & & & &
\end{tabular}

Fuente: Elaboración propia. 


\subsection{Flujo de Caja Efectivo}

Se presenta un flujo de caja a largo plazo ya que es quien mantiene con liquidez el negocio. En la tabla 8.5 se detalla un consolidado de información el cual como resultado nos indica si la liquidez del negocio es positiva o negativa.

Tabla 8.5

Flujo de Caja

\begin{tabular}{|c|c|c|c|c|c|c|}
\hline & AÑO 0 & AÑO 1 & AÑO 2 & AÑO 3 & AÑO 4 & AÑO 5 \\
\hline \multicolumn{7}{|l|}{ INGRESOS } \\
\hline Aporte & $51,455.49$ & 0.00 & 0.00 & 0.00 & 0.00 & 0.00 \\
\hline Ventas & 0.00 & $135,000.00$ & $141,750.00$ & $148,837.50$ & $157,767.75$ & $167,233.82$ \\
\hline Ingresos Financieros & 0.00 & 366.73 & 436.53 & 545.84 & 698.75 & 720.80 \\
\hline TOTAL INGRESOS & $51,455.49$ & $135,366.73$ & $142,186.53$ & $149,383.34$ & $158,466.50$ & $167,954.61$ \\
\hline \multicolumn{7}{|l|}{ EGRESOS } \\
\hline Activos Tangibles & $10,618.60$ & & & & & \\
\hline Activos Intangibles & $4,164.29$ & & & & & \\
\hline & & 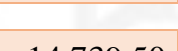 & 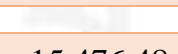 & & 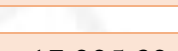 & \\
\hline Materiales & & $14,739.50$ & $15,476.48$ & $16,250.30$ & $17,225.32$ & $18,258.84$ \\
\hline Ins. Ind. & & 192.00 & 192.00 & 192.00 & 192.00 & 192.00 \\
\hline Servicios & & $5,280.00$ & $5,385.60$ & $5,493.31$ & $5,603.18$ & $5,715.24$ \\
\hline MOI & & $52,565.33$ & $52,565.33$ & $52,565.33$ & $67,349.33$ & $67,349.33$ \\
\hline MOD & & $8,213.33$ & $8,213.33$ & $8,213.33$ & $16,426.67$ & $16,426.67$ \\
\hline Alquiler & & $1,200.00$ & $1,200.00$ & $1,200.00$ & $1,200.00$ & $1,200.00$ \\
\hline MOA & & $37,781.33$ & $37,781.33$ & $37,781.33$ & $41,066.67$ & $41,066.67$ \\
\hline GMKT & & $6,690.00$ & $7,024.50$ & $7,109.55$ & $7,198.85$ & $7,292.62$ \\
\hline MOV & & 0.00 & 0.00 & 0.00 & 0.00 & 0.00 \\
\hline Impuesto a la renta & & $1,724.59$ & $3,417.41$ & $5,286.48$ & 0.00 & $2,249.00$ \\
\hline TOTAL EGRESOS & $14,782.89$ & 128,386.09 & $131,255.99$ & $134,091.64$ & $156,262.01$ & $\mathbf{1 5 9 , 7 5 0 . 3 7}$ \\
\hline Caja Inicial & 0.00 & $36,672.60$ & $43,653.23$ & $54,583.77$ & $69,875.47$ & $72,079.96$ \\
\hline Ingresos & $51,455.49$ & $135,366.73$ & $142,186.53$ & $149,383.34$ & $158,466.50$ & $167,954.61$ \\
\hline Egresos & $14,782.89$ & $128,386.09$ & $131,255.99$ & $134,091.64$ & $156,262.01$ & $159,750.37$ \\
\hline Caja Final & $36,672.60$ & $43,653.23$ & $\mathbf{5 4 , 5 8 3 . 7 7}$ & $69,875.47$ & $72,079.96$ & $80,284.21$ \\
\hline
\end{tabular}

\subsection{Capital de trabajo}

Todo lo que implique el capital de trabajo tiene relación a los insumos que el negocio necesite y con la fuerza de trabajo que está conformado por el equipo de Ayde Co. 
Tabla 8.6

Capital de trabajo - Inversiones en Capital de trabajo (3 meses)

\begin{tabular}{|c|c|c|c|c|}
\hline & Mes 1 & Mes 2 & Mes 3 & Total \\
\hline \multicolumn{5}{|l|}{ INSUMOS } \\
\hline Hilo & 2 & 2 & 2 & 6 \\
\hline Telas & 100 & 100 & 100 & 300 \\
\hline Aguja & 1.5 & 1.5 & 1.5 & 4.5 \\
\hline Alfileres & 2 & 2 & 2 & 6 \\
\hline Tijera & 50 & 50 & 50 & 150 \\
\hline Piquetera & 2 & 2 & 2 & 6 \\
\hline Regla & 15 & 15 & 15 & 45 \\
\hline Papel de molde & 0.7 & 0.7 & 0.7 & 2.1 \\
\hline Tiza & 1 & 1 & 1 & 3 \\
\hline \multicolumn{5}{|l|}{ FUERZA DE TRABAJO } \\
\hline Gerente General & $6,000.00$ & $6,000.00$ & $6,000.00$ & $18,000.00$ \\
\hline Costurera & $2,550.00$ & $2,550.00$ & $2,550.00$ & $7,650.00$ \\
\hline Diseñador & $1,700.00$ & $1,700.00$ & $1,700.00$ & $5,100.00$ \\
\hline Asesora de imagen & $1,800.00$ & $1,800.00$ & $1,800.00$ & $5,400.00$ \\
\hline TOTAL & $12,224.20$ & $12,224.20$ & $12,224.20$ & $36,672.60$ \\
\hline
\end{tabular}

Fuente: Elaboración propia.

\subsection{Gastos Pre Operativos}

Los gastos pre operativos se basan principalmente en la constitución de la empresa. Mencionamos que queremos convertir la confección de prendas a medir en una empresa formal. Asimismo, se considera la amortización en base a 5 años.

Tabla 8.7

Gastos Pre Operativos

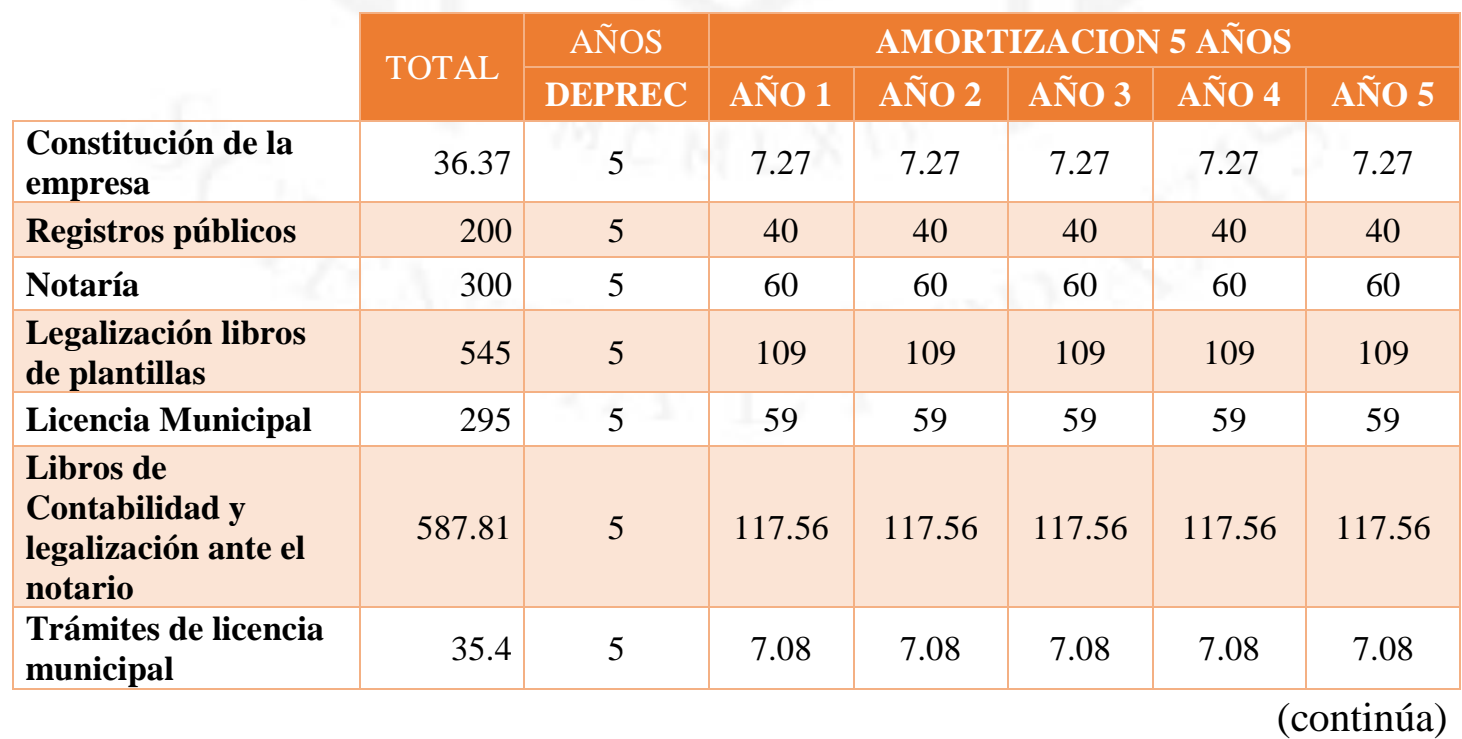


(continuación)

\begin{tabular}{|l|r|c|c|c|c|c|c|}
\hline Registro de Marca & 710.44 & 5 & 142.09 & 142.09 & 142.09 & 142.09 & 142.09 \\
\hline $\begin{array}{l}\text { Capacitación del } \\
\text { personal }\end{array}$ & 644.26 & 5 & 128.85 & 128.85 & 128.85 & 128.85 & 128.85 \\
\hline $\begin{array}{l}\text { Campaña de } \\
\text { Lanzamiento }\end{array}$ & 810 & 5 & 162 & 162 & 162 & 162 & 162 \\
\hline TOTAL & $\mathbf{4 , 1 6 4 . 2 9}$ & & $\mathbf{8 3 2 . 8 6}$ & $\mathbf{8 3 2 . 8 6}$ & $\mathbf{8 3 2 . 8 6}$ & $\mathbf{8 3 2 . 8 6}$ & $\mathbf{8 3 2 . 8 6}$ \\
\hline
\end{tabular}

Fuente: Elaboración propia.

\subsection{Inversión Inicial}

La inversión inicial es la consecuencia de la sumatoria de los gastos pre operativos (ya analizado en 8.7) más los activos tangible y el capital de trabajo.

Tabla 8.8

Activo fijo tangible

CANTIDAD MONTO (S/.) TOTAL (S/.)

\begin{tabular}{|l|c|c|c|}
\hline Laptop & 2 & $1,900.00$ & $3,800.00$ \\
\hline Impresora & 1 & 199 & 199 \\
\hline Estante de telas & 4 & 269.9 & $1,079.60$ \\
\hline Máquina de coser & 1 & 950 & 950 \\
\hline Máquina remalladora & 1 & $3,450.00$ & $3,450.00$ \\
\hline Mesa para cortes & 1 & 400 & 400 \\
\hline Plancha & 1 & 160 & 160 \\
\hline Colgadores & 1 & 80 & 80 \\
\hline Sillas & 2 & 150 & 300 \\
\hline Maniquí & 1 & 100 & 100 \\
\hline Espejo & 1 & 100 & 100 \\
\hline & & TOTAL (S/.) & $\mathbf{1 0 , 6 1 8 . 6 0}$ \\
\cline { 2 - 4 }
\end{tabular}

Fuente: Elaboración propia.

Tabla 8.9

Total inversión inicial

\section{TOTAL}

\begin{tabular}{|r|r|}
\hline Gastos pre operativos & $4,164.29$ \\
\hline Activos tangible & $10,618.60$ \\
\hline Capital de trabajo & $36,672.60$ \\
\hline TOTAL & $\mathbf{5 1 , 4 5 5 . 4 9}$ \\
\hline
\end{tabular}

Fuente: Elaboración propia.

\subsection{Matriz Interna - Externa}

En base a las matrices de MEFE y MEFI definimos la matriz interna-externa el cual al aplicarlo nos posiciona como una empresa que debemos retener y mantener ya que nos encontramos en el tercer cuadrante. 
Tabla 8.10

\section{Matriz EFE}

\section{\begin{tabular}{l|l} 
VALOR & CLASIFICACIÓN
\end{tabular}}

VALOR

PONDERADO

OPORTUNIDADES

1. Mayor población femenina

2. Orientación del gobierno

3. Eventos de moda

4. Redes sociales

\begin{tabular}{l|l}
0.11 \\
0.09
\end{tabular}

0.15

AMIENAZAS

1. Sector retail en aumento

2. Diseñadores con locales propios

0.17

30.33

\begin{tabular}{l|l}
3 & 0.27
\end{tabular}

40.6

3. Confeccionistas cerca a zonas empresariales

4. Prendas chinas

0.11

4

0.68

-

$0.14 \quad 3$

2

0.22

0.1

3

0.42

\begin{tabular}{l|r}
0.10 & 2.5 \\
0.13 & 3
\end{tabular}

1

0.25

Fuente: Elaboración propia.

Tabla 8.11

Matriz EFI

\section{VALOR}

FORTALEZAS

\begin{tabular}{|l|l|l|l|}
\hline 1. Experiencia & 0.13 & 4 & 0.52 \\
\hline 2. Know How & 0.14 & 4 & 0.56 \\
\hline 3. Logística & 0.11 & 4 & 0.44 \\
\hline 4. Procesos definidos & 0.17 & 4 & 0.68 \\
\hline
\end{tabular}
DEBILIDADES

1. Capacidad financiera

2. Poco reconocimiento (cliente)

0.12

3. Acabados especializados (bordados)

0.09

4. Management

0.11

0.13

1

\begin{tabular}{|c|c|}
\hline 2.5 & 0.3 \\
\hline 2 & 0.18 \\
\hline 2.5 & 0.275 \\
\hline 2.5 & 0.325 \\
\hline & 3.28 \\
\hline
\end{tabular}

Fuente: Elaboración propia. 
Figura 8.1

Matriz Externa

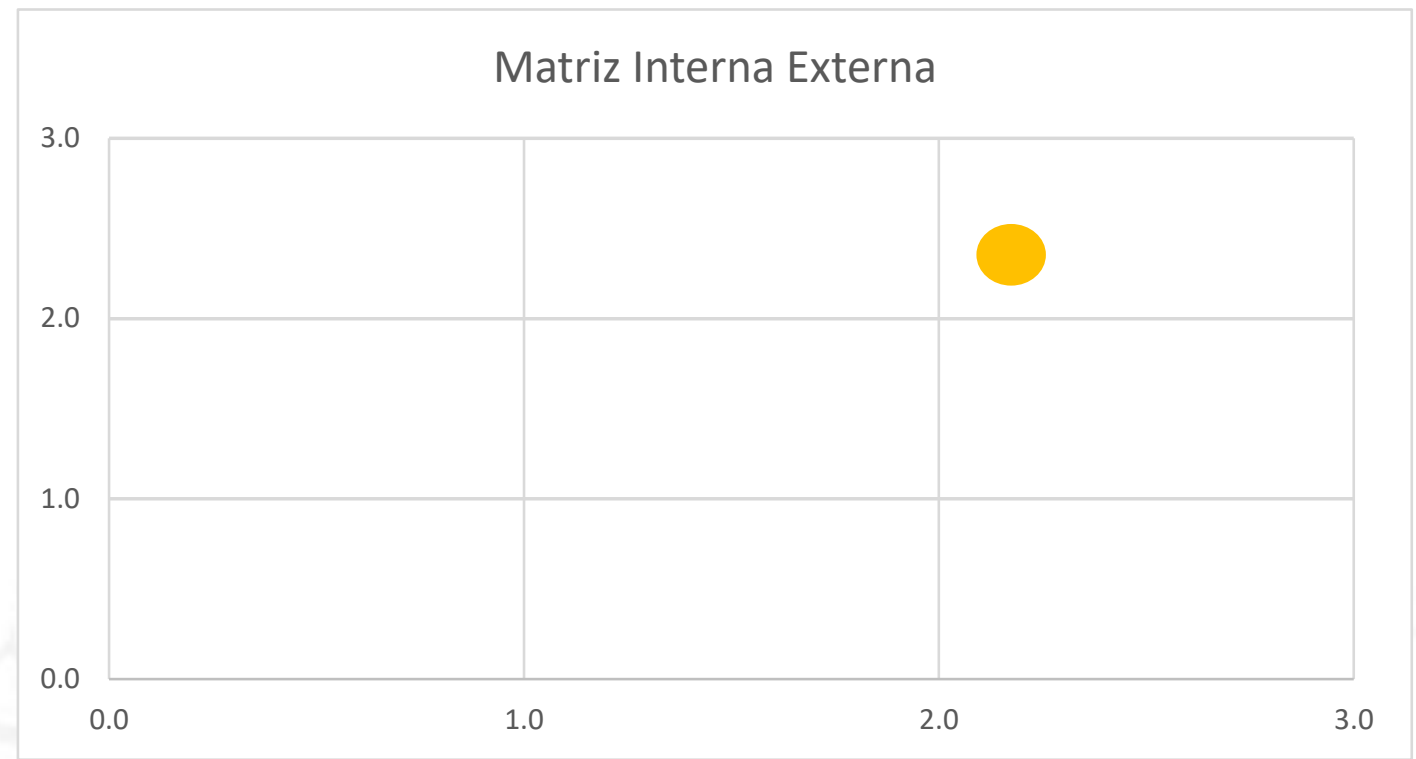

Fuente: Elaboración propia. 


\section{CAPÍTULO IX: CONTROL DEL PLAN DE MARKETING}

\subsection{Criterios de control e indicadores de gestión}

A continuación se detallarán los indicadores de gestión para el plan de marketing.

\section{Tabla 9.1}

Criterios de Control e Indicadores de Gestión

\begin{tabular}{|l|l|l|}
\hline Reconocimiento de marca & Recordación de marca & $\begin{array}{l}\% \text { de clientas que recuerdan la } \\
\text { marca. }\end{array}$ \\
\hline & Nivel de servicio & $\begin{array}{l}\% \text { de clientas satisfechas o } \\
\text { insatisfechas luego de haber } \\
\text { tomado el servicio. }\end{array}$ \\
\hline Rentabilidad & Penetración anual & $\begin{array}{l}\% \text { de personas que tomaron el } \\
\text { servicio mínimo una vez al año }\end{array}$ \\
\hline & Ventas & $\begin{array}{l}\text { S/. de ventas respecto al año } \\
\text { anterior }\end{array}$ \\
\hline & Ganancia por prenda & $\begin{array}{l}\text { Nivel de rentabilidad por cada } \\
\text { tipo de prenda. }\end{array}$ \\
\hline & TRO & $\begin{array}{l}\text { Número de veces que nuestras } \\
\text { clientas vuelven a comprar. }\end{array}$ \\
\hline
\end{tabular}

Fuente: Elaboración propia. 


\section{CONCLUSIONES}

- Luego del análisis del sector se concluye que la industria es atractiva ya que contamos con acceso a proveedores y al poder de negociación con el cliente. Sin embargo, debemos tomar en cuenta la competencia que aunque no tengamos datos exactos, esta se encuentra cerca al público objetivo como oficinas en San Isidro o Surco.

- Al realizar el focus group se identificó el valor que las clientas potenciales le dan al factor tiempo. Esto se debe a que la mayor parte de las clientas trabaja o tienen hijos y otras tareas que cumplir durante el día. Al ser un factor importante, están dispuestas a pagar un precio mayor al promedio que pueden encontrar en una tienda de retail.

- Se debe tener en cuenta una buena selección de personal. Personal que escuche y entienda todos los requerimientos de cada cliente para que se pueda plasmar en una prenda bien confeccionada y una cliente satisfecha.

- Respecto a la fase de implementación debemos tomar en cuenta la inversión que se requiere para la compra de maquinaria. Se determina que la inversión en activos será por medio de socios y así no recurrir a préstamos bancarios y pagar tasas de interés altas.

- Aprovechando el desarrollo del internet y lo accesible que es hoy en día nos sirve de soporte para reducir los costos respecto a publicidad o marketing, ya que al invertir en Facebook dependerá de las veces que se desee que el anuncio aparezca en Facebook. En cuanto a las demás redes sociales, todas son accesibles y gratuitas el cual no solo beneficiará a la empresa si no a las clientes.

- De acuerdo a los resultados del flujo de caja se puede concluir que la confección de prendas de vestir a medida es un negocio rentable según el total que se obtuvo en el VAN (S/. 6,214). 


\section{REFERENCIAS}

Arellano Marketing. (2017). Los 6 Estilos de Vida en América Latina. Recuperado de http://www.arellanomarketing.com/inicio/estilos-de-vida/

BCP se mantiene en proyección de inflación en 2,5\% este 2018. (04 de junio del 2018). El Comercio. Recuperado de http://elcomercio.pe/economia/peru/bcp-sigueesperando-inflacion-cierre-2-5-2018-noticia-525075

Euromonitor. (2018). Store-based Retailing. Recuperado de http://www.portal.euromonitor.com/portal/magazine/homemain

Gobierno crea nuevo régimen societario: la SACS, para emprendedores. (12 de setiembre del 2018). Gestión. Recuperado de https://gestion.pe/economia/gobierno-crea-nuevo-regimen-societario-sacsemprendedores-244186

Gonzales Litman, T. (2018). Crece por año consecutivo el mercado del lujo en Perú. Fashion Network. Recuperado de http://mx.fashionnetwork.com/news/Crecepor-ano-consecutivo-el-mercado-del-lujo-en Peru,987929.html\#.Wz6XGNVKjIV

Hesterly, W. y Barney, J. (2015). Strategic Management and Competitive Advantage Concepts and Cases, Global Edition. Pearson Education Limited.

Hilacha y Trapitos, un juego ecológico. (05 de julio del 2010). Gestión. Recuperado de https://archivo.gestion.pe/noticia/505814/hilacha-trapitos-juego-ecologico

Instituto Nacional de Estadística e Informática. (2018). Comportamiento de la economía peruana en el primer trimestre de 2018. Lima: Autor.

Ipsos Apoyo. (2017). Estadística poblacional 2017. Lima: Autor.

Ipsos Apoyo. (2017). Hábitos, usos y actitudes hacia la telefonía móvil. Lima: Autor.

Ipsos Apoyo. (2017). Perfil del usuario de redes sociales. Lima: Autor.

Ipsos Apoyo. (2017). Perfiles zonales Lima Metropolitana 2018. Lima: Autor.

Kotler, P. y Keller, K. (2016). Dirección de marketing (15. ${ }^{a}$ ed.). México: Pearson.

LIF Week y la apuesta de los nuevos diseñadores. (23 de abril del 2018). Gestión. Recuperado de http://gestion.pe/tendencias/moda/lif-week-apuesta-nuevosdisenadores-232093

Lovelock, C. y Wirtz, J. (2015). Marketing de servicios:Personal, tecnología y

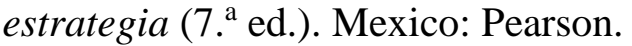

Malhotra, N. (2008). Investigación de Mercados (5. a ed.). México: Pearson Educación. 
Maza, K. (18 de enero del 2018). INEI: PEA femenina creció más que la masculina. Perú21. Recuperado de http://peru21.pe/economia/inei-pea-femenina-creciomasculina-392324

Osterwalder, A. y Pigneur, Y. (2013). Generación de modelos de negocios: Un manual para visionarios, revolucionarios y retadores (12. ${ }^{\mathrm{a}}$ ed.). Madrid: Deusto.

Porter, M. E. (2003). Ser competitivo: nuevas aportaciones y conclusiones. Deusto.

Zara. (2018). Abrigo Estructura. Recuperado de https://www.zara.com/pe/es/abrigoestructura-p05274221.html?v1=6875010\&v2=1055007

Zara. (2018). Falda plisada colores Recuperado de https://www.zara.com/pe/es/faldaplisada-colores-p04387950.html?v1=7058510\&v2=1055452

Zara. (2018). Pantalón popelín lazo. Recuperado de https://www.zara.com/pe/es/pantal\%C3\%B3n-popel\%C3\%ADn-lazop02753032.html?v1=6458888\&v2=1055448

Zara. (2018). Top halter espalda. Recuperado de https://www.zara.com/pe/es/top-halterespalda-p09325010.html?v1=6460747\&v2=1055442

Zara. (2018). Vestido plisado combinado. Recuperado de https://www.zara.com/pe/es/vestido-plisado-combinadop08741224.html?v1=7023532\&v2=1055438 
ANEXOS 


\section{ANEXO 1: Guía de entrevistas a profundidad}

Fichas técnicas de Entrevistas a profundidad

Presentaremos la guía con una serie de preguntas que fueron contestadas por el público objetivo. Asimismo se presentó la idea de negocio con el fin de explorar la aceptación de la idea de negocio.

* ¿Cuántos años tienes?

* ¿Ocupación?

¿En qué distrito vives?

* Tienes Smartphone?

* ¿Sabías que las prendas puedes ser a tu medida?

¿Qué opinas sobre el servicio de confección a medida?

¿Alguna vez solicitaste un servicio?

¿Cómo lo contactas?

*Has tenido algún problema o percance con la confeccionista?

* ¿Estarías dispuesta a solicitar un servicio de confección a medida?

¿Qué esperas de la prenda? ¿Calidad? ¿Acabado?

* ¿Cada cuánto tiempo renuevas tu ropa?

* ¿Cuánto inviertes en ropa?

¿Dónde buscas los modelos?

¿Cuántas prendas mandas a confeccionar?

- ¿Qué prendas solicitas? ¿Pantalones, blusas, vestidos?

* ¿Crees que el servicio es importante? ¿Por qué?

* ¿Te parece buena idea que la confeccionista vaya hasta tu casa?

\section{Concepción confección a medida}

Somos una empresa conformada por mujeres emprendedoras especializadas en confección de prendas de vestir a medida como sastres, blusas, vestidos cocktail, vestidos 
de noche, vestidos de novia, entre otros. Buscamos la total satisfacción de nuestros clientes brindando servicio de lunes a sábado con horarios a disposición de nuestros clientes.

Nuestro cliente tendrá la libertada de elegir su diseño mediante imágenes de revistas, páginas web, redes sociales, creaciones propias. Asimismo, se le ofrecerá revistas con las últimas tendencias para que tenga más opciones de elegir el modelo que desee.

Las citas se darán con previa anticipación con el fin de atender a todos los clientes entregando el mejor servicio y asesoría. La representante de la empresa será quién asista a casa del cliente para la selección del modelo de la prenda, la toma de medidas, la prueba de la prenda antes de finalizar el acabado, la entrega final de la prenda y las veces que sea necesario.

*Qué opinas del nuevo servicio?

* ¿Lo tomaría?

* ¿Cuánto más estaría dispuesto a pagar?

* ¿Qué te motivaría a solicitar el servicio?

* ¿Hay algo que no lograste entender?

¿Tienes alguna sugerencia?

Datos de los entrevistados

\begin{tabular}{|c|c|}
\hline Nombre & Características \\
\hline 1. Francisca Gargurevich & Mujer / Ama de casa / 53 años \\
\hline 2. Mayra Arauco & Mujer / Trabaja / 25 años \\
\hline 3. Rocio Corrales & Mujer / Trabaja / 26 años \\
\hline 4. Diana Navarrete & Mujer / Estudia y trabaja / 23 años \\
\hline
\end{tabular}

Fuente: Elaboración propia. 


\section{ANEXO 2: Guía de Entrevistas a expertos}

Para la entrevistas a expertos recurrimos a costureras con experiencia en confección a medida. Respondieron las siguientes preguntas para enriquecer la investigación.

\section{Inicio de la entrevista}

Se da la bienvenida, luego se explica que el propósito de la entrevista es conocer su opinión sobre el servicio de confección a medida.

* ¿Cuántos años en el sector tienes?

* ¿Trabajas para alguien o eres independiente?

* Si decido empezar en el sector, ¿Qué debo tener en cuenta? (máquinas de coser, insumos, etc.)

* ¿Tienes una marca propia?

* ¿Cuántos clientes puedes tener al mes?

* ¿Cuántas prendas puedes confeccionar en un día? ¿Semana? ¿Mes?

*Cómo encuentras el sector? Crees que está en crecimiento?

* ¿El negocio de confección a medida es rentable?

* ¿Qué se necesita para tener éxito?

* ¿Cada cuánto te actualizas con cursos/talleres?

* ¿Cómo logras conseguir clientes?

* ¿Cuáles son las características de tus clientes? ¿Edad? ¿Distrito? ¿Ocupación?

* ¿Qué prendas te demandan más tiempo?

* ¿Qué prendas solicitan más?

* ¿Cuáles son tus modos de cobrar? (contra entrega/ 50\% adelantado) 


\section{Datos de los entrevistados}

\begin{tabular}{|c|c|c|c|}
\hline Nombre & Especialidad & Organización & Cargo \\
\hline 1. Ayde Cordova & $\begin{array}{l}\text { Corte y } \\
\text { confección }\end{array}$ & Independiente & Independiente \\
\hline 2. Maco Calderón & $\begin{array}{l}\text { Diseño y } \\
\text { confección }\end{array}$ & Independiente & Independiente \\
\hline 3. Yuliya Yulienka & $\begin{array}{l}\text { Diseño y } \\
\text { confección }\end{array}$ & Independiente & Independiente \\
\hline 4. Violeta Sandoval & $\begin{array}{l}\text { Corte y } \\
\text { confección }\end{array}$ & Independiente & Independiente \\
\hline
\end{tabular}

Fuente: Elaboración propia. 


\section{ANEXO 3: Guía de Focus groups}

Presentamos la guía para el focus group detallando los temas que se discutieron respecto al servicio de confección a medida diferenciado.

\section{Introducción}

Presentación del moderador.

* Presentación individual de los integrantes.

a. Nombre

b. Ocupación

* Explicar el motivo del focus group.

* Informar sobre la duración del focus group.

\section{Preámbulo}

Presentar las reglas.

* Indicar que no hay respuesta "correcta o "incorrecta"

* Explicar que la sesión será grabada para luego ser analizada

\section{$\underline{\text { Exploración superficial }}$}

Breve revisión del conocimiento sobre el tema.

* Frecuencia. ¿Qué tan seguido solicitan un servicio de confección a medida?

* Hábitos de compra

* ¿Qué tipo de prendas creen que puede confeccionarse a medida?

* ¿Qué tipo de prenda solicitan? (vestidos de fiesta, pantalones de vestir, blusas, etc.)

* Para qué ocasiones solicita el servicio?

* ¿Cómo logran contactarse con una confeccionista? (internet, recomendaciones)

\section{$\underline{\text { Exploración profunda }}$}

Revisión de las percepciones y motivaciones de compra y solicitud del servicio (beneficios percibidos y esperados)

* ¿Prefieren comprar un vestido en tienda o mandarlo a confeccionar? 
* ¿Por qué prefieren solicitar un servicio de confección y no comprar en alguna tienda?

* ¿Cuánto están dispuestas a pegar por una prenda?

¿Tienen alguna costurera preferida? ¿Cuál es su nombre?

* Cuando toman el servicio ¿suelen participar del proceso? (Da sugerencias, propone ideas, aprueba el tipo de tela)

Presentación del nuevo concepto

* Presentación del nuevo concepto.

Discusión de las percepciones, actitudes y motivaciones ante el producto.

Exploración de la percepción de novedad y credibilidad del concepto.

* ¿Qué opinan respecto a recibir el servicio en la comodidad de su hogar?

* Exploración de los aspectos de agrado y desagrado del concepto.

* Exploración de atributos valorados de producto (importancia del servicio)

* Exploración de identificación de beneficios (racionales, funcionales, emocionales) del producto.

Exploración del grado de aceptación del producto.

* Exploración de ventajas o desventajas frente a otros productos/servicios.

* Exploración de intención de toma del servicio.

\section{$\underline{\text { Cierre y despedida }}$}

Agradecimiento y despedida.

\section{Datos de los entrevistados}

\begin{tabular}{|l|l|l|}
\hline Focus & Fecha: 06-05-16 & Fecha: 07-05-16 \\
\hline Moderador & Héctor Flores y Mayra Palomino & Héctor Flores \\
\hline $\mathbf{N}^{\circ}$ de Participantes & 6 & 5 \\
\hline Características & Mujeres & Mujeres \\
\hline Filtro (edad) & 30 años a más & 20 a 29 años \\
\hline
\end{tabular}

Fuente: Elaboración propia. 


\section{ANEXO 4: Cuestionario}

A continuación se mostrará el cuestionario que fue contestado por mujeres que había tomado un servicio de confección a medida y otras que no han tomado aún un servicio de confección a medida.

Servicio de confección a medida

Somos una empresa conformada por mujeres emprendedoras especializadas en confección de prendas de vestir a medida como sastres, blusas, vestidos cocktail, vestidos de noche, vestidos de novia, entre otros.

*Obligatorio

1. Edad *

- $20-27$

○ $28-34$

○ 35 - a más

2. Ocupación *

○ Estudio

- Trabajo

- Estudio y Trabajo

- Ama de casa

o Otra:

3. ¿Cuenta con smartphone? *

○ $\mathrm{Si}$

O No

4. ¿Alguna vez solicitaste el servicio de confección a medida? (Si marcas "No" pasa a la pregunta 11)*

$\circ \mathrm{Si}$

○ No

5. ¿Cuál fue tu expectativa al tomar el servicio?

Tiempo de entrega

Buen acabado de la prenda

Atención

Calidad de la prenda

- Facilidad de pago

6. ¿Cada cuánto solicitas el servicio? 


\section{Mensual}

Bimestral

Por temporadas (verano, otoño, invierno, primavera)

Otro:

7. Cuando solicita la confección de alguna prenda, ¿Cuántos modelos pide?

$1-2$

$3-4$

$5-6$

7 - a más

8. Cuando selecciona un modelo, busca en:

Revistas

Web

Redes Sociales

Otro:

9. Generalmente usted

- Entrega la tela

- El servicio incluye la tela

10. ¿Cuánto invierte cada vez que solicita el servicio de confección?

Servicio de confección a medida diferenciado

Nuestra propuesta es el servicio de confección sobre medida buscando la total satisfacción de las clientas por lo que nos diferenciaremos brindando los servicios complementarios de toma de medidas, prueba y entrega en la comodidad de sus domicilios.

11. ¿Consideras importante nuestra propuesta? *

○ $\mathrm{Si}$

○ No

12. ¿Por qué? *

13. ¿En qué medida estarías dispuesta a tomar nuestro servicio con la propuesta mencionada? *

- Definitivamente si lo tomaría

- Probablemente si lo tomaría

- No sé si sí o si no lo tomaría

- Probablemente no lo tomaría

- Definitivamente si lo tomaría

14. ¿Por qué tu respuesta en la pregunta 13 ? 
15. De acuerdo a nuestra propuesta. ¿Cómo calificaría nuestros beneficios? (Entendiendo 1 como "poco importante" y 5 como " muy importante") *

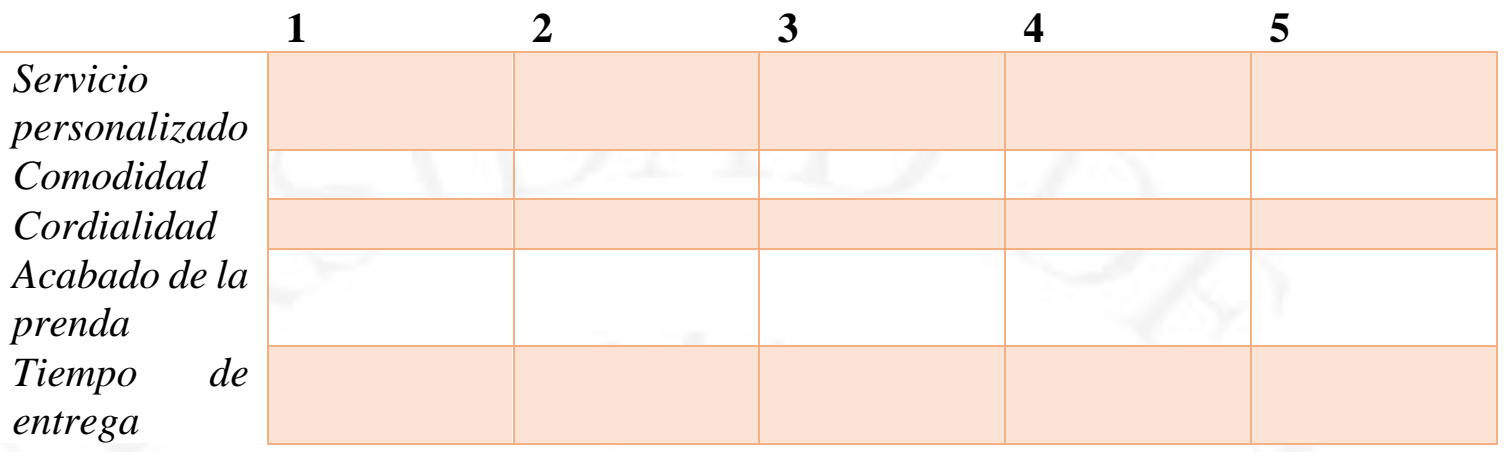

Fuente: Elaboración propia.

16. ¿Cuánto más (en porcentaje) estarías dispuesta a pagar por nuestra propuesta frente a los servicios de confección sobre medida convencionales? $*$

○ Menos de $10 \%$ más

- Entre $11 \%$ y $20 \%$ más

- Entre $21 \%$ y $30 \%$ más

○ Más de $30 \%$ más

17. ¿Desearía recibir promociones? $*$

○ $\mathrm{Si}$

○ No

18. Sugerencias para el servicio de confección a medida

\section{Datos de la encuesta}

\begin{tabular}{|c|c|}
\hline Encuesta & \\
\hline Muestreo & Virtual \\
\hline Características de la unidad muestral & Mujeres de 20 años a más \\
\hline Tipo & No probabilístico \\
\hline Técnica de muestreo & Por conveniencia y estratíficado \\
\hline Procedimiento de muestreo & $\begin{array}{l}\text { La encuesta fue resuelta en línea enviado } \\
\text { personalmente a mi entorno. Así mismo } \\
\text { fueron reenvíadas a amistades de género } \\
\text { femenino de mi entorno. }\end{array}$ \\
\hline Tamaño de muestra & 109 \\
\hline
\end{tabular}




\section{ANEXO 5: Gráficos de resultado de la encuesta}

Fuente: Elaboración propia

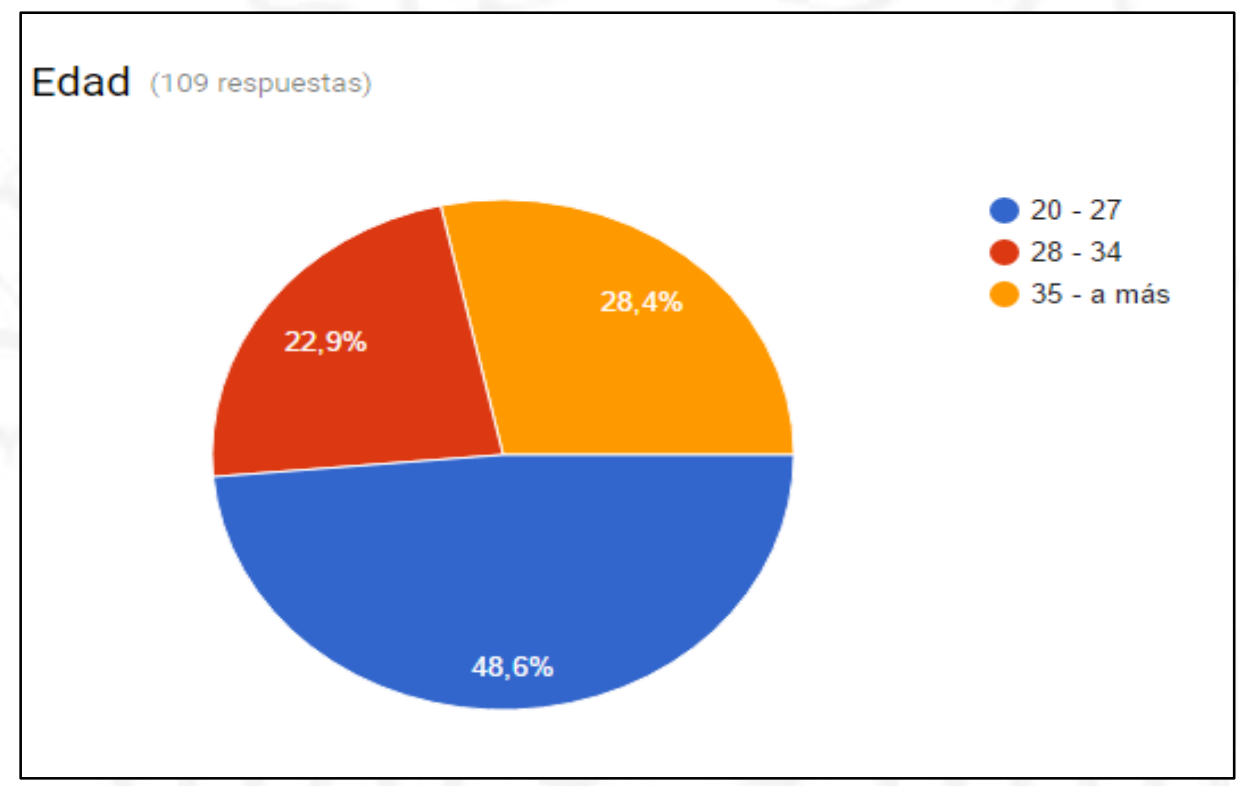

Fuente: Elaboración propia.

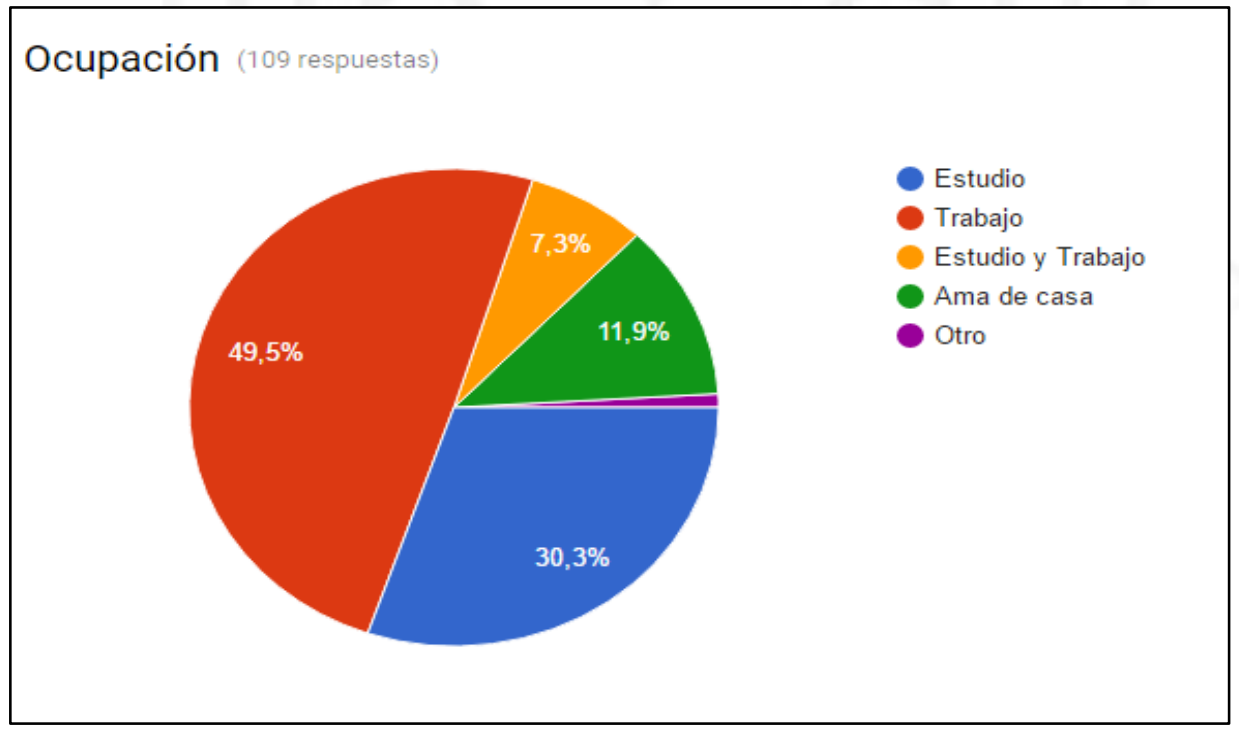

Fuente: Elaboración propia 


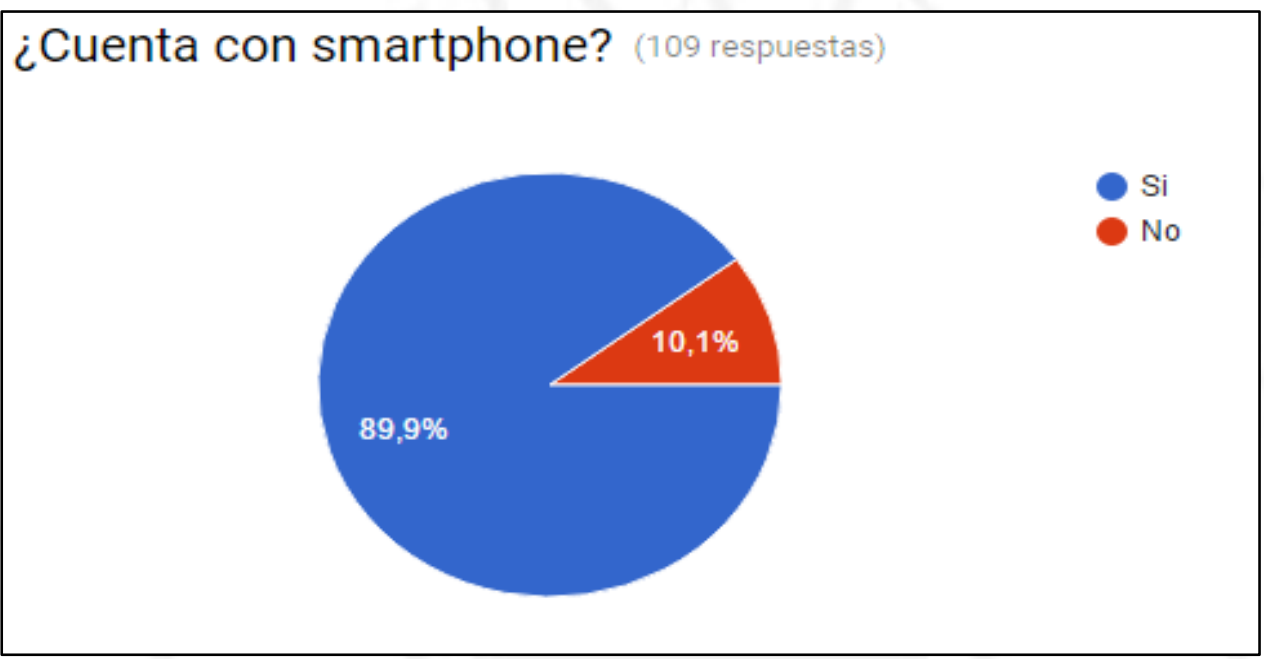

Fuente: Elaboración propia.

¿Alguna vez solicitaste el servicio de confección a medida? (Si marcas "No" pasa a la pregunta 11)

(109 respuestas)
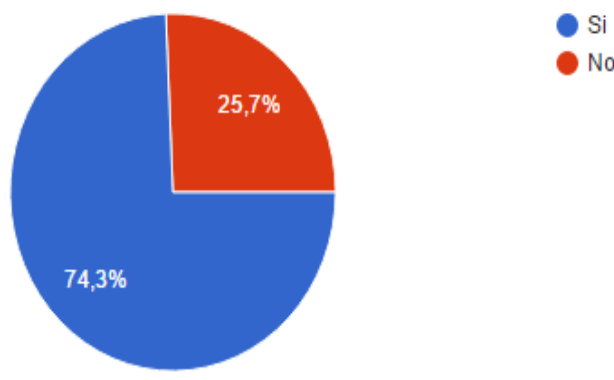

No

Fuente: Elaboración propia. 
¿Cuál fue tu expectativa al tomar el servicio? (85 respuestas)

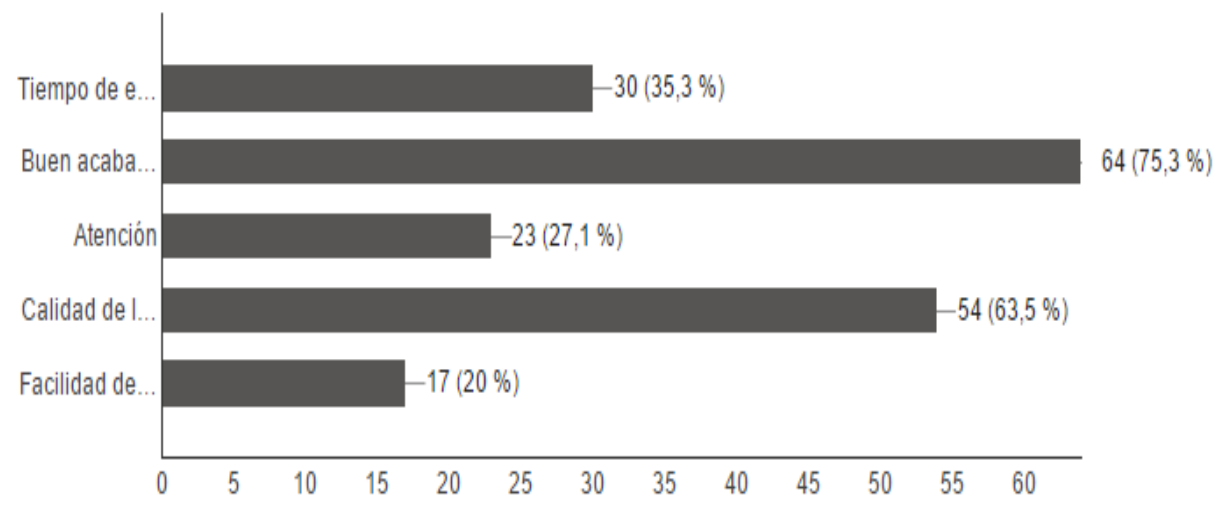

Fuente: Elaboración propia.

¿Cada cuánto solicitas el servicio? (61 respuestas)

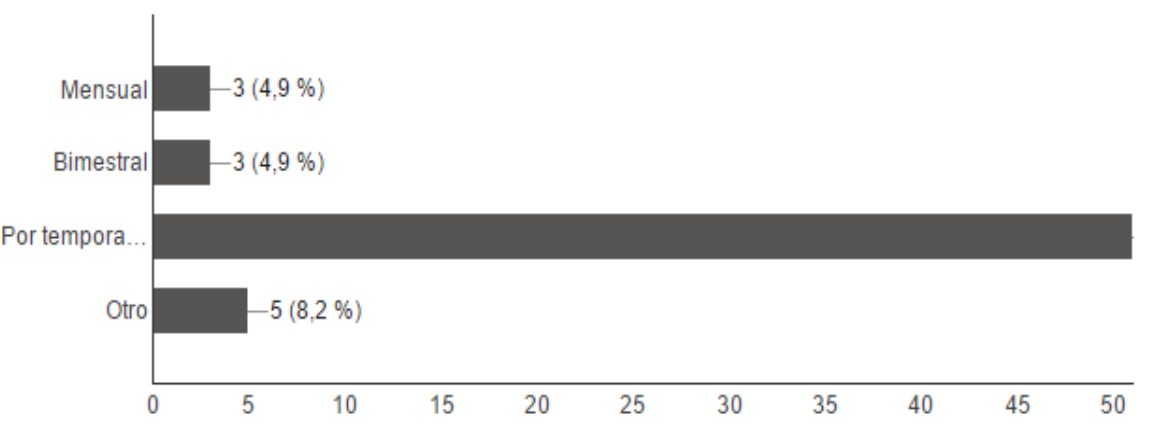

Fuente: Elaboración propia. 
Cuando solicita la confección de alguna prenda, ¿Cuántos modelos pide?

(84 respuestas)

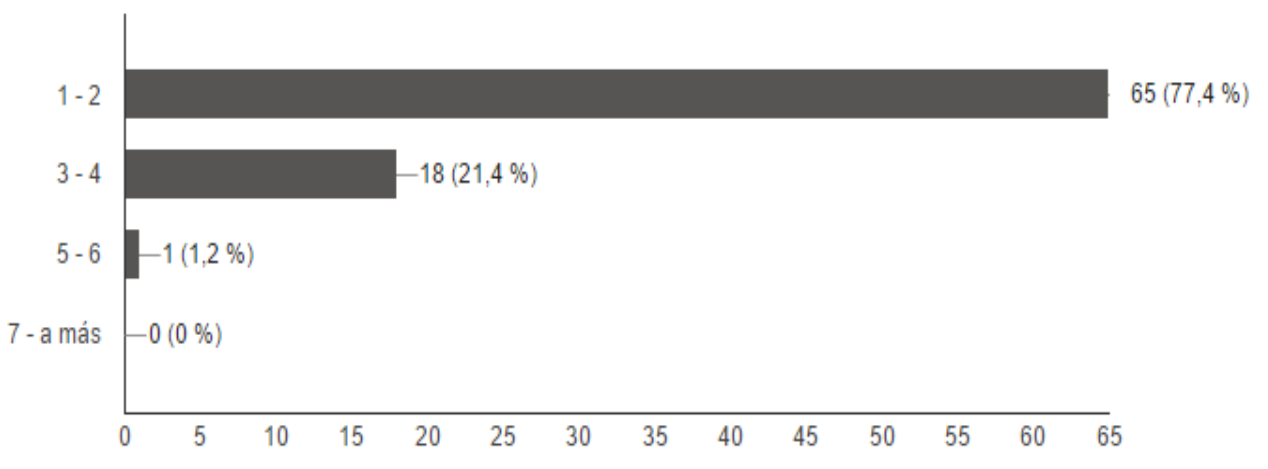

Fuente: Elaboración propia.

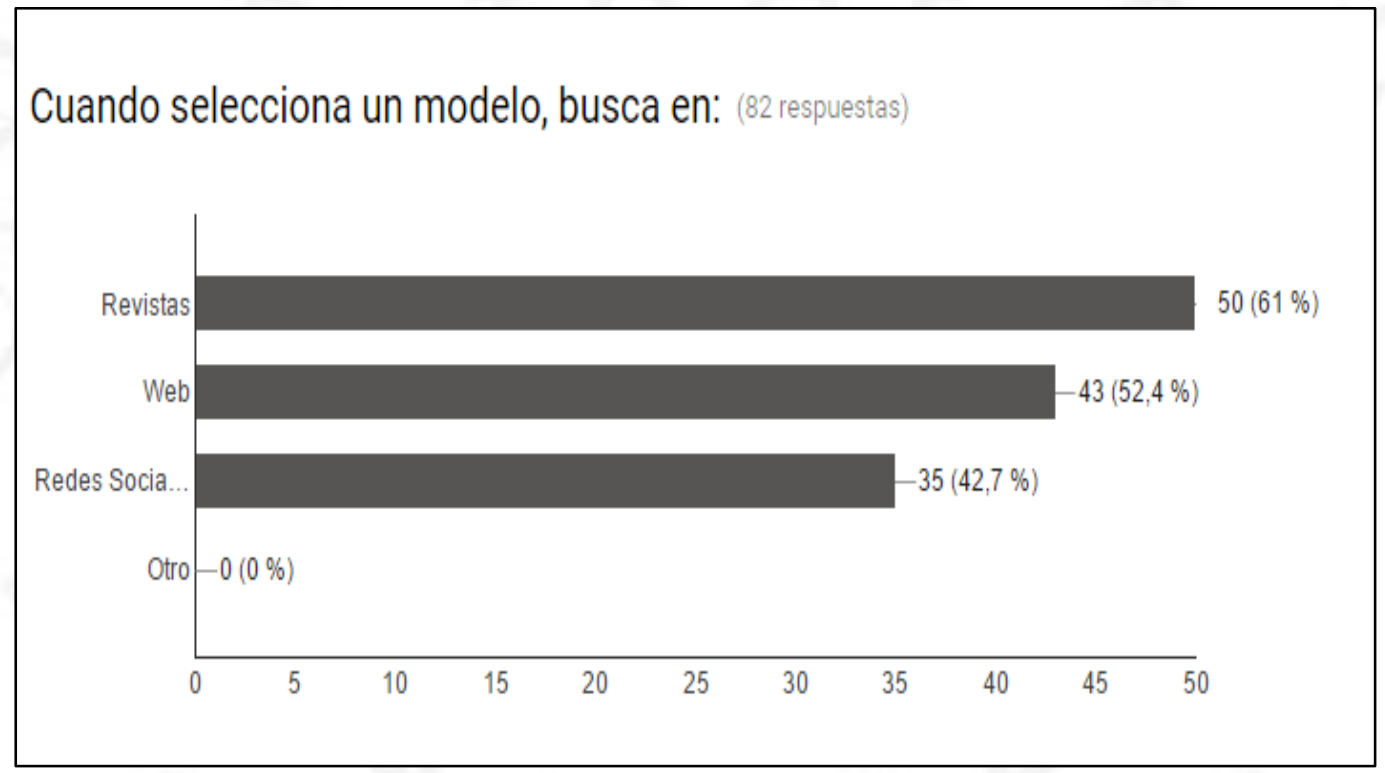

Fuente: Elaboración propia. 
Generalmente usted (84 respuestas)

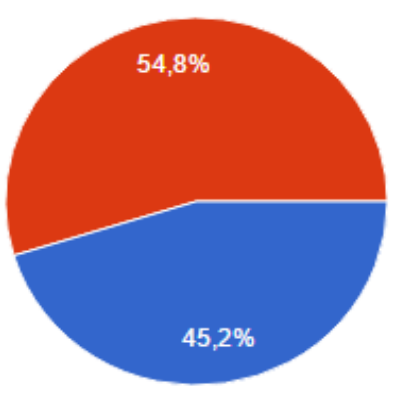

Entrega la tela

El servicio incluye la tela

Fuente: Elaboración propia.

¿Consideras importante nuestra propuesta? (109 respuestas)

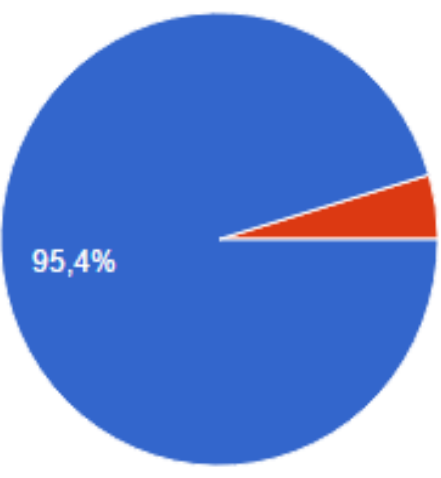

Fuente: Elaboración propia. 
¿En qué medida estarías dispuesta a tomar nuestro servicio con la propuesta mencionada?

(109 respuestas)

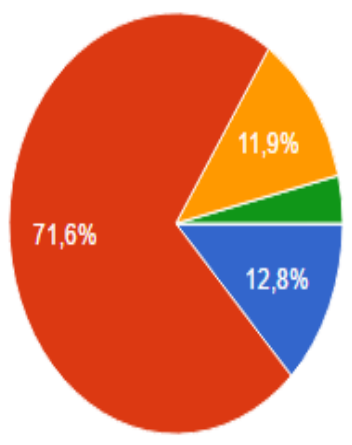

Definitivamente si lo tomaría

Probablemente si lo tomaría

No sé si sí o si no lo tomaría

Probablemente no lo tomaría

Definitivamente no lo tomaría

Fuente: Elaboración propia.

De acuerdo a nuestra propuesta. ¿Cómo calificaría nuestros beneficios? (Entendiendo 1 como "poco importante" y 5 como " muy importante")

$1 \square 2 \square 3 \square$
9

90

60

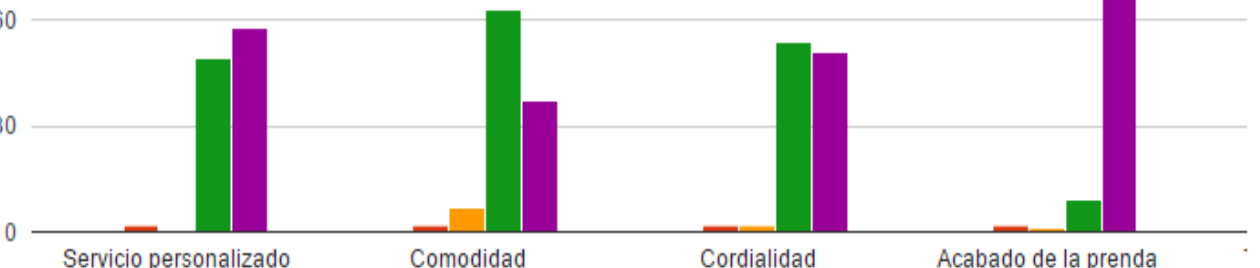

Servicio personalizado

Comodidad

Cordialidad

Acabado de la prenda

Fuente: Elaboración propia. 
¿Cuánto más (en porcentaje) estarías dispuesta a pagar por nuestra propuesta frente a los servicios de confección sobre medida convencionales?

(109 respuestas)

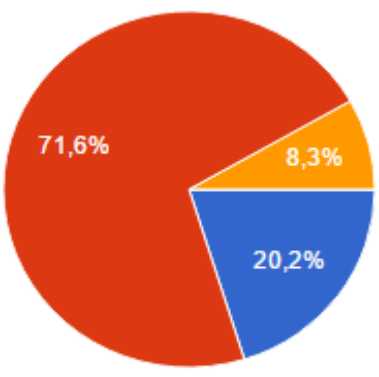

Menos de $10 \%$ más

Entre $11 \%$ y $20 \%$ más

Entre $21 \%$ y $30 \%$ más

Más de $30 \%$ más

Fuente: Elaboración propia.

¿Desearía recibir promociones? (109 respuestas)

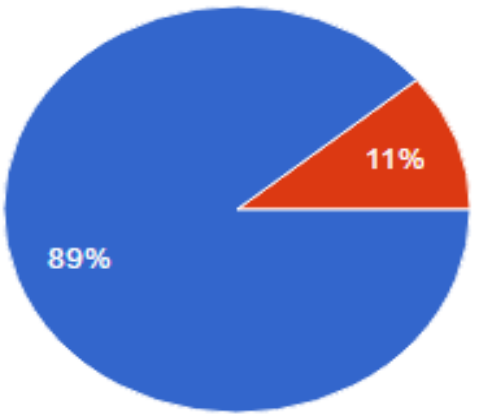

Fuente: Elaboración propia. 